Portland State University

PDXScholar

\title{
Our Vision of Health for Future Generations: an Exploration of Proximal and Intermediary Motivations with Women of the Choctaw Nation of Oklahoma
}

Danica Love Brown

Portland State University

Follow this and additional works at: https://pdxscholar.library.pdx.edu/open_access_etds

Part of the Social Work Commons

Let us know how access to this document benefits you.

\section{Recommended Citation}

Brown, Danica Love, "Our Vision of Health for Future Generations: an Exploration of Proximal and Intermediary Motivations with Women of the Choctaw Nation of Oklahoma" (2019). Dissertations and Theses. Paper 4803.

https://doi.org/10.15760/etd.6687

This Dissertation is brought to you for free and open access. It has been accepted for inclusion in Dissertations and Theses by an authorized administrator of PDXScholar. Please contact us if we can make this document more accessible: pdxscholar@pdx.edu. 
Our Vision of Health for Future Generations:

An Exploration of Proximal and Intermediary Motivations

With Women of the Choctaw Nation of Oklahoma

by

Danica Love Brown

A dissertation submitted in partial fulfillment of the requirements for the degree of

Doctor of Philosophy

in

Social Work and Social Research

Dissertation Committee:

Roberto Orellana, Chair

Laura Nissen

Alma Trinidad

Kelly Gonzales

Portland State University

2019 


\begin{abstract}
Health disparities and substance misuse are increasingly prevalent, costly, and deadly in Indian Country. Although women historically held positions of influence in pre-colonial Tribal societies and shared in optimum health, their current health is relegated to some of the worst outcomes across all racial groups in the United States. Women of the Choctaw Nation of Oklahoma $(\mathrm{CNO})$ have some of the highest prevalence estimates in physical inactivity and excessive drinking in the United States. Building on the Indigenous Stress Coping model of indigenous health, "Our Vision of Health for Future Generations" explores the intersection of a historical event, the Trail of Tears, and its lasting impact on the contemporary health outcomes in tribal members. This inquiry is positioned within the Yappallí Choctaw Road to Health project that explores these broader issues. This culturally-centered study explores proximal and settings-based/intermediary motivations of twenty-three women who completed the Yappallí project, walked the Trail of Tears, and developed a holitobit ibbak fohki "sacred giving" community health event. Analysis was conducted using the Listening Guide method, that highlighted the contrapuntal voices of embodiment, motivation, challenges, and transformation. Participants shared stories in relation to both their individual health concerns (proximal), and deep love and commitment for the health of their family, community and for future generations (intermediary). This study provides another framework for the development of indigenized research, by using in-depth interviews, haklo "listen deeply" as a form of indigenous storywork that is centering of the experiences of marginalized people, and reflexivity as anukfilli "Deep Reflection".
\end{abstract}




\section{Dedication}

This work is dedicated to our ancestors who sacrificed for the People and created a path of resistance forged in love and sacrifice that sustains us today, to the future generations who continue on this path and the Choctaw Nation of Oklahoma. To the sacred feminine energy and the ancestral memory that keeps us strong, and to "Iholitopa pishki" our beloved mother earth and my grandmothers, for grounding and centering this work. Yakoke, chi hullo li. 


\section{Acknowledgements}

I would like to acknowledge my family, friends and intellectual ancestors who have paved the way for me to be able to engage in this work and the indigenous and allied scholars who supported the development of my epistemological approach to this work: Dr's Karina Walters, Michelle Johnson-Jennings, Tessa Evans-Campbell, Ramona Beltrán, Bonnie Duran, Linda Tuhiwai-Smith, Leonie Pihama, Colleen Hackett, Tom Becker, and Grazia Cunningham, Kristian Williams, Lara Messersmith-Glavin, Alexis Brown and Jennie Brixey. My advisory committee, Dr's Roberto Orellana, Lara Nissen, Alma Ouanesisouk Trinidad, and Kelly Gonzales.

This study would not be possible if it were not for the Choctaw Nation of Oklahoma and Yappallí Choctaw Road to Health project staff, Sandra Stroud and Rachel Davis, who graciously guided and supported me through this process. Most importantly, I would like to acknowledge the participants of the Yappallí Project and the sacrifice they made to create a vision of health for the next generation. I give my deepest gratitude to our grandmothers who walked the Trail of Tears, and all those who came before us who worked for the betterment of our People. It is with deep love and respect that I participate in this work in loving memory of my adviser, elder, and intellectual ancestor, Dr. Charlotte Tsoi Goodluck, hozho naash "walk in beauty".

This study was funded through the Indigenous Wellness Research Institute and the Northwest Portland Area Indian Health Board Northwest Native American Research Centers for Health. This study received approval through the Human Subjects Research Review Committee at Portland State University and the Choctaw Nation of Oklahoma Institutional Review Board. 


\section{Table of Contents}

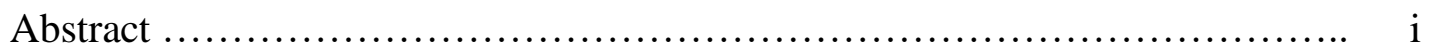

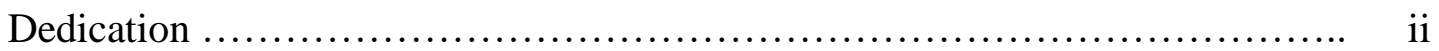

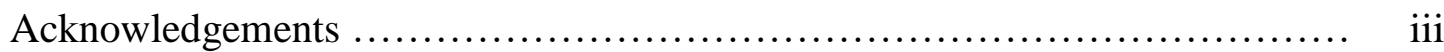

List of Tables ...................................................... vi

List of Figures.................................................... vii

Chapter 1: Introduction...................................................... 1

Research Purpose..................................................... 4

Parent Study: Yappallí Choctaw Road to Health ............................... 5

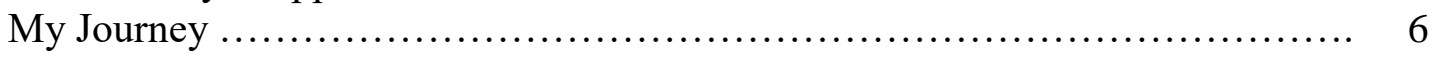

Chapter 2: Literature Review................................................. 9

Health Disparities in American Indian Communities........................... 9

American Indians and Substance Use .................................... 14

Trauma: Impact on Food and Health..................................... 16

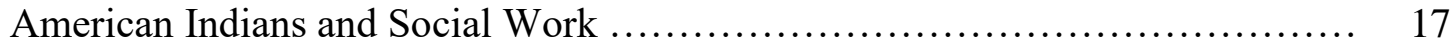

American Indian Women Health......................................... 20

Social Work and Historical Trauma ....................................... 24

Information-Motivation-Behaviors Skills Model .......................... 25

American Indians Connection to Place.........................., ......... 28

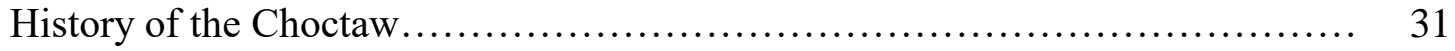

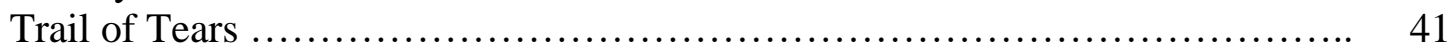

Chapter 3: Theoretical Models.............................................. 45

Decolonization...................................................... 45

Tribalist............................................................... 49

Historical Trauma................................................... 55

Conceptual Frameworks of the Yappallí project........................... 63

Conceptual Frameworks for Our Vision of Health......................... 66

Chapter 4: Methodology................................................... 73

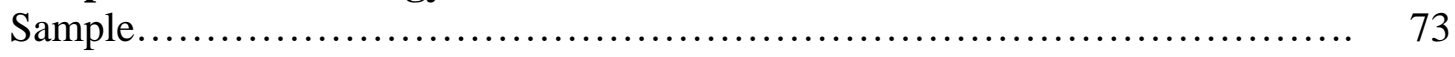

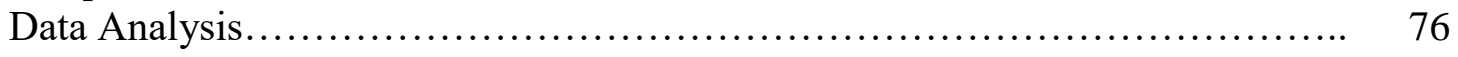

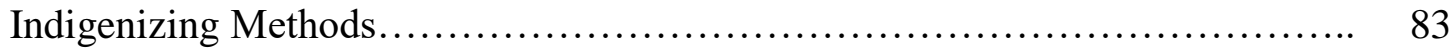

Chapter 5: Findings...................................................... 85

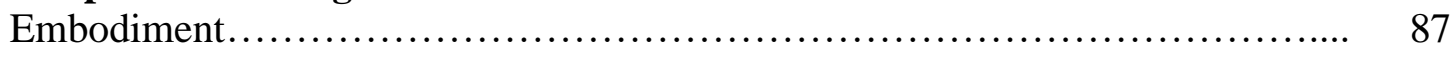

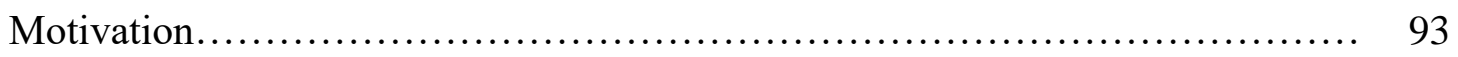

Challenges.......................................................... 101

Transformation....................................................... 108 
Chapter 6: Discussion....................................................... 112

Contrapuntal Voice..................................................... 118

Implications for Practice............................................... 122

Implications for Policy.............................................. 126

Implications for Research........................................... 129

Limitations........................................................... 140

Reflexivity-Anukfilli “Deep Reflection"................................... 142

Chapter 7: Conclusion........................................................ 146

References............................................................ 149

Appendix A. Interview Guide............................................... 164

Appendix B. Human Subjects Approval ..................................... 165

Appendix C. Informed Consent .......................................... 168

Appendix D. Interview Transcripts...................................... 171 


\section{List of Tables}

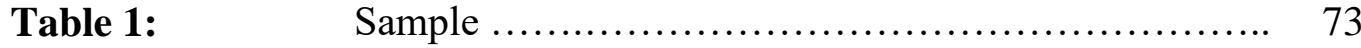

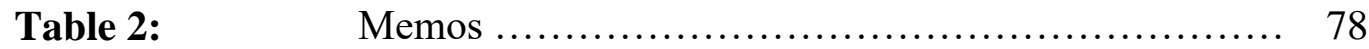

Table 3: $\quad$ Categorizing content examples $\quad \ldots \ldots \ldots \ldots \ldots \ldots \ldots \ldots . \quad 81$

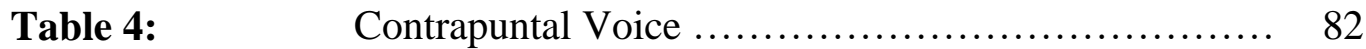

Table 5: $\quad$ Contrapuntal Voice with examples ................. 85 


\section{List of Figures}

Figure 1: $\quad$ Indigenist Stress-Coping (ISC) Model ................ 64

Figure 2: $\quad$ Conceptual Diagram of Yappallí Information Motivation Behavior (YIMB) ................... 65

Figure 3: $\quad$ Contrapuntal Voice Interactions $\quad \ldots \ldots \ldots \ldots \ldots \ldots \ldots \ldots, 119$ 


\section{Chapter 1: Introduction}

Health disparities and substance misuse are increasingly prevalent, costly, and deadly in Indian Country. American Indian (AI) health is anchored in a historical context and manifested across generations which impacts contemporary forms of health. The impact of removal from tribal homelands, grief and loss of culture and identity, and the challenges AI communities face to reconcile are examples of federally supported acts of genocide against the traditional peoples of these lands, currently known as the United States. One of the consequences of these policies was the forced removal of indigenous peoples from their traditional homelands. Removal from traditional homelands severed tribal people's connections to resources, such as the land, that gave meaning to their identity from which their creation stories originated. This traumatic act has manifested across the generations for many, as profound soul wounding and unhealed grief, which continues to impact their health in contemporary times. Given the historical positions of AI women as healers and leaders in pre-colonial Tribal societies, this act of removal interrupted the balance of gender roles within Tribal cultures, the position of women and non-men as sacred has resulted in contemporary perceptions that undermine and harm the health of AI women and non-men. A full characterization of these factors await further inquiry, and understanding these relationships is important for reestablishing health and wellness for tribal communities. Decolonizing, tribalist theories and historical trauma are the conceptual models that inform this study to help understand, both the impact of white settler colonization on tribal people and the liberation from colonization.

Particularly powerful is the process by which colonization has become internalized among AI peoples and serves to shape health outcomes. For example, U.S. 
federal policies stemming from Manifest Destiny defined AI peoples as "not human", "savage" and "expendable," today these ideas shape society-level and individual-level frameworks about the potential of AI peoples. Genocide against the indigenous people in the Americas is one of the most massive and longest lasting campaigns in human history (Anti-Defamation League, 2005; Chenault, 2011; Dunbar-Ortiz, 2014; Duran and Duran, 1995; Jahoda, 1975; Newcomb, 1992). Genocide, assimilation, and the long-term effects of the termination policies are traumatic events that have resulted, for many AIs, as unhealed trauma that is carried and shared across the generations. Researchers are beginning to recognize the influence of historical and intergenerational trauma on the health of AI peoples (Yellow Horse Brave Heart, 1998 and 2004; Yellow Horse Brave Heart, Chase, Elkins and Altschul, 2011; Chenault, 2011; Duran, E., 2006; Duran and Duran, 1995; Lewis, 2012; Newcomb, 1992; Walters, 1999; Walters and Simoni, 2002; Walters, Simoni and Evans-Campbell. 2002; Walters, Beltran, Huh, Evans-Campbell, 2011; Walters, Beltran, Evans-Campbell, and Simoni, 2011; Walters, Mohammed, Evans-Campbell, Beltran, Chaw and Duran, 2011; Walters, LaMarr, Levey, Pearson, Maresca, Mohammed and Jobe, 2012) and are working to develop decolonized and indigenized methods and interventions to address these issues.

Historical trauma is associated with poor health outcomes among AI women and non-men, and women of the Choctaw Nation of Oklahoma (CNO), for example, have some of the highest obesity, physical inactivity and excessive drinking prevalence in the country (Walters and Johnson-Jennings, 2014). A significant body of robust research (Yellow Horse Brave Heart, 1998 and 2004; Brown, S., 2007; Duran, E., 2006; Duran and Duran, 1995; Evan-Campbell, 2008; Stites, 2001, Walters, 1999; Walters et al, 
2002a) demonstrates the harmful impact of colonialism on indigenous cultures in the America's and its continued impact on indigenous peoples across the planet, manifesting through cultural and historical trauma which has been shown to have a direct relationship to the internalized and lateral oppression seen in AI communities that impacts the quality of life for indigenous peoples and health outcomes in this generation.

Recently AI scholars, who are citizens of the $\mathrm{CNO}$, have theorized that the Trail of Tears, is a historically anchored traumatic event that continues to impact health issues in the lives of CNO tribal members, that were specifically displaced through the Indian Removal Act of the 1830s (Schultz, Walters, Beltran, Stroud, and Johnson-Jennings, 2016; Walters and Johnson-Jennings, 2014). Building on the Indigenist Stress-Coping (ISC) model (Walters and Simoni, 2002; Walters et al., 2002), these researches developed the Yappallí Choctaw Road to Health project to address health issues with the CNO. "Yappalli", translated in the Choctaw language means "to walk slowly and softly." This can be seen as walking "with reverence" or "blessing the grounds" (Schultz et al., 2016; Walters, Johnson-Jennings, 2014). Researchers are searching for the answer to the question, "What is the Choctaw road to health for future generations?" and are attempting to address historically anchored and place-based traumatic events, and their connection to current health inequities. They want to create and teach this current generation to have a vision of health for the generations to come, just as their ancestors had a vision for them. The Yappallí project is an innovative, culturally grounded Choctaw health promotion model centering in Motivational Interviewing (MI) that emphasizes experiential learning, personal challenges and engagement with place to address health related issues that impact the lives of tribal members of the CNO. 
These scholars have theorized that there is a connection between "historically anchored traumatic events and current health inequities among American Indians" (Schultz et al, 2016). This connection is relational as highlighted by the indigenous people's relationship with the land, to each other and spirit. "Not only did Choctaws believe that they were one with the earth of Nanih Waiya [the land at the center of their creation stories], the spiritual teachings also conveyed the consequences that would follow if they were to leave these lands" (Akers, 2004, pp. 3), the removal of the Choctaw people had, and continues to have, dire consequences for the People. Federal policies continue to be enacted in this country, since the time of contact, have created historical trauma and impact current day experiences and health disparities of AI people.

\section{Research Purpose}

"Our Vision of Health for Future Generations" is a culturally-centered qualitative study utilizing in-depth participant interviews, in the Choctaw language haklo "to listen deeply", and the Listening Guide Method of data analysis to explore the underlying motivations of change for a settings-based health promotion intervention - the Yappallí Choctaw Road to Health project. This study explores the culturally-based individual level (proximal) motivations, as well as community level (settings-based/intermediary) motivations that influence population health changes relative to health disparities with women from the Choctaw Nation of Oklahoma who participated in the Yappallí project between 2015 and 2017. Specifically, this study asked questions about the participant's motivations to participate in the Yappalli project, challenges participants experienced, and transformations they experienced due to their participation in the Yappallí project. 
Additionally, participants were asked about their vision health for future generations. This study is building on current research addressing historical trauma from a decolonized and indigenous framework and to address gaps in social work and health research that addresses the specific needs of tribal and AI women, and research that includes and empowers the voice of AI women in the form of narrative storywork, while shifting the focus from pathological focus to a resilience focused understanding.

Additionally, this study works to address gaps in methodological understanding of how to create decolonized and indigenized methods of social work research models.

"Our Vision of Health for Future Generations" was a collaboration between the Choctaw Nation of Oklahoma (CNO) and the University of Washington and the Yappallí Choctaw Road to Health project (NIDA R01 DA037176). This project was feasible because of the preliminary work accomplished with study mentors, Dr. Orellana, Dr. Walters, Dr. Johnson-Jennings and Dr. Ramona Beltrán. Additionally, this study was feasible because of the technical support of the Indigenous Wellness Research Institute and the Northwest Portland Area Indian Health Board Northwest Native American Research Centers for Health. I have the unique benefit of working with an all-indigenous research sponsor team who, with their combined experience, have been conducting research with indigenous communities for over twenty-five years.

\section{Parent Study: Yappalli Choctaw Road to Health}

Yappallí Choctaw Road to Health (NIDA R01 DA037176) is a culturally focused, strengths-based outdoor experiential obesity-substance use risk prevention and health leadership program. The 3-month intervention (i.e., individual meetings; group sessions, 
culture camp, and Choctaw Trail of Tears walk) is grounded in the Indigenist Stress Coping (ISC) model and the Yappallí Information Motivation Behaviors skills framework. The Yappallí project proposes to evaluate the program among 150 at-risk adult Choctaw women across 5 regions of the $\mathrm{CNO}$, where AI women have some of the highest obesity, physical inactivity and excessive drinking prevalence in the country. The Yappallí project is a longitudinal study designed to evaluate the intervention impact on substance use and obesity prevention with primary aims of: (1) substance use harm reduction and substance use and intentions to use; and (2) reduction in weight/BMI, increase in leisure-time physical activity; and adoption of healthful food habits. The five community sites included in the target sample are women over the age of 18 , enrolled in the $\mathrm{CNO}$, and at risk for obesity and substance misuse.

\section{My journey}

My names are Ahchishi Okshulba "Honeysuckle Breeze”, Onnahinli Fichik (Danica) "Morning Star", and Aspen Leaves Turning Gold. I am Choctaw of the Watonlak Oshi "White Crane" Clan and Scottish of the Clan Ross, born and raised in Northern New Mexico. I come to this work as a multiracial woman, tribally enrolled citizen of the Choctaw Nation of Oklahoma, who grew up in the diverse and beautiful community of Northern New Mexico. These life experiences have shaped my worldview and continue to inform my research practices as well as my desire to develop ontological, epistemological, and methodological frameworks grounded in decolonized and indigenous knowledge, and emerge from a deep love and respect for the People, our ancestors, and for iholitopa pishki "our beloved mother earth". By continuing to develop 
as a trained researcher, I engage in work that can best translate these practices for the betterment of the People. My epistemological approach has been shaped by my relationships with my parents, my grandfathers and grandmothers, my siblings, and members of my community and tribal relations. Because of them, I have a deep respect for and love for the people I serve. This also shapes my understanding of the fields of social work and research, and will continue to inform my practice, scholarship and research.

My Choctaw clan is Watonlak Oshi, "white crane". This has a significance to my understanding of my place in the world and this work. Watonlak Oshi has a strong link to spiritual health according to Choctaw teachings. Watonlak Oshi symbolizes the mind taking flight into the spiritual side. Watonlak Oshi feathers were often worn by Choctaw healers who were skilled in inducing trances as a symbol of fully engaging in the spirit. Stick ball players also wore crane feathers as well while they engaged in the spiritual game. Watonlak Oshi symbolizes letting cognitions rest and healing through mindfulness and transcending the trauma mentality. Watonlak Oshi also encourages one to seek out appropriate healing preferences and decisions and skills towards increasing spiritual health. Watonlak Oshi clan informs my relationship to my work as a social worker and researcher.

It has been an honor to be involved with the Yappallí project both as a volunteer, a participant in the feasibility study, and as a lifelong learner who is mentored by the principal investigators, Dr. Walters and Dr. Johnson-Jennings. I have walked the Trail of Tears four times - once in 2013 and 2016-2018. In 2013, I participated in a feasibility study; in 2016-2018, I participated as a support volunteer. Every time, I have had deep, 
transformative experiences that informs this body of work and continues to shape my worldview. Over one hundred and seventy-five years ago, my grandmothers, aunties, and sisters of my past walked the Trail of Tears. These ancestors held tenderly in their hearts a vision for of health for future generations of Choctaw peoples, defined as "healthy and thriving.", they held this vision for me. Their vision was to create health and balance for the People and preserve the Choctaw culture for many generations to come. This, along with their love for the Choctaw people, carried them forward, step after step, across generations to my own. Out of love, our ancestors loved us that they sacrificed themselves for the wellbeing of their children and their children's children.

Guided by this vision and in honor of their teachings and sacrifice, I extend my love to my people and future generations by carrying their vision forward to the future generations as an offering to their own hearts, resistance and strength. Despite this vision and resilience, staggering health disparities in the Choctaw Nation of Oklahoma and other AI communities continue and are well documented. While on the trail, we contemplated different health issues facing the Choctaw people in contemporary times. The purpose of these journeys was not to dwell in the "drama of the trauma" but to revisit the original instructions these survivors had for us and to carry that vision forward. We also hoped to bring back these experiences to inform our health practices and service to our people, i toksvli isht ahalayah "service with the deeply caring responsibility". This work is centered in this concept. 


\section{Chapter 2: Literature Review}

\section{Health Disparities with American Indians}

American Indian (AI) communities are a rapidly growing and diverse population: the 2.3 million AIs in the United States (US) constitute approximately $1.7 \%$ of the total population and are expected to grow $26 \%$ to 2.9 million persons by the year 2030 (USCB, 2010). Over the past several centuries, AI's have endured a series of traumatic events which have had devastating consequences for AI health and wellness. AI health is anchored in a historical context and manifested across generations which impacts contemporary forms of health. The impact of removal from homelands, grief and loss of culture and identity, and the challenges AI communities face to reconcile are examples of federally supported acts of genocide against the traditional peoples of these lands currently known as the United States.

One of the consequences of these policies was the forced removal of indigenous peoples from their traditional homelands, through the American Indian Removal Act of 1830, signed into law by Andrew Jackson. Removal from traditional homelands severed tribal people's connections to resources, such as the land and traditional food sources, that gave meaning to their identity from which their creation stories originated. This traumatic act has manifested across the generations for many, as profound soul wounding and unhealed grief, which continues to impact their health in contemporary times. In recent years, the crisis has manifested in AIs disproportionately bearing the burden of health disparities in the US. AIs are 1.6 times more likely to suffer from being overweight than non-Hispanic whites (US DHHS, 2014) and experience alarming rates of Type 2 diabetes, cancer, and cardiovascular diseases, which have been linked to pediatric 
obesity (Jones, 2006). In 2013, AI/AN men and women had the highest rates of being overweight (respectively at $32 \%$ and $49 \%$ ) compared to other races and rates were rising (US DHHS, 2014). In 2010, 59.2\% of AI did not meet federal physical activity guidelines, as compared to $45.1 \%$ of Whites. AIs die at higher rates than non-AIs from diseases such as diabetes, cancer, cardiovascular and substance-related diseases such as cirrhosis, unintentional injuries, and suicide (Brockie, Elm and Walls, 2018; IHS, 2006; Jones, 2006). AI also have a higher prevalence of behavioral risk factors, particularly cigarette smoking, being overweight, absence of leisure-time and general physical activity levels, binge drinking, and diets characterized by high fat content and inadequate servings of fruit and vegetables (Aldworth, 2009; Beals, Manson, Whiteshell, Spicer, Novins and Mitchel, 2005; Brockie, et al., 2018; Johnson-Jennings, Belcourt, Walls, Town, and Walters, 2014; Johnson-Jennings, Tarraf, and Gonzalez, 2015; Jones, 2006; Novins, Aarons, Conti, Dahlke, Daw, Fickenshcher, Fleming, Love, Masis and Spicer 2011; Thompson, Johnosn-Jennings, Bauman, and Protor, 2015; Walters et al., 2012). Women of the Choctaw Nation of Oklahoma (CNO) have some of the highest rates of being overweight, physical inactivity and excessive drinking prevalence in the country (Walters and Johnson-Jennings, 2014).

Health disparities and substance misuse are increasingly prevalent, costly, and deadly in Indian Country- fueling a twin epidemic. Behavioral patterns seen with one being overweight share core elements with drug misuse behaviors, such as continued engagement in problematic behaviors despite dire consequences to one's own health, family, and community and has been designated as a research priority area at National Institute on Drug Addiction (NIDA) (Volkow and Wise, 2005). AI women, in particular 
exhibit significant disparities in being overweight and substance misuse prevalence and higher rates of premature mortality and morbidity as a result. Despite these disparities, there is a scarcity of research addressing the health and substance prevention needs of AI women and AI women are not engaging in interventions that address these health issues. Timing for addressing these efforts is critical given that AI communities are a rapidly growing and diverse population. AI women are disproportionately affected by many social and behavioral factors that contribute to substance use related health disparities, i.e., younger, more female-headed households, larger families, lower high school graduation rates, lower median incomes, and are more economically impoverished compared to non- AI populations (Torres-Slimming, Orellana and Suarez-Maynas, 2014; Walters et al.; 2011a; Walters et al., 2011b; Walters and Simoni, 2002a; Walters and Simoni, 2002b, Walters et al., 2002). Given the historical positions of AI women as healers and leaders in pre-colonial Tribal societies, this act of removal interrupted the balance of gender roles within tribal cultures, the position of women and non-men as sacred has resulted in contemporary perceptions that undermine and harm the health of AI women and non-men. A full characterization of these factors await further inquiry, and understanding these relationships is important for reestablishing health and wellness for tribal communities, which would benefit in the development and implementation of social work and health interventions and research methods.

Particularly powerful is the process by which colonization has become internalized among AI peoples and serves to shape health outcomes. For example, U.S. federal policies stemming from Manifest Destiny defined AI peoples as "not human", "savage" and "expendable," today these ideas shape society-level and individual-level 
frameworks about the potential of AI peoples. Genocide against the indigenous people in the Americas is one of the most massive and longest lasting campaigns in human history (Anti-Defamation League, 2005; Chenault, 2011; Dunbar-Ortiz, 2014; Duran and Duran, 1995; Jahoda, 1975; Newcomb, 1992). Genocide, assimilation, and the long-term effects of the termination policies are traumatic events that have resulted for many AIs as unhealed trauma that is carried and shared across the generations. Historically, research has focused on the "pathology" of indigenous people, with the inference being that these health indicators, or ways of coping with colonialism, are pathological (Boven and Morohashi, 2002; Duran and Duran, 1995; Gone, 2007 and 2012). Much of this research focuses on the negative impacts of such indicators; such as substance misuse and mental health, its effect on indigenous communities, and the impact of historical trauma. Additionally, AI people have not been drawn to interventions that have a focus on deficits and pathology. "New insights reveal that development interventions have failed to induce people to participate because these interventions have lacked both the will and the instruments to allow people to use their own knowledge" (Boven and Morohashi; 2002, pp. 12). There has been increased understanding of the importance of having interventions and providers who have cultural humility (competence). "Virtually all of the current analysis of these disparities reiterate that 'culture counts' when it comes to studying, understanding and (hopefully) redressing the untenable inequities" (Gone, 2007, pp. 290). Gone (2007) states there has been little acknowledgement of how AIs have been affected (historically and currently) by "the confluence of power and history" (pp.292). Duran and Duran (1995) state that "indigenous approaches to prevention and treatment benefit by being accompanied by postcolonial histories of alcohol in Indian 
Country" (pp. 126), addressing the complex and intersectional nature of addiction, mental health, and health disparities within AI communities.

Duran, E. (2006) and Duran and Duran (1995) discuss a holistic understanding of mental illness, framing it as postcolonial, using indigenous knowledge to underline the western philosophy of mental illness to understand the complex nature of mental health impacted by what they refer to as "post-colonial stress disorder" among AI communities. They identify disease or disorder as having a "spirit," that these spirits are part of who we are, and that it is not helpful pathologize these spirits or conditions; they suggest creating a relationship with the spirit, to create balance and harmony. Indigenous communities around the globe have historically acknowledged neuro-diversity. The word coined in te reo Māori for autism is Takiwātanga, (tōku/tōna anō takiwā) "my/his/her own time and space" (Opai, 2017), underlining a holistic understanding of neuro-diversity, rather than pathology.

Duran, E. (2006) believes when working with AI communities a "liberation discourse provides some of the practical knowledge needed to heal the wounded souls of our people and communities" (pp. 13). Both western and indigenous knowledge have "evolved through cross-cultural contact and interaction for centuries. Consequently, neither scientific knowing likely exists in pure form as a bounded system of knowledge" (Gone, 2012, pp. 495). Western based knowledge is only one of many forms of knowledge systems, indigenous knowledge is another form of knowledge system that have been developed and tested, for the benefit of local communities, over millennia. It would suffice to say that it would benefit fields of social work to embrace decolonized 
and indigenized understanding of health and wellness, not only for the benefit of AI people, but also for the benefit of non-indigenous people.

\section{American Indians and Substance Use}

AIs have a long history and complicated relationship with mind altering substances. Historically, AI people have used substances in ceremony and ritual since time immemorial. This tradition has continued through the Pan-American Indian ceremonies of the Native American Church (NAC), with the use of peyote as sacrament. But AI's relationship with substances, primarily alcohol, has been more complicated and intersectional than the NAC's relationship to peyote. "The United States used whiskey as an agent of conquest" (Akers, 2004, pp. 23). Alcohol was introduced into AI communities as a weapon against them, and has been used against AI communities as a tool of colonization and of social control sense 1492, continuing to this day. Distilled alcohol was introduced to AIs by European traders (Akers, 2004; Duran and Duran, 1995; Faiman-Salva, 2000; Galloway, 1998; Pesantubbee, 2005) from the point of contact, introducing and using alcohol to manipulate trade negotiations in their favor, then criminalizing the use of alcohol in tribal communities, including the Choctaw. "The U.S. government even issued a daily ration of whiskey to the Choctaws who were gathered for treaty negotiations at Dock's Stand in 1820, despite vehement protests of Choctaw leaders" (Akers, 2004, pp. 23). Alcohol was an effective tool of domination and manipulation, it was then used as a tool of social control to increase their power and dominance over AI communities even after treaty negotiations concluded. The U.S. then 
criminalized alcohol after AI community members became dependent, thus criminalizing dependence on the substance.

Although alcohol was introduced and used by government officials and settlers as a tool of social control, it was AI people who were labeled as "deviant" and became a "justification for paternalistic policies with the aim of obtain Native American land" (Duran and Duran, 1995, pp. 104). Alcohol very quickly became enmeshed into the AI identity. Thus the "definition of alcohol is centered on the struggle of related terms and their binary opposites: tradition assimilation, and savagery civilization" (Duran and Duran, 1995, pp. 119). The Choctaw had strict protocol against the use and selling of alcohol within the boundaries of the Choctaw territory prior to removal and were critical if the white missionaries that were known to bring alcohol into the Nation labeled “expressly for Indian trade!" (Akers, 2004 pp. 119). The Choctaw's disapproval of white settlers selling alcohol with in the Nation boarders was met with contempt from white settlers and government agents. The Choctaw understood that the use of alcohol was the quickest way to destroy Choctaw cultural ways and leaders believed that this left tribal members open to deceit by white settlers (DeRosier, 1981). Yet, with this complex and intersecting relationship with substances, substance dependence is primarily viewed as a moral condition, thus interventions tend to be based on this theory of "addiction" and not in the complex nature of substance use disorders within this socio-cultural context. To this day, the legacy of alcohol misuse is left for AI women who deal with the brunt of the consequences of addiction and historical trauma in their families, tribes and communities. They are left with broken communities, lack of resources and held account to family and community to be the primary caretakers with little support. 


\section{Trauma's Impact on Food and Health}

Traditional AI protocol honors the sanctity of food "...as the creator made them and as our ancestors nurtured them" (Nelson, 2008, pg.181). Traditionally, food is viewed as medicine; the land from which it grows and the seeds from which they grow from are all sacred. There are many AI creation stories that include stories of the first foods being a manifestation of a sacred spirit in physical form, such as the 'Corn Mother" or "Three sisters". For many AI's Traditional Indigenous Knowledge (TIK) has been broken by the process of colonization, through the removal of AI people form their traditional homelands, traditions food systems, and the introduction of "commodities". Commodities given to AI's included canned meats, soups, and juices; pasta; cereal; rice; cheese; peanut butter; corn syrup; flour; dry, evaporated milk; and vegetable oil. Food that were not traditional, that were high in sugar, fat, and carbohydrates, that AI were not accustomed to. During the removal of AI people form their ancestral homelands, to be placed on reservations, these policies having a significant impact on the health of AI people and our access to healthy food.

The United States food programs provided foods that were higher in fat and calories and lower in fiber than AI traditional foods. "The use of the term 'Comod-Bod' in tribal communities captured the essence of the changes that occurred. The addition of commodities to American Indian diets was part of a group of changes that together have influenced current health problems" (Chino, Haff and Dogge-Frances, 2009). "ComodBod" is a term used on Indian reservations to denote a person who is extremely overweight. Obesity is quite common on American Indian reservations due largely in part to the consumption of monthly USDA commodities under the Food Distribution Program 
on Indian Reservations (FDPIR) for low-income American Indian households. Along with this change in the diet, there was a change in the relationship AI people had with food. Food once was viewed as medicine, it was scared, now is viewed as something to be consumed.

Food as medicine refers to a focus on our relationships with our local landscapes, plants and animals for nourishment, healing and wellbeing. Historically, indigenous peoples have honored shared relationships with traditional foods to promote wellness and balance. The legacy of colonization disrupted the critical relationship between indigenous communities and their food, thereby disrupting health (e.g., traditional food practices, access to traditional foods and community involvement in growing and sharing traditional foods)-leading to increased diabetes and diseases related to obesity. Strong indigenous cultural strengths and protective health factors can inform efforts to address health inequities related to reducing obesity and diabetes. Beyond prevention of disease, and promotion of wellness within communities, food has a central role within indigenous life ways and traditions carrying a spiritual significance for many communities. Food has the unique ability to help develop identity, facilitate and strengthen relationships while restoring health balance.

\section{American Indian Social Work Practice}

Social work as a field of study has historically lacked success in working with AI communities, primarily because the field has focused on and moved towards evidencebased practices and other standardized methods in trying the "help" these communities (Gone, 2007; Sinclair, 2003a and 2003b). Additionally, social workers lack a clear 
understanding of the multidimensional nature of AI communities and retain stereotypical beliefs about these diverse, complex, and beautiful cultures. The reality is that AI cultures are very diverse and it is unrealistic for any social worker to be competent in working with all AI and/or in all tribal communities (Lewis and Ho, 1975; Garrett, 1999), there is a movement to refer to "cultural competence" as "cultural humility". AI cultural diversity is "not the 'blood' but rooted in forms of life that exist at the confluence of historical and contemporary forces" (Kirmayer, Simpson and Cargo 2003, pp. S19). Social workers need to have a clear understanding in how colonization has negatively impacted these communities, the legacy of historical trauma that is caused by the history of colonization, how they have benefited from it, as well as their own beliefs about AIs and the complex and intersecting issues affect AI identity. Social workers of today have a moral and ethical responsibility to respond to the needs of the most affected communities. The historical efforts of any dominant culture to construct "helping systems" have often done more harm than good with those who hold alternative or different values, practices or beliefs. As social workers of the future, this is a pattern they should aspire to avoid contributing to in any way.

Being AI means different things to each person. For some, it means that they are descendants of the original people of North America. For others it means a way of life or a way of being; a feeling, how one sees the world and one's self; a way of interacting with nature, family, and Creator. Indigenous culture in North America is rich in tradition, history, spirituality, art, economics, and politics. According the United States Department of the Interior (US DOI) (2018) there are currently 567 federally recognized tribes in the lower 48 states, 223 village communities in Alaska and the Hawaiian Islands; each with 
its own identity, culture, and languages. Additionally, there are a significant number of AIs who live in urban areas and are influenced by urban culture who still attempt to remain connected to a tribal or AI identity. Many AI are transient in that they move back forth to reservations and urban centers.

Additional factors to take into consideration are the complex and diverse nature of AI values. "According to the theory of value orientation, traditional AI values can be summarized by a profile of value orientation that describes a culturally preferred set of solutions to the common problems faced by all peoples" (Garrett, 1999, pp. 86). Neely (1991) referrers to traditional value orientation as "harmony ethic", which guides behaviors and beliefs, and is based in an ancient wisdom of communal cooperation to maintain harmony with ourselves, community, land, and spirit (Garrett, 1999; Nelson, 2008a; Neely, 1991; Wilson, S., 2008). "Harmony ethic is a system based upon caring for fellow human beings through the expression of deep respect and kindness" (Garrett, 1999, pp. 90). There are a number of factors that affects one's connection to, and experience of, cultural values. Garrett (1999) states that these include "level of acculturation (traditional, marginal, bi- cultural, assimilated, pan-traditional); geographic region; family structure; religious influences; and tribally specific traditions” (pp. 196). Many AI people discuss a common experience of "living in two worlds" and struggle with identity and place, to be accepted by the AI community and by the dominant culture. In reality AI people live in multiple worlds, with multiple intersections of experience that make this experience dynamic (Buchwald, Beals, Manson, 2000; Garrett, 1999; Garrett and Pichette, 2000). This struggle, the degree to which an individual acculturates, or not, and how one acculturates into a community, or not, can have a significant impact on 
one's social, intellectual, emotional, and spiritual wellbeing, sense of belonging, and mental health status, and affects our overall health. The field of social work, health sciences and social service providers have yet to come to terms with how to engage with these communities and to support them in ways that are empowering and engaging.

\section{American Indian Women and Health}

Although women historically held positions of influence in pre-colonial Tribal societies, and they shared in optimum health, their current health status is relegated to some of the worst outcomes across all racial groups in the United States (Brown, D., 2016; LaFromboise, Heyle and Ozer, 1990; Pesantubbee, 1999; Torres-Slimming et al., 2014; Walters et al., 2011b; Walters and Simoni, 2002; Walters et al., 2002). Choctaw women were recognized as gifted healers, spiritual advisors, and midwives (Pesantubbee, 1999; Swanton, 1931). According to Swanton (1931), women were just as likely as men to be alikchis, doctors, of all fields. "Women alikchis had herbal knowledge as well as ritual knowledge, and they were recognized as having the ability to foresee coming events" (Swanton, 1931, pp118). AI women have had to deal with the brunt of the consequences of substance misuse and trauma in their communities, and feel strong emotional pulls in many directions. In many AI communities, it is the women and nonmen who are the givers and keepers of health and wellness, they hold the family together, hold traditional practices, culture and ceremony, and who carry the burden of the loss of life, land, and spirit. Women carry life through birth, the caring of children and the home; they also carry the burden of maintaining the psychological and spiritual wellbeing of the community (Duran and Duran, 1995; LaFromboise et al, 1990; Mihesuah, 2003). "In a 
society that valued and depended upon reciprocal relationships women and men contributed to the well-being of their families and communities. Although the nature and extent of their contributions varied according to need and conditions, both engaged in all areas of Choctaw life" (Pesantubbee, 1999, pp. 390) Consequently, because of their multiple levels of investment in the community, tribe and family, many AI women suffer greatly from substance misuse, mental health and physical health inequalities, impacted by historical trauma. Despite these disparities, there is a paucity of research addressing the health and substance prevention needs of adult AIs in general, but even less information is available on prevention needs of AIs living in Oklahoma, and virtually no community-based prevention efforts target AI women. Compounding this, many interpretations about AI women remain incorrect, underdeveloped, perpetuate negative stereotypes, and continue to regulate AI women to the margins of society.

AI women have historically been under represented in social work and health research, but even less understood is the specific cultural influences and experiences of women within their Tribal communities. "There have been fewer empirically based research studies conducted with only American Indians as the subjects" (Goodluck, 1998, pp. 28). Very few studies have been conducted with Tribal women, Goodluck (1998) address this issue in her work with women of the Navajo Nation when she interviewed 20 self-identified Navajo girls in addressing their ethnic identity. Leighton and Kluckhohn (1947) conducted a psychological and medial study with Navajo children and their parents. Lefley (1974) conducted a study with the Miccosukee and Seminole Nations addressing levels of acculturation, self-esteem and self-concept, by interviewing 72 children and their mothers. 
There has been some health research conducted with AI women. Evans-Campbell, Lindhorst, Huang, and Walters (2006) conducted a study to determine the prevalence of interpersonal violence among urban AIAN women and the behavioral health and mental health factors associated with this violence. They found that among respondents, over $65 \%$ had experienced some form of interpersonal violence, $28 \%$ reported childhood physical abuse, $48 \%$ reported rape, $40 \%$ reported a history of domestic violence, and $40 \%$ reported multiple victimization experiences (pp. 1416). This study indicated that AI women experienced high levels of emotional trauma related to these events. A history of interpersonal violence was associated with depression, dysphoria, help-seeking behaviors, and an increase in high-HIV risk sexual behaviors. Research conducted by Henderson and Ainsworth (2003), reviewed qualitative data from the Cross-Cultural Activity Participation Study (CAPS), they synthesize the major findings of studies designed to identify minority women's perceptions of physical activity. They interviewed 30 African American and 26 American Indian women with constant comparison techniques. This study showed fewer than $30 \%$ of minority women in the United States obtain moderate activity in amounts sufficient to derive health benefits. More than half of all women interviewed lead sedentary lives, and among women of color this percentage is even higher. This lead minority woman for being at risk for premature death, some chronic diseases, and obesity is associated with physical inactivity. "If behavioral changes, health improvement, and an enhanced quality of life are to be achieved, researchers must understand how individuals perceive physical activities" (Henderson and Ainsworth, 2003, pp. 313). This study indicates it is important to understand physical activity patterns and how they occur so that effective interventions might be devised and 
encouraged. Scholarship addressing these issues is important for us to continue to understand these roles and how to developed a nuanced understanding of how this vital knowledge can inform practice, policy and research.

There is very little research conducted with Choctaw women. Waters and Johnson-Jennings (2014) conducted the Yappallí Pilot Intervention to field test the Yappallí model. They, along with twelve Choctaw and five allied participants, walked 254 miles along the original Trail of Tears. Data from this intervention informed the current intervention to focus on women; focus on obesity and substance use prevention; and tailor curricular content given the time and attention participants could realistically give during the walk. I assisted in the pilot testing of the curriculum and in the implementation of the curriculum on the Trail of Tears portion of the RO1 funded intervention (Walters and Johnson-Jennings, 2014).

Yappallí qualitative findings were compiled in a study named "'I'm stronger than I thought': Native women reconnecting to body, health, and place” (Schultz, et al, 2016). The goal of this study was to identify conceptualizations of health and features of an intervention to facilitate motivations of behavioral change in reclaiming health practices. The analysis drew on two sources of qualitative data from Choctaw tribal members: fourteen 14 semi-structured interviews and two focus groups $(\mathrm{N}=9)$. Relationships with other tribal members, stronger tribal identities, individual/group responsibility and understanding "what it means to be Choctaw" emerged as key components in participants' descriptions of health. Balance and holistic views integrating mental, physical, and spiritual aspects of health as well as the importance of cultural traditions and the need to reclaim traditions and ceremonies within tribal health practices were also 
articulated (Schultz et al, 2016). There is a clear lack of social work or health research addressing the specific needs of AI women, and there is even less research addressing the needs and experiences of women for specific tribal communities.

\section{Social Workers and Historical Trauma}

Social work and health professionals have a moral and ethical mandate to address the symptoms of historical trauma, this work can have a positive impact on survivors as they a break their silence and tell their stories. Additionally, there is an altruistic function that occurs by creating a shared societal narrative and giving to others of their stories or by re-connecting survivors to their geographic and social community, as well as humanity in general. "For Indigenous peoples, the concept of holism extends beyond the mental, physical, emotional and spiritual aspects of individual lives and includes relationships with families, communities, they physical environment, and the spiritual realm” (Quinn, 2007, pp. 77). Historical trauma happens within communities in specific physical places, so it stands to reason that healing should also occur within communities in those locations (such as the Trail of Tears). Thus, for complete healing, survivors need to revisit to those specific places where their ancestors were harmed not to relive the trauma, but to transform that experience in a contemporary context. That is, to renew balance and to create a vision for the seventh generation. The seventh generation is an indigenous concept is derived from the Constitution of the Iroquois Nation "In every deliberation, we must consider the impact on the seventh generation... even if it requires having skin as thick as the bark of a pine" (Hill, 2001). In a sense, we are traveling back 
in time and place to walk with our ancestors- past, present and future- for the purpose of healing these deep wounds so the seventh generation can live healthy lives.

Many scholars suggest the need to differentiate between the traumatic event and one's response to that event. In fact, some make the distinction between historical trauma and historical trauma response (Denham, 2008; Duran, 2006; Yellow Horse Brave Heart, 1998 and 2004). "It is important to recognize that traumatic events do not always result in psychiatric distress; individuals, as well as societies, differ in the manner in which they experience, process and remember events" (Denham, 2008. pp. 395). In other words, it is not the traumatic event itself that causes humans distress, but rather the reactions to that traumatic event. Denham (2008) found that the "resilient dimensions of its narrative praxis - that is, the active employment, telling and interpretation of narratives - illustrate how personal situations or experiences are given meaning and often interpreted in relation to a specific narrative or ancestor whom the individual closely identifies" (pp. 406). In the telling of these stories, the narratives are told and retold, to reflect the meaning and movement of trauma as a method of resilience. It is not simply through the gathering of memories that creates transformation of trauma, but the process of shaping and articulating the narrative within a specific cultural context (Denham, 2008). Vizenor (1994 and 2008) refers to this as "survivance".

\section{Information-Motivation-Behavioral Skills (IMB)}

A central framework for this study is addressing the proximal and intermediary motivations of the participants and Information-Motivation-Behavioral Skills (IMB) model is the used to inform the Yappallí project curriculum. IMB model (Fisher, Fisher 
and Harman, 2003) is a "social psychological conceptualization for understanding and promoting health related behavior" (pp. 82-83), which helps to understand the psychological determinants of behaviors that can improve or impair health outcomes. This concept highlights the relationship between the information, motivation and behavioral skills, and posits that if individuals are well informed, they will be motivated to act and thus change their behaviors. The reality is that even well informed individuals are inclined to not be motivated to engage in behaviors that improve their health. Thus motivation "influences whether even well informed individuals will be inclined to undertake health promotion actions" (Fisher et al., 2003, pp. 85).

There are many factors that influence motivation and individual's desire or willingness to take action. There are internal and external factors that can influence motivation. Motivation results from the interaction of conscious and unconscious factors such as the intensity of desire or need, incentive or reward value of the goal, and expectations of the individual and of his or her peers (Fisher et al., 2003; Osborn and Egede, 2010). Deci and Ryan (2008) note that there are both historical and contemporary theories of motivation that treat motivation as a unitary concept, "focusing on the overall amount of motivation that people have for particular behaviours or activities" (pp. 182). They attempt to differentiate these types of motivation, though Self Determination Theory as autonomous and controlled motivation.

The most notable distinction is "autonomous" and "controlled" motivation. "Autonomous motivation comprises both intrinsic motivation and the types if extrinsic motivation in which people have identifies with an activities value" (Deci and Ryan 2008, pp. 182). Whereas controlled motivation "consists of both external regulation, in 
which one's behavior is a function of external contingencies of reward and punishment" (Deci and Ryan 2008, pp. 182). These two forms of motivation lead to different outcomes and can hypothesis as to why AI women are not benefiting from or engaging in health interventions. Social work and health research has not focused on the autonomous motivation, or self-determination of AI communities.

Behaviors skill refers to the "performance of health promotion actions" (Fisher at al., 2008, pg. 85) and the extent to which individuals attempt to elicit self-motivational statements or "change talk," or any type of discussion about change. This is often accomplished through questions or comments designed to promote greater awareness/concern for a problem, recognition of the advantages of change, increased intent/optimism to change, or elaboration on a topic related to change (Fisher et al., 2003; Osborn and Egede, 2010).

Within the Yappalli project the 'information' component is the critical determinant of health behavior change; it provides the cognitive motivation and comprises the relevant information that influences motivation towards behavioral change. A distinctive version of 'information' included in the Yappalli intervention is the inclusion of cultural knowledge. This includes: "original instructions" (Chanspo Ikhvnanchi or sometimes Chanspo Tikbat) or ancient teachings related to food, activity, and medicines. The 'motivation' aspect relates to affect and attitude towards positive health behaviors. It utilizes existing social support systems and community support (love and commitment to the health and wellness of the next generation). Motivation is also enhanced by recognizing potential barriers (e.g., emotional triggers or disruptions in relational worldview) and finding ways to overcome them. The 'behavioral' aspect 
reflects the 'action' component that nurtures the development of skills needed to ensure behavioral change and health leadership. Information and motivation synergistically act as tools to develop behavioral skills, which then, ultimately improves health outcomes. This study explores the autonomous motivations conceptualized as culturally-based individual level (proximal) motivations, as well as community level (settingsbased/intermediary) motivations that influence population health changes relative to substance use and health disparities.

\section{American Indians Connection to Place}

Place and AI's connection to land is an important aspect of AI identity culture, worldview, and tradition; as outlined in the Creation stories of the Choctaw and many other Tribal Nations. Who they are as a people is intimately tied to their connection to place. Since time immemorial indigenous people across the globe have acted as guardians and stewards of the earth and biological diversity of this planet (Ausubel, 2008; Pierotti and Wildcat, 2000). Traditional Indigenous Knowledge (TIK) and Traditional Ecological Knowledge (TEK) has been grounded in the management of complex reciprocal relationships between humans, biodiversity and the planet, this includes a commitment to past, present and future generations and the seventh generation. By living in harmony, balance and developing respect of all living being's indigenous peoples developed a balanced relationship with each other, community, spirit and nature. Many indigenous traditions view land as relations, referring to the earth as Iholitopa Ishki "our beloved mother earth". Believing they are duty bound to protect and care take their relative. "Our connection to the land has to be the foundation of our society. For untold generations, we 
evolved from the land, and we learned to come to an understanding that this is our basis of teachings" (Sam, 2008, p. 40). In many AI teachings, this is the original instruction of the People.

The survival of humanity is tied to the survival of the land and our connection to spirit. "Indigenous scholars suggest that the most effective space to share cultural knowledge is in the place in which that culture was developed" (Schultz et al., 2016), and subsequently the healing of historically anchored trauma, connected to place, can be healed or transformed when returning to the place of the trauma. AI people, historically, have a special relationship with the land; it is not one of ownership, but of love and reverence "...the concept of place is deeply rooted in a profound relationship with the land; particular original tribal lands that are part of ancestral knowledge, ceremonial memory and historical significance" (Schultz et al., 2016, pp. 22).

This is reflected in the Choctaw's relationship Nanih Waiya, the land at the center of their creation stories. "This place is sacred; it is the place that was destined to be their homeland." (Akers, 2004, pp. 3). The Choctaw believe that humans are part of this place, that Nanih Waiya is in their DNA, epigenetically passed down from generation to generation. The Choctaw believe that this land, Nanih Waiya is Iholitopa pishki "our beloved mother", a mother that can facilitate the healing of her People. For indigenous people interaction, experiences, and healing happen in places of historical and spiritual significance. Indigenous scholars (Brown, D., 2016; Cajete, 1994; Cajete, Mohawk, Rivera, 2008; Lowan, 2009, Schultz et al., 2016; Simpson, 2002 and 2004; Walls, Johnson, Whitebeck, Hoyt, 2006; Walters et al., 2011, Wilson, K. 2003) would suggest that reconnecting with place and ancestral homelands maybe one way of connecting with 
traditional health knowledge and integrating this knowledge into cultural approaches to health promotion, as well as the healing of historically anchored trauma.

TEK “assumes that humans are, and will always be, connected to the natural world, and that there is no such thing as nature that exists independent of humans and their activities" (Pierotti and Wildcat, 2000, pp. 1335). In contrast to the western science views that the natural world as separate and in control of by humans, in which the natural world is to be exploited for economic and aesthetic purposes (Pierotti and Wildcat, 2000). TEK respects nonhuman life, the bonds between human and nonhuman life, respecting and incorporating nonhuman ethical codes of behavior, the importance of place and the understanding that humans are just one part of the ecological system. TEK also acknowledges that indigenous peoples take TEK with them in forced and voluntary migrations, which contributes to their survival. Such as in the survival of the Choctaw on the Trail of Tears and their relocation to the Indian Territory, or what is now called Oklahoma. Additionally, Pierotti and Wildcat (2000) view TEK as the intellectual foundation of indigenous theory and practice of both politics and ethics, grounded on natural place and connection to the natural world, and is based on generations of empirical observation of the natural world that is multidisciplinary. Thus, "one such tactic involved representing sound ecological management in strongly ethical (or religious) terms and developing a view of the environment that stressed specific concrete bonds between nature and the human community" (Pierotti and Wildcat, 2000, pp. 1336). The heterogeneity of indigenous peoples is reflected in their intimate relationships with land and the biodiversity within these places. The removal of the People from their traditional homelands is, and was, an act of genocide that continues to impact AI communities. 
Within many indigenous cultures there is a common belief that "we are all related". This is not a metaphor of romanticized world-view, this is a realization that all life, human, nonhuman, and the environment, are all connected and that "no single organism can exist without the web of other life forms that surround it and make existence possible" (Pierotti and Wildcat, 2000, pp. 1338). AI scholars (Berkes, Colding and Folke, 2000; Pierotti and Wildcat, 2000; Wildcat, 2005; Wilson, K., 2003) believe there can be improvements to scientific research and management; the identification of new paradigms to better understand the natural world and our relation to it; broad societal change away from the western science and toward a holistic and ethical paradigm; and there are opportunities for practical and productive collaboration for the healing of historical trauma and the liberation of humanity. This culturally-centered study will explore proximal and settings-based/intermediary motivations that influence health changes with women who live in Oklahoma and have participated in the Yappallí project, a settings based health promotion intervention developed in collaboration with Choctaw researchers and the Choctaw Nation of Oklahoma, specifically addressing the participant's connection to the Trail of Tears.

\section{History of the Choctaw}

The Choctaw's world view, their relationship to their traditional homelands and agriculture, the removal from their traditional homelands, traditional ways of life, and their subsequent experiences of racism, violence, and attempted genocide, contributes to the substantial health disparities they are experiencing today. Prior to the colonization of their lands, the Choctaw people lived in thriving, heathy communities, connected to each 
other, to their land and to the agriculture cultivated in their communities. They had a deep and spiritual connection to all of their ancestral domain and the removal form their traditional homelands contributed to the historical trauma they continue to experience.

The Chahta (the original name of the Choctaw people), have two creation stories. In brief, it is said that the People were created from a sacred mound, Nanih Waiya (Henry, 1901). It was from this mound that the Creator formed the first of the People. These people crawled through a long, dark cave into daylight and became the first Choctaw. In the second story, two brothers, "Chahta" and "Chikasa" lead the People on a 43-year journey from the Northwest to the Southeast, following the prophecy wherein they were told there was fertile land and abundant game. The prophecy told that as long as the People lived in this place it would provide peace and prosperity for eternity. The brothers lead the People, and each night they would post a pole at the front of camp. In the morning the brothers would follow in the direction the pole was leaning, until one morning the pole was standing upright, known to be the location of Nanih Waiya. Chahta stayed in what we now know as Mississippi and established the Choctaw Nation. While his brother, Chikasa, continued to journey further east and established the Chickasaw Nation (DeRosier, 1981; Galloway, 1998; Jahoda, 1975). It is believed that the Choctaw people lived in this place $4000-8000$ years prior to contact with Europeans. Nanih Waiya is known to be the center of the universe for the Choctaw people, "where the earth was actually part of the Choctaw, the living and the dead" (Akers, 2004, pp. 3).

The Choctaw are members of the "Mississippian" cultures and are of the Muskhogean linguistic groups found in the southeastern part of the United States of the Americas, and are heirs to the mound builders and cultivators of tanchi "corn" (DeRosier, 
1981; Dunbar-Ortiz, 2014; Galloway, 1998; Jahoda, 1975). Mississippian culture is a term referring to the precolonial populations existing in the southeastern woodlands during A.D. 800-1500, centering their culture on the horticulture and the cultivation of corn, beans and squash. Little is documented about the daily life of precolonial, cultures of the Mississippian period. What is believed is “...many, if not all, Mississippian populations could be generally characterized as having a settlement system consisting of dispersed farmsteads surrounding a local center, with this system representing a flexible compromise solution to the opposing pressures of optimum energy utilization and optimum social-cohesion-boundary-maintained abilities (Smith, B., 1978, pp. 491).

Smith, B. (1978) attributed three factors to define Mississippian boundary conditions; adaptive niche; settlement system; structure and level of complexity of the sociopolitical organization (pp. 474), these cultures revolving around the cultivation of corn, squash, and beans, commonly referred to as the "Three Sisters". The term "Three Sisters" emerged from the Iroquois creation myth.

"It was said that the earth began when 'Sky Woman' who lived in the upper world peered through a hole in the sky and fell through to an endless sea. The animals saw her coming, so they took the soil from the bottom of the sea and spread it onto the back of a giant turtle to provide a safe place for her to land. This 'Turtle Island' is now what we call North America. Sky woman had become pregnant before she fell. When she landed, she gave birth to a daughter. When the daughter grew into a young woman, she also became pregnant (by the West Wind). She died while giving birth to twin boys. Sky Woman buried her daughter in the "new earth. From her grave grew three sacred plants-corn, beans, and squash. These plants provided food for her sons, and later, for all of humanity." (Erney, 1996. 38). 
Three Sisters is a highly sophisticated form of companion planting, developed and utilized by many indigenous cultures across the Americas. Scientifically, the planting of these three plants together has benefits for all of them. The corn takes nitrogen from the soil. Bacterial colonies on the roots of the bean capture nitrogen from the air and put some into the soil. The corn supports the vines of the beans. The squash, with its sprawling vines and leaves, keep the weeds down. The closeness of the plants conserves water and prevents water loss and soil erosion. When cooked and eaten together these three vegetables provide a complex protein that is equivalent to $8 \mathrm{oz}$. of fish (Erney, 1996).

Historical records indicate that squash was first cultivated in the southeast as early as 2000 B.C., with tropical flint corn seen 200 B.C. Domesticated corn has been identified in central Mexico dating back 10,000 years (Dunbar-Ortiz, 2014). Corn could be grown widely, yet will eventually exhaust the soil, unless it is grown with beans. Galloway (1998) reports both of these cultigens became available around 800 B.C. which coincides with the appearance of Mississippian cultures in this area. As populations grew, so did the dependence on plant based food sources (primarily corn), rather than hunting as the primary source of food. Thus, Mississippian cultures, economics, and religion were centered on this vital food source (Dunbar-Ortiz, 2014), influencing the creation of settlement socio-economic-political systems which rooted families in a specific location (DeRosier, 1981). The Choctaw were able to develop one of the largest and most advanced societies east of the Mississippi, primarily due to their relationship with the land and agriculture (DeRosier, 1981; Silverberg, 1986). The Choctaw were so proficient in the cultivation of corn and the raising of livestock, they were able to trade with other 
tribes, and white settlers as well. This helped the Nation to stabilize and settle into one place and to establish a large territory, with the economic, societal, and spiritual connection being in relation with corn.

The importance of tanchi to the Choctaw people is expressed through the Green Corn dance. The Green Corn dance, 'Tanchushi Hilha' was, and continues to be, the most sacred, spiritual, and social ceremony for the Choctaw people, as well as other Southeastern tribes. The Green Corn dance was held during the ripening of the corn crop in late July. It is a time of community building, rekindling friendships, reconciliation, purification and decontamination, re-separating restoring balance, making new beginnings, and giving praise and thanksgiving to the Great Spirit (Akers, 2004; Choctaw Nation of Oklahoma, 2016). The Green Corn Dance and ceremony lasted four days. The first day was setting up camp and re-establishing connections with old friends and sharing story. On the second day, everyone fasted or 'okissa', while the Choctaw doctor, 'alikchi', administered herbal drinks to participants to purge their bodies while males and females were bathed separately in a purifying herbal solutions. The third day, they broke their fast with a feast and the Stomp Dance which was held around the central fire, the dance lasting from dusk till dawn. The men lead chants which was echoed by other male chanters. Women danced using turtle shell rattles fastened to their ankles. The fourth day was spent visiting friends and relatives and in breaking camp.

The Choctaw communities consisted of extended families, or "house groups" (Haag and Willis, 2001) living in permanent structures made out of log and stucco grouped together in settlements near river basins (Haag and Willis, 2001), farmed land (Galloway, 1998) and old temple mounds (Silverberg, 1968). Archaeologists referred to 
the Mississippian tradition of mound building as the "Woodland Tradition," established around A.D. 700 (Silverberg, 1996). The tradition of mound building was classified as burial, temple, sacrifice, and chieftain (Silverberg, 1996). The mounds are an important aspect of Choctaw culture, as indicated in our creation stories, and our connection to Nanih Waiya. These flat-topped mounds are reminiscent of the stone temples found in Mexico, 'teocallis.' These mounds are an indication that Mississippian cultures shared knowledge with the Mayan and Aztec of Mexico (Silverberg, 1968), along with the sharing of corn that was first cultivated in Mexico 10,000 years prior, and the similarities of our Stomp Dance with their dances. In Choctaw oral tradition, there are stories of knowledge sharing with our relatives from Mexico.

Kinship was important aspect of Choctaw culture, it provided identity to the individual, family, clan, and village (Akers, 2004). "It [kindship] defined all Choctaw people, and, therefore, all people who were not Choctaw. Kinship dictated behavior and ordered what and how each human related to all others" (Akers. 2004, pp. 43). Clans were basic units of kinship and were matrilineal. Specifically, the Choctaw attempted to uphold the teachings of their ancestor's original instructions, 'Chaspo Ikhvnanchi,' through traditional clans, social activities, and roles managed through seven societal teachings, which included, Nashoba (wolf), Koi (Cougar), Halupa Hishi (Holly Leaf), Issi (Deer), Shawi (Raccoon), Watonlak (Crane), and Mahli (Wind). Fictive relationships were also established between peoples to define relationships to the satisfaction and benefit of all involved (Akers, 2004). This process of engaging people from outside the Choctaw Nation was to establish expectations and behavior around these relationships. 
The Choctaw traditionally were a matriarchal society which was intimately associated with the clan system. Prior to colonization, people performed tasks that were gender specific, and among many tribes there were more than two genders. Although people had different roles based on their gender, none was considered to be inferior to the other. "In the pre-contact period Choctaws were successful agriculturalists; the women tilled the soil, sowed the seed, and harvested crops." (Mihesuah, 2003, pp. 45). This significantly contributed to the Nation's success, politically and economically. In precolonial Choctaw culture, women held positions of power, religious importance, and maintained control of descended tribal property (Mihesuah, 2003; Pesantubbee, 2005). Clans were determined by one's relationship with their mother. Children's lineage was transferred through their mother and they belonged to their mother's clan. Choctaw women received and maintained communal, family, and private property, and were responsible for all decisions related to this (Haag and Willis, 2001, Mihesuah, 2003; Pesantubbee, 2005). Choctaw women are still held with reverence, as the givers and keepers of life, "powerful, life-givers, independent and self-reliant" (Akers, 2004, pp.107).

In many AI cultures spiritual and physical worlds overlap. The Choctaw believed that "...this giant, all-encompassing system of life proceeded with order and reasonable predictability as long as two essential properties maintained: balance and harmony" (Akers, 2004, pp. 41). Akers (2004) believes that balance was understood as an avoidance of excess of all things and separation of forces of opposition to create harmony. Examples of opposition are fire and water, north and south, Upper world and Under world, etc. Akers (2004) goes on to define harmony to be the absence conflict and 
the avoidance of excess. The Choctaw believed that resources were to be shared with the community and the earth could not be manipulated or transformed for human profit (Akers, 2004).

Relationships were central to Choctaw spiritual and physical worlds. They viewed themselves as part of the great system of life (Akers, 2004). The very earth was considered to be the mother, chashki yakni or iholitopa pishki translated to mean "Beloved Mother." Choctaw people believe that we are one with all that was, is, is to be, and that we are not separate form this earth and the ancestral domain. The ancestral domain includes all living and non-living beings, land, the underworld and upper world, the sky, the wind, the whispers on the wind, and all that is and was. They believe they were part of the land, the soil, and an important element of the ecosystem. It is believed that all the forces of nature are significantly more powerful than humans and that the ancestral domain has a deeper depth of knowledge and wisdom than humans, and communicates with humans through dreams and visions (Akers, 2004).

The Choctaw believe that their ancestral homelands were given to them by the Great Spirit, and to leave these lands would lead to dire consequences. Separating the spiritual and the physical worlds is impossible for the Choctaw. Throughout the removal and reestablishment of the Choctaw, they believed that the prophecy was coming true; because of the significant deaths, famine, disease, small pox, drought, etc., that impacted the life of the Choctaw. After the Trail of Tears, many Choctaw returned to Mississippi because they feared the prophecy was coming true (Akers,2004) and believed they and their loved ones would suffer greatly if they were to leave. 
The Choctaw had a democratic-anarchical government system centered on community, democracy, and anarchical understanding of individuals and autonomy (DeRosier, 1981; Noley, 1985). The governmental system was divided into three districts - Northwest, Northeast, Southern, each with a miko "principle chief", this position was not hereditary, "but an illustrious ancestor was the greatest advantage an aspirant for office could possess" (DeRosier, 1981, pp. 8), other personal assets were military service and proven leadership or administrative ability. The miko was responsible for overall leadership of the district along with the support of elected captains and sub-captains; along with war chiefs. The war chiefs were under direct supervision of the miko, which was a unique attribute of Choctaw government; the subordination of the military to civil authority (DeRosier, 1981; Noley 1985).

One of the prominent features of Choctaw culture was the concept of communal property and holitobit ibbak fohki "sacred giving" The democratic-anarchical understanding of individuals and communal nature of Choctaw society provided a culture in which everyone participated equally (Noley, 1985). The wealth, primarily the abundance of food cultivated by the Choctaw women, was shared with all in the community and outside of the Nation as a form of holitobit ibbak fohki. No single person aspired to full political power, because it was believed complete authority could not be possessed and individual autonomy was supported. One of the defining political events for the Choctaw was the National Council Meeting, organized by the mikos, war chiefs, captains, and sub captains and was held during the Green Corn Dance. According to DeRosier (1981), the council meeting consisted of an elaborate ceremony with the host miko lighting a fire atop a burial mound in the village. The delegates would meet and 
smoke pipes, passing them to one another. The official meeting started with a speech from the assistant to the miko explaining why the national council meeting had been called. Then delegates could voice their opinion, with unlimited speaking time. Then pipes were smoked again and the miko would give their view on the subject. At the end of each topic, if the delegates agreed they would state 'a' (yes). "Elected officials, unlimited debate, civilian rule, and local self-government enabled the Choctaws to achieve an amazingly efficient and yet democratic political system (DeRosier, 1981, pp. 9). Rarely was there dissention.

Although the Choctaw held a desire for peace and did not venerate war, they loved their land and would fight fiercely to protect it. They were known for their warrior practices, specifically their defense and willingness to die for the land. "The warrior's proudest boast was Chahta siah - "I am Choctaw" (DeRosier, 1981, pp. 12). Within the Choctaw culture women fought alongside the men, many times fighting alongside their husbands. These women fought with great skill, patience, strategy, and brutality. The Choctaw were a proud and peaceful people, democratic-anarchical, and economically sound prior to European contact. This speaks to the deep loss and wounds the Choctaw experienced with the gradual loss of their traditional territories through a series of treaties and subsequently through the Treaty of Dancing Rabbit Creek, the final treaty signed with United States, that set the stage for the Trail of Tears and forced removal form their ancestral territory, their beloved Nanih Waiya. 


\section{Trail of Tears}

"It is with considerable diffidence that I attempt to address the American people, knowing and feeling sensibly my incompetency; and believing that you're highly and well improved minds would not be well entertained by the address of a Choctaw. But having determined to emigrate west of the Mississippi river this fall, I have thought proper in bidding you farewell to make a few remarks expressive of my views, and the feelings that actuate me on the subject of our removal ... We as Choctaws rather chose to suffer and be free, than live under the degrading influence of laws, which our voice could not be heard in their formation... I could cheerfully hope, that those of another age and generation may not feel the effects of those oppressive measures that have been so illiberally dealt out to us; and that peace and happiness may be their reward." (Harkins, 1832)

The Indian Removal Act, signed into law by President Andrew Jackson on May 28, 1830, authorized the president to grant "unsettled" lands west of the Mississippi in exchange for Indian lands within existing state borders. The Act opened land inhabited by the Tribes in the Southeast to non-Indian settlement; many tribes resisted this relocation policy but many also were forcibly relocated (Galloway, 1998; Native American Rights Fund, 2013). "Indian removal from the Southeast through sustained policy of forced removal and relocation had devastating impacts on the tribes involved and is most commonly referred to as the Trail of Tears" (Schultz et al., 2016). The Choctaws were the first to be removed under the Indian Removal Act of 1830 between the years of 18301833.

On September 27, 1830 the Treaty of Dancing Rabbit Creek was signed. This Act specified that the Choctaws could remain in their ancestral homelands of Mississippi if they relinquished their sovereignty and culture as Choctaw people. In the weeks leading 
up to the negotiations, "the worst elements of white society, gamblers, saloon keepers, frontiers rowdies, prostitutes" (DeRosier, 1981, pp. 120) flocked to the Dancing Rabbit Creek to swindle the Choctaw from what little possessions they had and provided the Choctaw alcohol prior to the signing of the treaty. This Act was the first removal treaty under the Indian Removal Act, mandating the ceding 11,000,000 acres of Choctaw territory to the United States and with the expectation the Choctaw move to "Indian Territory," now known as the state of Oklahoma (a Choctaw word translated as "Red People"). This was the last major land cessation treaty signed by the Choctaw. The Bureau of Indian Affairs (BIA), housed under the Department of War, said it would offer special incentives to any Choctaw willing to leave their traditional homelands and relocate to the new land. Each Choctaw who decided to relocate would be paid $\$ 10$ in gold, given a new rifle and three-month supply of powder and ammunition, be fed along the way, and be provided with a qualified guide to lead them to their new homelands (Akers, 2004). The money for this removal was funded by the Choctaws ceding of this land; essentially, they funded their own removal and genocide. The Choctaw were told that whoever remained in Mississippi would be recognized as US citizens (Faiman-Salva, 2000; Galloway, 1998, NARF, 2016; Pesantubbee, 2005), as long as they relinquished their Choctaw identity and culture.

After the signing of the treaty, the "predominant mood of the Choctaw was neither one of anger nor of satisfaction. Rather, a feeling of sadness seemed to pervade the nation" (DeRosier, 1981, pp. 128). The Choctaw understood they must comply with the demand of the Unites States, or be subject to extermination and genocide. The removal from their beloved traditional homelands, and consequently for their culture and 
spirituality created a deep wound for the People. The forced removal of the Choctaw people, overseen by the United States Army, covered approximately 500 miles in hazardous conditions, was significantly impacted by poor planning, and inadequate supplies and funding (DeRosier, 1981). Additionally, there was harsh winter weather which lead to cholera and starvation which significantly impacted the mortality rate of the Nation (Schultz et al., 2016).

There is little documentation as to actual numbers of Choctaw who were removed from the Choctaw territory between $1830-1833$, but some account that more than 12,500 Choctaws were removed between 1830-1833, with an estimated death toll ranging from 2500 to 6000 (Akers, 2004; DeRosier, 1981; Dunbar-Ortiz, 2014; Foreman, 1972;

Schultz et al., 2016; Wright, 1928). In mid-November 1830 the Choctaw were boarded onto the Walter Scott and Reindeer steam-boats and moved up the Arkansas River toward their new homeland. At the Arkansas Post, the Army halted the steam-boats, saying they were needed to transport a new detachment of American soldiers, and unloaded all of the Choctaws at the Arkansas post. A blizzard set in with strong, cold northerly winds, snow, and sleet. Most of the Choctaws were not dressed in clothing appropriate for the weather, with some of the children naked. The military party stationed at the Arkansas Post only offered 60 small army tents for more than 2,000 Choctaws. Food was in short supply; thus strict rationing of food was imposed. Despite this strict controlling of food, within a few days most of the rations were gone. By the time help arrived, both the Choctaw and soldier's rations consisted of one handful of boiled or parched corn, one turnip, and two cups of water per day (Akers, 2004; DeRosier, 1981; Faiman-Salva, 2000; Foreman, 
1932; Galloway, 1998; Jahoda, 1975; Pesantubbee, 2005; Wright, 1928). Certainly not enough food to stave off hunger in harsh weather conditions.

To make matters worse, the temperature remained below freezing for days, and the Arkansas River became so clogged with ice that the Reindeer and Walter Scott steamboats were iced in and could not make it back down river (Foreman, 1972). Choctaw hunters had their weapons confiscated and they were not allowed to leave the post to gather food or hunt. After eight days, the government begin moving the Choctaws to Fort Smith, bringing food and blankets, but many of the Choctaw had already frozen to death or died of pneumonia. It has been told that over 600 Choctaws died at the Arkansas Post. Throughout the removal of the Choctaw they experienced perilous conditions from the poor planning, inadequate supplies, and harsh weather, leading to cholera, starvation, dysentery, and other diseases that caused the death of so many Choctaw people during this removal (Akers, 2004; DeRosier, 1981; Faiman-Salva, 2000; Foreman, 1972; Galloway, 1998; Jahoda, 1975; Wright, 1928). These conditions continued to impact the Choctaw throughout the migration to their new land.

In an interview with an Arkansas Gazette reporter, one of the Choctaw Chiefs (thought to be either Thomas Harkins or Nitikechi) was quoted as saying that the removal to that point had been a "trail of tears and death". The "Trail of Tears" quotation was picked up by the press. It soon became a term analogous with the removal of any AI tribe from their ancestral homelands (Akers, 2004; DeRosier, 1981; Faiman-Salva, 2000; Foreman, 1972; Galloway, 1998; Jahoda, 1975; Wright, 1928). 


\section{Chapter 3: Theoretical Models}

The theoretical models that inform this study are Decolonizing, Tribalist and Historical Trauma theories. These theories intersect in many ways, but also inform this study in specific ways. Decolonizing theory attempts to explain both the effect of and the liberation from colonization, specifically white settler colonialism; tribalist theory to address issues of heteropatriarchy and feminism; and historical trauma to address the complex nature of the impact and health from genocide and trauma in tribal communities. There is a gap in the literature addressing the intersectional nature of these theories and this study attempts to clarify the impact of both the effect of and liberation from white settler colonization.

\section{Decolonizing Theory}

Decolonizing theory attempts to explain both the effect of colonization and the liberation from colonization. Colonization, specifically white settler colonialism is a distinct type of colonialism that functions through the replacement of indigenous populations with an invasive settler society that, over time, develops a distinctive identity and sovereignty (Arvin, Tuck and Morrill, 2013). Settler colonial states include Canada, the United States, Australia, and South Africa, is upheld by white supremacy, heteropatriarchy and capitalism (Arvin, Tuck and Morrill, 2013; Beltrán, Alvarez, and Fernandez, 2018; Smith, A., 2015) and directly affects the AI experience in complex ways, disproportionately targeting AI women. These experiences explain how colonization impacts the AI word view, historical trauma, AI and gender identity, and health disparities. Duran and Duran (1995) state "[a] postcolonial paradigm would accept 
knowledge from differing cosmologies as valid in their own right, without their having to adhere to a separate cultural body for legitimacy" (pp. 6). Decolonizing attempts to create knowledge that is healing for both the indigenous mind, as well as, the western mind. Indigenous scholars are working to develop knowledge to "explore the theoretical intersections of indigenous ontology and epistemology with research methodologies in an attempt to create research that is useful to the people and respects Indigenous Ways of Knowing in research" (Sinclair, 2003, pp. 120). Many indigenous researchers and scholars (Beltrán et al., 2018; Beltrán, and Begun, 2014; Brown, D., 2016; Duran and Duran, 1995; Gone, 2012; Schultz et al., 2016; Sinclair, 2003a and b; Tuhiwai- Smith, 1999; Walters et al., 2002) challenge the hegemony of western research through the worldview as indigenous persons. They address this through approaches that come from the People intended to address the impact of colonization while empowering and liberating these knowledge systems.

According to Waziyatawin and Yellow Bird (2005), decolonization is "the intelligent, calculated and active resistance to the forces of colonialism that perpetrate the subjugation and/or exploitation of our (Indigenous) mind, bodies, and lands, and is engaged for the ultimate purpose of overturning the colonial structure and realizing indigenous liberation" (pp. 2). Decolonization must begin in the minds of individuals, both indigenous and non-indigenous people. From a decolonized perspective, race is a political and an economic social construct which does not exist except to produce cultural genocide. Freire (1970 and 1998) discusses this perspective within the context of the oppressed and the oppressor. The oppressed learn about humanity through the oppressor. Freire believes that liberation comes from the oppressed. To become human is a process 
of liberation for both the oppressed and the oppressor. One will not give up more power for less power, so it is in the experience of the oppressed to liberate both themselves and the oppressor. The first step in the process of decolonization is to "question the legitimacy of colonization” (Waziyatawin and Yellow Bird, 2005, pp. 3). In this process, there is empowerment in the naming of colonization and its effects on the human condition.

In the process of colonization TIK, TEK, Indigenous Ways of Knowing, indigenous worldviews, language, and customs were destroyed. "Part of the colonization process is to render invisible the successes of indigenous science and knowledge while simultaneously infusing public discourse with images of Indians as intellectually inferior" (Walters, Stately, Evans-Campbell, Simoni, Duran, Schultz, Stanley, Charles, and Guerrero, 2008, pp. 148). A more advanced form of decolonization would be moving towards conceptualizing the world from an indigenous perspective or indigenizing knowledge (Duran and Duran, 1995) by developing models of research, treatment, intervention, systems, leadership, etc. that are based on Indigenous Ways of Knowing, TIK, TEK, and traditional values.

Duran and Duran (1995) define indigenizing as "the replacement of Eurocentric models with local, native idioms" (pp. 125). They add that indigenization relies on the knowledge "produced by native people from within native culture, this creating native subjects (those who know and act) rather than objects (those who are known and acted upon) of scientific and programmatic discourse" (pp. 125). Indigenizing research thus includes developing mutual beneficial partnerships with and for indigenous communities. Walters, Stately et al. (2008) suggest, as a starting point, the following principles for 
decolonizing and indigenizing research; "reflection, respect, relevance, resilience, reciprocity, retraditionalization and revolution" (pp. 154). In doing this we are participating in active resistance to colonization.

Waziyatawin and Yellow Bird (2005) believe that the most the most effective strategy against decolonization is to utilize indigenous language. "Because the colonizers attempted to methodically eradicate our Indigenous languages, our efforts to recover the language are also the most powerful form of resistance" (Waziyatawin and Yellow Bird, 2005, pp. 3). There has been a concerted effort in the Americas to reclaim, document, record, and teach indigenous language as well as to document song and oral traditional stories. It is believed in many AI cultures that the reclamation of language is vital to the survival of indigenous culture; that the termination indigenous languages is an act of genocide. The use of indigenous language in the development of health/behavioral health interventions and research models creates both a framework for decolonizing knowledge and a process of resisting against colonization. Such is the case with the Yappalli project. The goal of decolonizing theories is to "cultivate strong, vibrant Indigenous communities in which solutions are derived from Indigenous cultural frameworks" (Pewewardy, 2009, pp. 252). In the United States, indigenous communities have done this through sovereignty, self- determination and education. Additionally, this is accomplished by maintaining cultural heritage through Pan-AI experiences such as through Pow Wows, the Native American Church, etc.

Walters, Stately et al. (2008) suggest that decolonizing research promotes indigenous peoples to "theorize their own lives; reconnect with the past and future generations; acknowledge and prioritize indigenous ways of knowing and healing; 
respect and prioritize the community's roles in defining the problems, resiliencies and strategies; and cultivate and build indigenous capacity to engage in both indigenous as well as Westerns research methodologies" (pp. 153). This process of decolonizing and indigenizing research can be empowering to individuals who participant in the research process, the community and the tribe.

\section{Tribalist Theory}

Tribalist theory is a de-colonial indigenous theory that addresses the intersection of heteropatriarchy and white settler colonialism which centers the experiences of indigenous people of all genders. This theory works to unpack the gender binary that white settler colonialism imposes on society and attempts to address impact of these binary roles on tribal people. The influence of while heteropatriarchal concepts of gender, sexuality and roles, continues to impact AI communities, negative stereotypes and the hyper sexualization and violence towards AI women and non-men (Arvin et al., 2013; Beltrán et al., 2018; Duran and Duran, 1995; LaFromboise et al, 1990; Mihesuah, 1996, Pesantubbee, 1999, Ross, 2009; Swanton, 1931). An anonymous French writer in 1755 described Choctaw women as "slaves to their husbands" who did "everything in the house, work the ground, sow, and harvest the crop" (Swanton, 1931, pp. 139). The colonial gaze of white supremacy and heteropatriarchy created and the imposed the guise of domesticity and negative stereotypes that AI women were oppressed, slaves, and submissive (Pesantubbee, 1999). The western understanding of women and non-men's roles are limited to domestic duties was perpetuated by scientist interpretations of these experiences. Pesantubbee (1999) notes "although colonization and missionization had a 
tremendous impact on women's roles, scholars have assumed that Choctaw women endured less change than men" (pp. 389). This could not be further from the truth, AI women and non-men continue to suffer greatly form the continued impact of white settler colonialism. Pesantubbee (1999) adds that Choctaw women continue to indirectly and directly influence the "religious, economic, and political life of the Choctaw with little notice being taken by white society" (pp. 396). Tribalist theory recognizes the different ways that gender directly and/or indirectly impact societies by acknowledging that everyone has an equal voice in societal/political systems.

"Pre-colonial Indigenous communities included gender roles and sexual identities that were much more fluid than ascribed under the male/female binary of Western construction" (Beltrán et al., 2018, pp.5). There is little accurate documentation about the realities of the traditional lives of AI women and non-men due to the lack of accurate documentation of these experiences, "the women had recognition, but it is difficult to ascertain the level of responsibility or status that they attained among their people because of the sexism inherent in white documentations of Choctaw society" (Pesantubbee, 1999, pp. 392), as well as the lack of accurate interpretation of these experiences. The lives of AI were primarily documented by white hetero males from western academic institutions. The lack of culturally relevant and accurate documentation about gender roles continues to perpetuate the stereotype of AI women and non-men. There needs to be a continued movement to develop a nuanced understanding of these roles and center to voice of AI women and non-men.

The work of this study is to center the voices and stories of Choctaw women and their experiences of creating a vision for future generations that inherently address the 
legacy of settler colonialism. AI women have borne the brunt of settler colonial violence and the consequences of settler colonialism (Arvin et al., 2013; Beltrán et al., 2018;

Duran and Duran, 1995; LaFromboise et al, 1990; Mihesuah, 1996, Pesantubbee, 1999, Ross, 2009; Swanton, 1931). AI women are guided by the social world that is influenced by different realities, that is in contrast to the white women. Moreton-Robinson (2000) suggest that we move beyond episteme that focus on white hetero-patriarchal privileges and experiences.

Central to the concept of colonization is heteropatriarchy (Arvin et al., 2013; Beltrán et al., 2018). Heteropatriarchy is a social-political system where cisgender men and heteropatriarchy are centered in power structures and contributes to gender bias and violence towards non males. This process of colonization had a significant impact on how AI's view gender and gender roles. "Internalized colonial heteropatriarchy further marginalizes notions of gender and gendered bodies in Indigenous communities" (Beltrán et al., 2018, pp. 3) and impacts the ways that women are treated. Pesantubbee (1999) addresses this within pre-nineteenth-century Choctaw society by noting that all functions of gender roles were necessary and valued in tribal societies.

"It did not matter if it were a small child gathering a handful of nuts or an adult male defending his family from enemy attacks-both contributions were equally valid and integral ways of maintaining community life and solidarity. Thus, Choctaw women would not be considered less important than men if they limited their activities to domestic concerns, and men would not be more important than women if they dominated the religious, economic, and political life of Choctaw society" (Pesantubbee ,1999, pp. 404) 
Additionally, tribalist theory acknowledges the inherent relational aspects to AI world views and finds that separating the functions of society into parts, domestic, economic, religious, and political, is also problematic "because separation belies the notion of reciprocity and interdependence that lies at the heart of Choctaw community" (Pesantubbee, 1999, pp. 404) verse the western notion of individualism.

Yet in contemporary society, AI women continued to be subjugated, marginalized, tokenized, and sexualized which leads to the devastating level of violence that is demonstrated in AI communities. According to Smith, A. (2015), "Heteropatriarchy is the building block of US empire. In fact, it is the building block of the nation-state form of governance" (pp.71). Duran and Duran (1995) developed a scheme of the progression of historical trauma that includes (1) first contact; (2) economic competition; (3) invasion war period; (4) subjugation and reservation period; (5) boarding school period; and (6) forced location and termination period (pp. 32-34). Chenault (2011) discusses how colonization directly resulted in the violence against AI women, and how historical factors continue to result in the disproportionate amount of violence imposed on $\mathrm{AI}$ women. AI women continue to remain an invisible population in the United States, yet hold significant positions in Tribal communities. Although there is significant research addressing the general needs of AIs, there is little research addressing the specific needs of AI women and virtually no research addressing community-based prevention efforts for AI women and families even though, traditionally, many AI communities' views of health and wellness revolve around a matriarchal society, and it was women and non-men who held the traditional roles of keepers and givers of life, health and wellness. 
There is much debate among AI scholars (Arvin et al., 2013; Beltrán et al., 2018; Goeman and Denetdale; 2009; Mihesuah, 1996; Ross, 2009) stating that feminism is long held to be in "purview of white rule" (Goeman and Denetdale; 2009, pp. 10). Mihesuah (1996) describes the concerns many feminist scholars find with the lack of attention to the heterogeneity of identity and experience among women, particularly women of color. Essentially, feminism has long been a period of white women's liberation and comes often at the expense of women of color, as well as non-gender conforming and trans women. Mihesuah (1996) adds that "(m)any feminist scholars express concern for the propensity of writers to ignore the heterogeneity among women, particularly among women of color" (pp. 15). Thus, many indigenous scholars do not identify as "feminist" because they perceive feminism as being a construct of colonization that perpetuates colonial violence against AI women and community. This violence continues today as reflected in the issue Missing and Murdered Indigenous Women (MMIW) and the lack of state investigations of these MMIW (Jiwani and Young 2006), the influx of violence and sex trafficking of indigenous women associated with "man camps" (Sweet, 2014), the removal of AI children form the community (Jacobs, 2005), the continued health conditions of AI women, to name a few issues.

There has been a movement toward the "retraditionalization" of gender roles. "Retraditionalization - or the extension of traditional care reflexivity taking and cultural transmission roles to include activities vital to the continuity of Indian communities with a predominantly non-Indian society - represents a major current attempt on the part of Indian women to integrate traditional and contemporary demands in a positive, culturally consistent manner" (LaFromboise et al., 1990, pp. 469). Tribalist theory attempts to 
engage this aspect of roles, while also understanding that the structure of indigenous cultural systems within a colonized society are intact.

Tribalist theory informed this work by addressing the complex intersections of experiences for indigenous women and non-men. Previous waves of feminism fail to address the complex intersectional experiences of AI women, including influences based on class, race and nation, social values, gender and sex, multicultural identities (blood quantum) and skin tone, and lateral oppression. What distinguishes tribalist theory (Mihesuah, 1996, pp. 18) thought is AI's common experience with settler colonization, specifically genocide, termination, exploitation of resources, removal from traditional homelands and traditional food sources, appropriation of our culture, repression of ceremony, population loss from disease, and institutionalized and lateral violence. This is unique from non-tribalist who tend to focus on economic and gender oppression or equal rights to access to employment, academia or other institutions (Arvin et al., 2013; Goeman and Denetdale, 2009; Ink, 2004; Jaimes, 1992; Mihesuah, 1996).

It is important to understand the impact of colonial heteropatriarchy on precolonial understandings of gender and sexuality in indigenous communities as understood through Tribalist viewpoint, the power that centering women, non-gender conforming and trans women can have on the development praxis, and the influence these people have on the health and wellbeing of their communities. Centering the sacredness of the feminine spirit in healing work, in social work research and in the lives of these communities and benefit in the healing of humanity and the earth. Tribalist theory informs my praxis as a social worker to better address the complex intersectional experiences of the communities that I serve and helps be to better center the experiences 
of the populations I work with. Tribalist theory helps to unpack the complex impact of white settler colonialism.

\section{Historical Trauma}

Historical trauma results from the long-term effects of the oppressive traumatizing policies, attitudes, and beliefs of the colonizer towards AI; the lack of resources and opportunities for AI; and current treatment of AI in this country. Yellow Horse Brave Heart (2004) defines historical trauma as “...cumulative emotional and psychological wounding over the lifespan and across generations, emanating from massive group trauma" (pp. 4), and Duran, E. (2006) refers to this a "soul wounding." These "soul wounding" symptoms of historical loss are interconnected; each one affecting the other to varying degrees. Historical trauma "can often produce complex and profound individual and collective bio-psycho-social-cultural-spiritual responses" related to significant health disparities (Beltrán and Begun, 2014, pp. 160). There is a direct connection between colonization to the effects of historical trauma - depression, substance misuse, and suicidal ideation and other health risk factors. The negative impact of broad social factors that have been influenced by colonization, such as racism, acculturation, poverty, are translated into everyday physical and emotional distress experienced by AI's. This trauma is epigenetically transferred from generation to generation and is expressed in many ways that are connected to the disproportionate rates of poverty, chronic physical and mental health issues, mortality rates, and substance abuse/dependency rates. Walters, et al (2011b) refers to this as the "embodiment of trauma". While the reasons for American colonization were primarily based on religious, economic, and political factors, 
in actuality this colonization attempted to destroy the social and cultural structures of indigenous peoples in every corner of the planet (Chenault, 2011; Dunbar-Ortiz, 2014; Duran and Duran, 1995; Lewis, 2012; Newcomb, 1992; Tuhiwai-Smith, 1999).

To understand the conditions that lead to the significant and disproportionate health inequities affecting AIs, we need to first recognize the effects of 525 years of colonization and the impact of historical trauma on AIs. Chenault (2011) defines colonialism as the "sustained series of events that are enacted by an invading power on another culture, which facilitates and perpetuates the development of a worldview and structures and social organization supporting an ideology of oppression" (pp. 20). This is both a formal and informal process of subjugation and exploitation of people, land, and resources. While the initial reasons for colonization were based on religious, economic, and political factors, colonization attempts to destroy the social and cultural structures of AI communities (Chenault, 2011; Dunbar-Ortiz, 2014; Duran, E. 2006; Duran and Duran, 1995; Newcomb, 2006; Tuhiwai-Smith, 1999).

Central to the philosophy of colonization is domination, control, and exploitation. In the United States, this manifests itself through federal and state policies of genocide, cultural assimilation and tribal termination policies, which have led to cultural historical trauma that have impacted health equity among these populations (Yellow Horse Brave Heart, 1998 and 2004; Yellow Horse Brave Heart et al., 2011; Chenault, 2011; Duran, E., 2006; Duran and Duran, 1995; Lewis, 2012; Newcomb, 1992; Walters, 1999; Walters et al., 2011a; Walters et al., 2012; Walters et al., 2011b; Walters and Simoni, 2002; Walters et al., 2002). Colonization is an intersection of systems and policies of domination and oppression, "beyond only historical designation" (Lewis, 2012, pp. 231). The methods of 
colonization were numerous and included genocide (Dunbar-Ortiz, 2014; Newcomb, 2006); forced assimilation of indigenous people through policies such as removal from our ancestral lands (Schultz, et al, 2016); boarding schools (Stites, 2001); the termination acts of the 50's, 60's and 70's (Newcomb, 1992); the appropriation of AI imagery through popular media and sports mascots (Pewewardy, 2009); the continued celebration of colonial legacies, such as Christopher Columbus (Waziyatawin and Yellow Bird, 2005); the continued theft of resource of land (Nelson, 2008a); lack of access to healthy food (Nelson, 2008b) and mental health services (Gone, 2007); and the use of alcohol as a tool of social control (Duran and Duran, 1995) and lack of access to appropriate health care (Johnson-Jennings et al., 2014).

Genocide of AIs is one of the most massive and longest lasting campaigns in human history (ADL, 2005; Chenault, 2011; Newcomb, 1992). In the present Geneva Convention genocide is defined as:

"Acts committed with intent to destroy, in whole or in part, a national, ethnic, racial, or religious group, as such: Killing members of the group; Causing serious bodily or mental harm to members of the group; Deliberately inflicting on the group conditions of life calculated to bring about its physical destruction in whole or in part; Imposing measures intended to prevent births within the group; Forcibly transferring children of the group to another group." (Adopted by Resolution 260 (III) A of the United Nations General Assembly on 9 December 1948)

Since 1942 to present, there are numerous examples throughout history of how colonizers have utilized many of these methods to "deal" with the AI population in this country. In fact, it was the policy of the United States government to exterminate AI, force assimilation and then terminate any legal relationship the government had with 
tribes. These policies were carried out in horrific ways, including assaults on unarmed women, children, and elders as in the historic massacre of the Cheyenne at Sand Creek Colorado (NARF, 2013); Indian Health Service-driven sterilization of Native women without their consent, (Rutecki, 2010); the operation of Indian Boarding schools where Native children were placed after being taken from their homes, forced to assimilate to Western culture and endured horrific conditions (Stites, 2001); the current establishment of blood quantum for tribal membership and cultural identity (NARF, 2013); and the extraction of vital environmental resources from tribal lands (Nelson, 2008b).

Termination policies were developed during the 1940s and continued through the 1960s. These policies terminated the U.S. government's recognition of sovereignty of tribes, trusteeship of reservations, and the exclusion of AI from state laws (NARF, 2013). Termination policies had a direct effect on the quality of life for AI communities because it further impacted the already limited resources and programs available to address issues of mental health, physical health, substance abuse and suicide within tribal communities. Through the termination policies, tribes became subject to state and federal taxes as well as other laws from which they had previously been exempt. Tribes were stripped of their cultural rights to traditional food sources, land, hunting, and fishing. It disbanded the tribe as a whole and incorporated members as official independent American citizens (NARF, 2013).

Furthermore, these policies directly impacted the implementation of these services. For example, denying tribes their rightful status as sovereign nations, the policy terminated federal support of most of the health care and education programs, as well as police and fire fighting departments available to AI on reservations (IHS, 2006). Given 
the considerable isolation and inherent social plus economic problems on reservations, not many tribes possessed the resources to continue to provide such services after termination was implemented. Few tribes were able to fight successful legal battles in efforts, to restore tribal government and the special relationship with the United States federal government (NARF, 2013). To this day, many tribes struggle to regain legal recognition and tribal rights.

The impact of colonization created shifts in AI ideology form the initial point of contact between European settlers and indigenous communities. After 1492, there was a devastating impact on the population of indigenous people in the Americas, which created shifts in the indigenous worldview and the socialization process. In a relatively short period of time, the population of indigenous people went from millions (if not hundreds of millions) to a few hundred thousand. This decline in population affected traditional values, culture, political, economic, family and community systems (Yellow Horse Brave Heart, 1998). This continues today through mass media's portrayal of AI culture, and in the tokenization of AI imagery through sports mascots and costumes (Pewewardy, 2009). Additionally, colonizing forces directly targeted traditional ceremonies. In the United States, AI ceremonial practices and religions were illegal until 1978 when the American Indian Freedom of Religious Freedom Act was passed, but this did not include the Native American Church until 1994 (Newcomb, 1992; NARF, 2013). Indigenous systems were replaced by "civilized" models that were in direct conflict with traditional worldviews; indigenous worldviews were disrupted and replaced by values that taught AIs they are uncivilized, heathens and barbaric (Chenault, 2011). This was a 
prevailing message that AI children received throughout their experience in the Indian boarding schools (Stites, 2009).

Compounding the impact of such trauma and loss was the fact that AI's bereavement practices, religions and ceremonies were made illegal. "Traditional American Indian/Alaskan Native mourning practices and cultural protective factors were impaired due to federal prohibition around 1883 against the practice of traditional ceremonies, which lasted until the 1978 American Freedom of Religion Act” (Yellow Horse Brave Heart et al., 2011, pp. 284). It is an important aspect of the human condition to mourn loss, to process grief and bereavement through our culture, rituals, and traditions (Weaver and Yellow Horse Brave Heart, 1999). When these practices were taken away from AI communities and made illegal, people were left with prolonged experiences of grief which compound the effects of historical trauma.

Colonization did not just have a direct result in the massive loss of people, land, and resources in past years. It also has direct effect on AI's current struggles- poverty, substance abuse, violence and suicide (Chenault, 2011; Duran, E., 2006; Duran and Duran, 1995; Lewis, 2012; Mihesuah, 2003; Pewewardy, 2009; Waziyatawin and Yellow Bird, 2005). Past policies of genocide has created the historical trauma currently impacting current and future generations of AI. Historical trauma and loss has a significant impact on the mental and physical wellbeing of AI people. When historical trauma is not dealt with - on an individual, community, and/or tribal level- it creates an environment that contributes to substance misuse, mental illness, and health disparities among AI populations (Yellow Horse Brave Heart, 2004; Duran and Duran, 1995; Gone, 2012; Johnson-Jennings et al., 2015). Walters, et al (2002) argued that lacking resources, 
being the perpetual object of discrimination, having traditional mourning practices and traditional ceremonies criminalized and our cultural experiences pathogized and politicalized, being the target of violence and colonization for generations, then life is made more stressful which, in turn, increases the risk of disease, poverty, instability, mental illness, substance abuse, and family breakdown. These are all factors that lead to health disparities. Addressing the interconnectedness of social determinants of health in AI communities (which are compounded by issues related to historical trauma, poor access to resources such as health care, food, services, housing, poverty etc.) are complex issues, social workers of the future are ethic bound to address these intersections.

Adding to empirical support about historical trauma, Walters et al. (2011b) discuss the "embodiment of historical trauma", the ways in which historical trauma is processed, stored in the physical body and epigenetically transferred through DNA. In fact, "researchers have begun to examine the impact of social and economic inequities on physical health and how embodiment of these inequities is manifested and influenced by social, cultural, economic, and biological progress" (Walters et al., 2011b, pp. 183). While this may be a relatively recent topic for researchers, the embodiment of historical trauma and loss is not a new concept for AIs. On the contrary, this knowledge has been passed down from generation to generation through our stories and oral traditions. My own grandfather explained to me that the memories of our grandmothers are passed down in our blood. There is a traditional understanding, metaphorically outlined through the medicine wheel, that discusses the physical, mental and emotional interconnectedness of the human experience. When one is not in balance, then there is "dis-ease." Walters et al. (2011b) outline the issues of epigenetics and its connection to historical trauma. 
Primarily, they state that there is an "indication that extreme environmental stress in one generation can alter the health outcomes for descendant generations" (pp. 184). Additionally, Walters et al. (2011b) outline biological expressions or pathways of historical trauma that contribute to health disparities, while also addressing the wide range of responses to historical trauma. Denham (2008) adds "it is important to recognize that traumatic events do not always result in psychiatric distress; individuals, as well as societies, differ in the manner in which they experience, process, and remember events" (pp. 395). That is to say that, distress resulting from an event can be attributed to, or meaning derived from, the experience. Denham (2008) also reminds us that the current understanding of trauma is privileged in psychological and psychiatric models of understanding and encourage researchers to move to a more holistic understanding of trauma and trauma response.

There has been extensive research conducted with AI communities addressing the complex nature of healing historical trauma. Yellow Horse Brave Heart (1998 and 2004) focuses her work on addressing historical trauma by, first, confronting the historical trauma and understanding the trauma, then releasing the pain of historical trauma and transcending the trauma. This work is echoed by Duran and Duran (1995) who added that it is critical to have a traditional component to any healing process. "It is not enough that the program have a traditional component; the program must have traditional Native American psychology as its core metaphor,” (pp. 88). To address the chronic and interesting epidemic of historical trauma in AI communities, Yellow Horse Brave Heart (1998) suggested the following steps: 1) confront past genocide; 2) do not let the People forget; 3) understand the trauma and trauma symptoms; 4) release our pain; 5) heal 
collectively; 6) transcend trauma through the Seven generations, ceremony, and collaboration; and 7) acknowledge and validate the trauma (Notes from conference presentation by Yellow Horse Brave Heart, Denver Colorado, 2006). Historical trauma is the central theory this study conceptualizes to address the motivations and impact of health disparities on the $\mathrm{CNO}$.

\section{Conceptual Frameworks of the Yappalli Choctaw Road to Health project}

Two conceptual frameworks informed the Yappallí Choctaw Road to Health project are the Indigenist Stress-Coping (ISC) (Figure 1) model and the Yappallí Information Motivation Behavioral (YIMB) (Figure 2) model. Emphasizing the resiliencies of AI women, Indigenous Wellness Research Institute (IWRI) researchers, developed and empirically tested a community-based ISC model (Walters and Simoni, 2002; Walters et al., 2002). This framework incorporates cultural resiliency factors that buffer the effect of traumatic stressors (e.g., institutional, environmental, communal, familial, and inter and intra-personal trauma-related stressors) on health risk behaviors (e.g., substance use), as well as physical health (e.g., diabetes) and mental health outcomes (e.g., depression and PTSD). Following is an infographic depicting the ISC model (Figure 1). The ISC model address issues related to the impact of historical trauma to health outcomes for AI women; identity attitude, traditional health practices, spiritual coping and enculturation.

According to Walters et al., "associations between life events and adverse health outcomes are moderated by pre-existing internal and external factors that function as buffers, making individuals psychologically and emotionally strong" (2002, pp. 107). 
Furthermore, they considered this model to be the most effective for depicting stress, coping, and health/mental health relationships among AI populations and further generalized this model to health and wellness research. This model "posits that the effect of life stressors (e.g. historical trauma) on health is moderated by cultural factors such as identity attitudes that function as buffers, strengthening psychological and emotional health, and mitigating the effects of stressors" (Walters et al., 2002, pp. 105-106).

Figure 1: Indigenist Stress-Coping (ISC) model

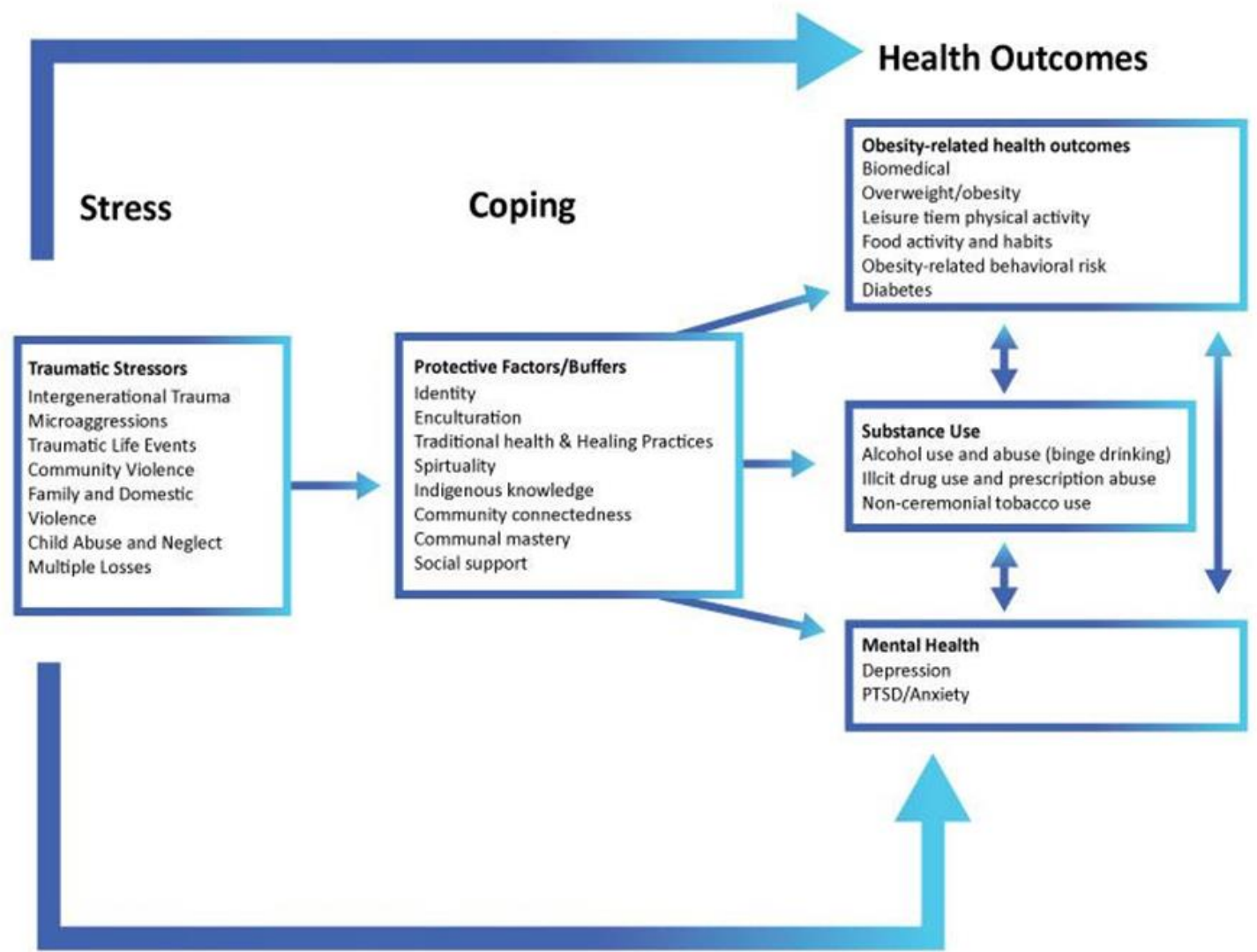

Therefore, this would support the idea that a connection between historical trauma, cultural buffers, and health equity. The focus of this model is the resilience of AI women, including identity, enculturation, spiritual coping and traditional healing 
practices (Walters 1999; Walters et al., 2002). Bombay, Matheson and Anisman (2009) note that resilience can be conceptualized as the intersections of several input factors (stressful events) and influenced by cultural factors (connection to and enculturation of individuals), indicating that resilience of individuals is influenced by community and context.

Similarly, the Yappallí Information Motivation Behavior (YIMB) model (Figure 2), the 'information' component is the critical determinant of health behavior change; it provides the cognitive motivation and comprises the relevant information that influences motivation towards behavioral change.

Figure 2- Conceptual Diagram of Yappallí Information Motivation Behavior (YIMB)

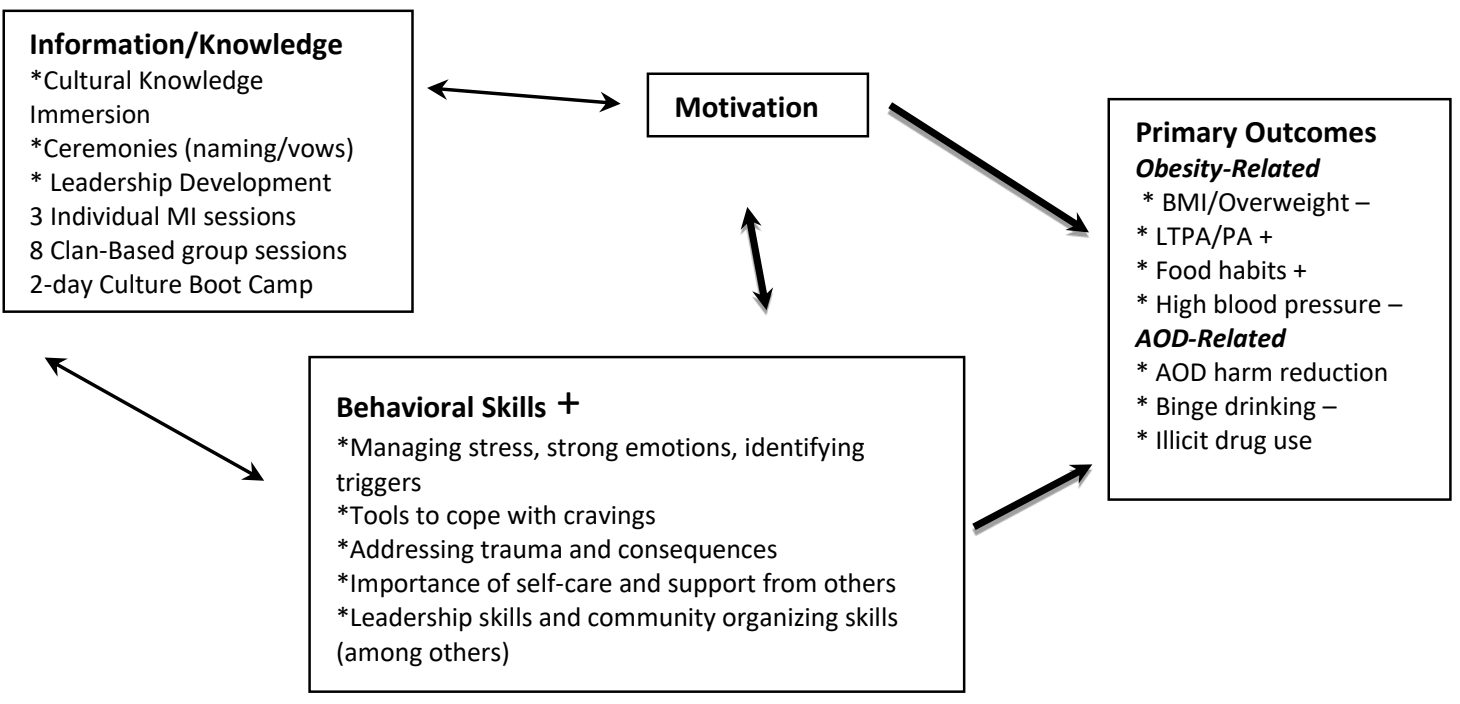

A distinctive version of 'information' included in the Yappalli intervention is the inclusion of cultural knowledge. This includes: Chanspo Ikhvnanchi "original instructions" or ancient teachings related to food, activity, and medicines. The incorporation of cultural and relational regenerative processes by drawing on historical clan structures and roles to provide guidelines for behavioral change. "Narrative 
transformative" strategies to think differently about food and substance behaviors based on cultural conceptualizations of the relationship to food and medicines. "Relational restoration" is intended to increase personal and social responsibility (e.g., vow-making to self and community) and generate individual and communal approaches to health promotion.

The 'motivation' aspect relates to affect and attitude towards positive health behaviors. It utilizes existing social support systems and community support (love and commitment to the health and wellness of the next generation). Motivation is also enhanced by recognizing potential barriers (e.g., emotional triggers or disruptions in relational worldview) and finding ways to overcome them. The 'behavioral' aspect of the YIMB model reflects the 'action' component that nurtures the development of skills needed to ensure behavioral change and health leadership. Information and motivation synergistically act as tools to develop behavioral skills, which then, ultimately improves health outcomes.

Conceptual Frameworks for Our Vision of Health Study.

Traditional Indigenous Knowledge (TIK) (Boven and Morohashi, 2002; Nelson, 2008) and Survivance (Vizenor, 1994, 1995 and 2008) are conceptual frameworks that inform the "Our Vison of Health for Future Generations" study. Particularly the aspects of TIK as a form of traditional knowledge and indigenous storywork as forms of survivance. Historically, TIK comes out of the biological and ecological sustainability fields (Boven and Morohashi, 2002, Nelson, 2008), but this knowledge system provides social work and health researchers important understanding of the complex human 
condition within the environments that we live and are impacted by. Survivance originally was a legal term that fell out of favor in the 18th century (BLT, 2007). The term was then adapted and influenced the work of nonfiction writer, poet and professor of Native American Studies, Gerald Vizenor a citizen of the Anishinaabe Nation. Survivance within these fields has been used as an analysis of the contemporary AI experience, literature and culture. Currently, survivance is being incorporated into fields of AI gaming, graphic novels and AI literature, poetry, science fiction and futurism writing (Glancy, 2008; LaPensée, 2014a and b; Vizenor, 1994). These frameworks provide this study with an interdisciplinary context to address the gaps in the current social work methodologies and provides social work researchers opportunities to address gaps in current research.

There is a great body of research discussing and addressing indigenous knowledge and indigenous views of health and wellness. According to Nuffic's Indigenous Knowledge Unit and UNESCO's Management of Social Transformations Programme (MOST) Indigenous Knowledge is defined as:

"a complete body of knowledge, know-how and practices maintained and developed by peoples, generally in rural areas, who have extended histories of interaction with the natural environment. These sets of understandings, interpretations and meanings are part of a cultural complex that encompasses language, naming and classification systems, practices for using resources, ritual, spirituality and worldview. It provides the basis for local-level decision-making about many fundamental aspects of dayto-day life: for example, hunting, fishing, gathering, agriculture and husbandry; food production; water; health; and adaptation to environmental or social change. Nonformal knowledge- in contrast to formal knowledge-is handed over orally, from generation to generation, and is 
therefore seldom documented (Boven and Morohashi, 2002, pp. 6)

Historically, there has been little discussion about how TIK and culture can be utilized to develop interventions by indigenous communities for indigenous communities. "Nothing about us, without us" is a common message heard throughout Indian Country. Today, there are scholars and organizations addressing this issue by training research professionals who are from indigenous communities; developing cultural humility in both indigenous and non-indigenous professionals; and utilizing indigenous knowledge that comes from a history that is time immemorial. Most encouraging, there seems to be a better understanding that the quality of life for of indigenous peoples was significantly better prior to the colonization of this country and that indigenous knowledge is valuable for the development and implementation of interventions in both indigenous and nonindigenous communities.

TIK needs to be a "revolutionary critical praxis and, as a collective process, it must be critical; it is systemic in the sense that is guided by dialectical method of inquiry; it is participatory in nature; it is a creative process incorporating elements of drama, music, oral history, narratives, and movement" (Grande, 2008, pp. 237). Through critical theories, we can address the complex nature of the human experience, address the relationships between these experiences and social structures, and reveal human needs. According to Freire (1970), "true solidarity is found in the plentitude of this act of love, in its existentiality, in its praxis" (pp. 32). Grande (2008) advocates for culturally-based education, defined as having six elements: use of AI language, is grounded in traditional culture, teaching strategies are in line with traditional cultures and knowledge, curriculum 
is based in traditional culture, there is community participation, and knowledge is based in the social and political norms of the community (pp. 235-236). Grande (2008) refers to the work of Vizenor regarding "survivance" which calls for AI people to move from survival and endurance or reaction to colonization to being "poignant and powerful", center in the decolonizing process.

A significant aspect of the AI experience is surviving 500 years of colonization, genocide, forced assimilation and termination policies, aka "survivance." Vizenor (1994) defines survivance as "an active sense of presence, the continuance of native stories, not a mere reaction, or a survivable name. AI survivance stories are renunciations of dominance, tragedy, and victimry. Survivance means the right of succession or reversion of an estate, and in that sense, the estate of native survivancy" (pp. vii).

Survivance would seem to connote survival, specifically, the survival of indigenous peoples in the face of colonization, victimization, and attempted dominance first by, the Catholic Church, and then by French and English settlers, of which continues to this day (LaPensée, 2014a and 2014b). Stromberg (2006) attempts to clarify the relationship between the two terms: "While 'survival' conjures images of a dark minimalist clinging at the edge of existence, survivance goes beyond mere survival to acknowledge the dynamic and creative nature of Indigenous rhetoric" (pp. 1). Survivance in this context mandates storytelling as a way of establishing AI identity in the present, as opposed to viewing storytelling merely as preserving traditions of the past. Hume (2006) believes that "[ $t]$ o be a keeper and sharer of stories is to take on a sacred trust" (p. 207). This philosophy is center to the framework of this study, it is centered in the praxis of love and sacred trust of gathering and sharing the stories of participants. This transforms 
the in-depth interview process form a western qualitative method, to an indigenized method.

Storytelling as the practice of survivance is open to new genres, structures, media and activities (LaPensée, 2014a and 2014b). Hume (2007) emphasizes Vizenor's belief that survivance stories are not restricted to traditional modes of communication. Although stories may be traditional, Vizenor does not consider them static. They change with the teller, with the needs of the audience, and with the changing circumstances of one's place and time, taking on any form that makes them a conduit for images of freedom or wisdom or the humor that helps one survive. To be effective, survivance stories need to be malleable and bend to the needs of the storyteller, the audience and the community (LaPensée, 2014a and 2014b), i.e. original instruction, relational restoration, and narrative transformation at noted in Walters et al. (2011a and 2012) work. This addresses the apparent paradox of asserting that no two groups of indigenous peoples are the same while simultaneously claiming that all indigenous peoples use storytelling in the same way. It is more appropriate to state that storytelling is common ground and that individual stories within individual canons of individual tribes reflect the diversity of the indigenous experience and in the development of one's identity. This tradition is not an experience of shedding identity. Rather, it is an exercise in reaffirming and reclaiming it. Hopkins (2006) suggests that stories are "layered with voices" and are a way for indigenous communities to "straddle past and present." Indigenous peoples understand that to survive we must share our stories. It is important in this contemporary world that we embrace new technology, including video and digital media outlets to tell our individual and collective story. 
TIK as an understanding, interpretation, and meaning is part of a cultural experience that is expressed through language, naming, classification systems, resource use practices, ritual, spirituality, and worldview. Much of TIK is expressed through stories, oral history, ritual, legends, ceremony, song, and other means of communication. One way to understand TIK is through our understating of original instructions, relational restoration, and narrative transformation (Walters, 2012). Additionally, when addressing substance abuse and mental health among AIs, researchers are encouraged to change the way they address these issues. Rather than looking at AI response to trauma as a pathology, we must look at these as coping skills that have kept indigenous people alive, after 500 years of colonization, by reframing how we conceptualize and name these conditions. For example, we can replace "substance abuse" with "our relation to medicine" or "obesity" by reclaiming our understanding that "food as medicine" (Walters and Simoni, 2002). We want to reframe these issues with respect to our relationships to food, medicine and the natural world.

There are several components of TIK that inform this study; Chanspo Ikhvnanchi or original instructions, relational restoration and narrative transformation, and indigenous storywork. Chanspo Ikhvnanchi are instructions about one's culture that are passed down from generation to generation. They can be implicit or explicit instructions based in cultural or familial values and beliefs. "Original instruction celebrates our interdependence and interconnection with the diversity of life and other" (Nelson, 2008a, pp. xxii). Many AIs feel disconnected from original instructions; these instructions have been broken and/or lost by the process of colonization. Recently, there has been a movement forged wherein AI communities are looking to reclaim the original 
instructions through the reclaiming of cultural language, oral history, stories, song and music, land reclamation, ceremony and tribal reclamation projects.

Relational restoration involves repairing the relational way of being and our responsibility to each other, to past and future generations. It is a process of recreating, or reestablishing, original instructions through a current lens of experience based in place, time and space, and which is grounded in relationship with family, community, tribe, land, spirit and our ancestral domain. The restructuring occurs in an attempt to recreate instructions in a contemporary context that are meaningful to the here and now (Walters and Johnson-Jennings, 2014).

The narrative transformation attempts to recreate meaning and create a new narrative through an individual experience by bringing one's own communication style, inflection and narrative to facilitate transformation. For example, instead of referring to "suicide" and "substance abuse" which focuses on pathology, we transform the narrative to "living" and "relation to medicine" now a focused on resilience (Walters and JohnsonJennings, 2014). Indigenous communities historically have done this through our oral histories and storytelling, observation, art, the use of silence, music, dance, and movement, while also incorporating new technology along the way (Castleden and Garvin, 2008; Hume, 2007; Vizenor, 1994 and 2008). This study utilizes the oral tradition of indigenous storywork, the use of the Listening Guide method of data analysis and reflexivity, Anukfilli, as a form of TIK and survivance. 


\section{Chapter 4: Methodology}

\section{Sample}

Participants of the "Our Vision of Health for Future Generations" study were selected from the Yappallí Choctaw Road to Health project. Interviewed were 23

Choctaw women, ages 26-83, from the first 3 years' cohorts, who completed the weekly groups and curriculum, walked the Trail of Tears, and started planning or implemented a holitobit ibbak fohki "sacred giving" community health event in their prospective communities. Interviews were completed face to face, in May and September of 2017 at the Choctaw Nation of Oklahoma. In-depth interviews, haklo "listen deeply". were conducted with a semi-structured interview, or "conversation with purpose". The women lead the interview and were encouraged to create and share their own narrative and story. I viewed myself as a guide through this process rather than an interviewer. This study focuses on the experiences of Choctaw women because they have had to live with the brunt of the effects of historical trauma in their communities, are traditionally the givers and keepers of life, and have an informed worldview and perspective on the issues of health and wellness that impact them, their families and their communities. Table 1 demonstrates the number of participants by cohort and by study.

Table 1: Sample

\begin{tabular}{llllll}
\hline $\begin{array}{l}\text { Cohort } \\
\text { (year) }\end{array}$ & $\begin{array}{l}\text { \# Yappallí } \\
\text { Participants }\end{array}$ & $\begin{array}{l}\text { \# Our Vision } \\
\text { of Health } \\
\text { Participants }\end{array}$ & $\begin{array}{l}\text { Completed } \\
\text { Yappallí } \\
\text { Curriculum }\end{array}$ & $\begin{array}{l}\text { Walked the } \\
\text { Trail of } \\
\text { Tears }\end{array}$ & $\begin{array}{l}\text { Completed } \\
\text { Community } \\
\text { Health Project* }\end{array}$ \\
\hline $1(2015)$ & 13 & 4 & 4 & 4 & 3 \\
$2(2016)$ & 29 & 7 & 7 & 7 & 7 \\
$3(2017)$ & 35 & 12 & 12 & 12 & 9 \\
\hline Total & 77 & 23 & 23 & 23 & 19 \\
\hline
\end{tabular}


* Some participants had started their community health project but had not completed it at the time of the interviews.

The initial discussion about this project came out of several conversations with the Yappallí staff at both the University of Washington and the CNO, with the intent to center community priorities of the Yappallí project and CNO and to develop a process for decolonizing the research. To develop a list of potential participants, I met with Yappallí project staff at the University of Washington and the CNO. Together, we developed and distributed a recruitment flyer to support passive recruitment of potential eligible study participants. The recruitment flyer included information about the project, how to participate in the study and study-staff contact information. Interested women contacted me directly via phone to register, schedule a date, time and location to complete the interview. To ensure optimal retention in all levels of this study, we followed procedures proven effective in our prior studies, such as covering costs for their time, child care, and transportation to and from the interview, and held the interview in a location deemed convenient for the participants. The interviews were conducted at $\mathrm{CNO}$ community centers and at the Choctaw Labor Day festival where one of the Tribal Council members donated his trailer for me to conduct the interviews in a quiet and convenient location.

In-depth interviews were conducted face to face and digitally recorded using two recorders later transcribed word for word and then checked for accuracy by me. Before transcription, I listened to the recordings twice with the intent to engage with the voice, tone and inflection of the participant prior to transcription. This study and the study protocols were approved by Institutional Review Boards at Portland State University 
(2015) and Cultural and Heritage Preservation department at the Choctaw Nation of Oklahoma (2015).

In-depth interviews, haklo, were used to gather stories of transformation and motivation of participants after engaging in the Yappallí Project. Such interviews can be viewed as a form of TIK. Historically, TIK has been passed down through oral traditions, narrative and storywork (Beltrán and Begun, 2014; Beltrán, Olsen, Ramey, Klawetter, Walters, 2014; Castleden, and Garvin, 2008; Wilson, S., 2008; King, 2003). Through the practice of storywork and oral traditions, indigenous people learn to live in right relationship with the themselves, their families, communities, and all of creation. Lowery (1999) and Lowery and Mattaini (1999) discuss the impact of shared power and shared narrative for indigenous people, specifically for AI women. "The sharing of power, to a lesser or greater extent, is increasingly represented in contemporary behavioral practice and with explicit attention could be extended much further" (Lowery and Mattaini, 1999, pp. 18). This understanding, interpretation and meaning are parts of a cultural experience that are expressed through language, naming and classification of the environment and systems, resource use practices, ritual, spirituality, and worldview.

In-depth interviews are a common method of data collection in qualitative research studies (Richie, Lewis, Nicholls, and Ormston, 2013; Hesse-Biber and Leavy, 2010). In this study, the use of in-depth interviews assumes that participants have unique and important information about their lives. Hesse-Biber and Leavy (2010) suggest that in-depth interviews require "active asking and listening" (pp. 119) and is a "meaning making endeavor embarked on as a partnership between the interviewer and his or her 
respondent" (119). It is viewed as a "conversation with a purpose" (Webb and Webb, 1975, pp. 130).

\section{Data Analysis}

Data were analyzed using the Listening Guide (LG) method The LG method allows the indigenizing of this process by centering the voice of participants while creating an integrated process of reflexivity that is inherent on indigenous knowledge. The LG method is a qualitative, relational, analysis method, founded in feminist and grounded theory, that centers the "multiplicity of voices" of participants (Petrovic, Lordy, Briogham and Delaney, 2015; Brown and Gilligan, 1993; Gilligan, and Eddy, 2017; Woodcock, 2016) as it lends well to an indigenized method of analysis. It does this through the development of "I" poems "that places emphasis on the psychological complexities of humans through attention to voice" (Woodcock, 2016, pp. 1) and centers the complex intersectional experiences of the participants. LG incorporates other qualitative methods, such as thematic, narrative analysis and grounded theory (Gilligan, and Eddy, 2017; Woodcock, 2016) and centers the participant in the data. The validity of research findings to determine accurate representation of the themes was established through an iterative process with two outside researchers, both Choctaw, who reviewed a subset of the data. The reviewers were asked to review the data of five interviews and were given a description of the LG method and asked to develop the "I" poems and listen for the contrapuntal voices. I met with the reviewers twice to review the contrapuntal voice and come to consensus about the findings. Below, I outline the analytical process of the LG as described by Gilligan (2015): 
Step 1) Listening for plot: This step began with listening to the recordings and reading the transcripts four times, "listening" for plot and tone, becoming acquainted with the details of the narrative, and listening for how the participant speaks and articulates their thoughts (Gilligan, 2015; Petrovic et al., 2015; Brown, and Gilligan, 1993; Gilligan, and Eddy, 2017; Woodcock, 2016). The purpose of this step is to attend to the narrative and that the participants share and to develop a synopsis of the themes and to gain a broad scope of the participant's story. This method "recogniz[es] that the researcher is an active instrument within qualitative research, the LG 's design requires the researcher to partake in reflexivity throughout the entirety of the research process" (Petrovic et al., 2015, pp.1). During this step some important considerations were made; emotion, repeated words or phrases, contractions and information or comments that stand out and tracked through memos.

LG as a reflexive method is uniquely suited to assist me in developing a process of addressing positionality in relation with the participants. Throughout this process, referring to my reflexive notes helped me to develop a closer researcher-participant connection and to develop a nuanced understanding of the participant and their experiences. Ultimately, it helped me to "hear" their story and center their voice in the process and to address my own bias. The following questions guided my reflexive journaling throughout the analysis of this study and helped me to develop a more nuanced understanding of my positionality within the research. I used the following questions suggested by Petrovic et at. (2015, pp. 3) to guide this process:

- In what ways do I identify with or distance ourselves from this person? 
- In what ways are we or our experiences different or the same?

- $\quad$ Are we upset or delighted by the story, amused or pleased, disturbed or angered?

In addition to the LG method of data analysis, I also created a process of selfreflexivity to provide "critical reflection to recognize and respond to the different amounts and kinds of social power... and the impact of structural power on the research process as a knowledge-producing activity" (Daley, 2010, p. 68). This process helps me to honor my own personal process development through TIK while addressing issues of power and my influence in the work. (Daley, 2010). As part of my cultural upbringing, I have always sought out the insight and wisdom of my elders, especially those who understand the complexity of a specific issue(s). This “...positions the research process in time, place, culture, and situation and promotes the use of researchers' reflexivity and critical reflection to recognize and respond to power structures and relations in the research process" (Daley, 2010, pp. 68). I seek out the guidance of my academic advisors, senior indigenous researchers, intellectual ancestors, while also developing a reflexive journal to process and explore issues of positionality and power. Table 2 excerpts from 4 different participant's interviews reflexive journal to highlight some of the process for me as a researcher.

Table 2: Memos: Examples of responses of the reflective process during the data analysis

\begin{tabular}{|c|c|c|}
\hline $\begin{array}{l}\text { In what ways do I identify with } \\
\text { or distance ourselves from this } \\
\text { person? }\end{array}$ & $\begin{array}{l}\text { In what ways are we or our } \\
\text { experiences different or the } \\
\text { same? }\end{array}$ & $\begin{array}{l}\text { Are we upset or delighted by the } \\
\text { story, amused or pleased, } \\
\text { disturbed or angered? }\end{array}$ \\
\hline $\begin{array}{l}\text { In reading the transcript I could } \\
\text { identify with the participant's } \\
\text { interests in learning about } \\
\text { traditional/natural "weeds" as } \\
\text { food and medicine. Although she } \\
\text { continues to learn about }\end{array}$ & $\begin{array}{l}\text { The participant spoke openly } \\
\text { about the intergenerational } \\
\text { trauma her family has suffered } \\
\text { from sexual abuse. Our } \\
\text { experience is the same in that I } \\
\text { too have been a victim of sexual }\end{array}$ & $\begin{array}{l}\text { The participant seemed to suffer } \\
\text { from a lot of medical conditions } \\
\text { that impacted her experience on } \\
\text { the trail. While I empathized } \\
\text { with her, I could not relate. It } \\
\text { seemed that her health impaired }\end{array}$ \\
\hline
\end{tabular}


identification, and has struggled with obtaining formal training due to both financial and geographic reasons, she is passing this knowledge on to her granddaughter and family.
I identify with how this person compares her experience to her ancestors. When talking about walking the trail, she frequently mentions that her ancestors did not have the luxuries they did, such as tents, or the ability to ride if they got tired. I frequently think of the ancestors during my life struggles. There was a time when I wanted to quit school and run away from my

responsibilities, my mentor told me this was my sacrifice to our people. I reminded myself, "your ancestors survived the Trail of Tears. You can survive this."

I identify with this participant's journey of finding her own autonomy as an Indian woman. She went on the trail to find out who she is aside of her family. As women we are caregivers. We are taught to be mothers, grandmothers, wives, sisters first. Taking time for selfreflection often induces guilt or shame. Having that space to ask yourself, "who am I," is both humbling and empowering. abuse. Although everyone's experience with sexual assault is different, our experience is the same in the way of witnessing trauma being passed down through generations, and feeling helpless to stop it. The participant talked about trying to protect her children and grandchild from what she went through, but to no avail. "There's three generations, and nobody is ever held accountable." I feel this is representative to the way western society and the justice system fail Native women and contribute to the disproportionate rates of abuse to women and girls.

Our experiences are similar in that our families hold unhealthy behaviors around food. I could relate with the participant's family members eating "nothing but fast food,". My mother was and most of her family were overweight, and while growing up I had to deal with food scarcity regularly, many times I was did not eat unless it was the school lunch. This created a problematic relationship to food that I still struggle with today. Colonialisms impact on our soci cultural norms around food has been devastating

Both the participant and I have experience in the helping field. We both come from working in western health systems, but have been reawakened, through different avenues, to traditional ways of knowing and being. Being "in tune with yourself," as the participant's states, has just as much, if not more, value to a person's wellbeing then any colonial medical intervention or standard of care. her ability to get the most out of the project and this made me feel sad that she was not able to benefit as much as she could have from the experience. But 1 $1 / 2$ years post walk she is still engaging in and unpacking her experiences and transformations.

I was disappointed in the participant not remembering the information told to her about Choctaw clans. At one point she states that she figured out what clan she was from, but forgot. She mentions several times that we don't have clans. I see this as the reason why the information didn't seem important enough for her to remember, as an acceptance of the Choctaw s loss of a clan system on the trail.

I was moved by how this participants experience on the trail prepared her for losing her husband. Her husband being sick before the Yappallí project started may have deterred her from participating. He knew that she needed this experience, and selflessly encouraged her to go, even though it would cut what precious time they had left together. To me it is a true testament of love. It's the 
I could identify with this participant's persistence and drive to educate our future generations. She spoke of holding an event for community youth that was "a disaster." I think anyone who does health education events as known this feeling of having everything you've been planning for fall apart during the event. Although this participant was disappointed with the outcome, she keeps working with tribal council and community to make change happen. This is a testament to being a true community health leader.
The participant makes multiple mentions to the fact that many services available in Durant are not accessible in her district. I have had relatable experience growing up in rural areas myself. Living in poverty makes distance to critical services even greater. Now living in an urban setting, I am reminded this when working with tribes who are hours away from the city, in not only in tribal member's ability to access services, but affordable healthy food as well. acknowledgement of the healing power of culture and connection.

The part of the participant's story where she talks about her experience with the ancestors on the trail gave me a lot to think about. She speaks of hearing drumming, singing, crying, and of feeling the pain the ones who had gone before felt before she was told the significance of the land she was on. Its empowering to hear of the power of ancestral DNA in a way that, although there isn't western scientific proof to explain what is happening, the participants experience cannot be denied.

Step 2) "I" Statements: I began this step by revisiting my study purpose, to regain focus of the study. This step provided an opportunity to determine and reconsider new themes and subthemes to promote a more in-depth analysis. At this point, I decided to focus on the themes of motivation, challenges and transformation, adding embodiment after the initial analysis. I focused on the participant's voice which was expressed in the "I" statements and resulted in development of the "I poems". "In this way, a researcher may meticulously attend to the thoughts, wishes, desires, needs, conflicts, and silences spoken by the informant by tracing them is a purposeful way (Woodcock, 2016, pp. 4). I created an excel spreadsheet and copy and pasted exact text from the transcripts into an excel document and categorizing the following content:

- Column 1: sentences that contain the words I/me/my/myself

- Column 2: sentences that contain the words you/your

- Column 3: sentences that contain the words we/us/our 
- Column 4: sentences that contain the words they/their/them/others

The majority of the text contained the words I/me/my/myself, then we/us/our, then they/their/them/others, with very few you/your statements, but often the "I" voice was combined with other voices. Woodcock (2016) states that this "may be interpreted as internal dialogue and/or dissonance within the informant" (pp. 4). I believe that this can also be explained by AI women's experiences in relationship to self, family and community.

Table 3: Categorizing content examples

\begin{tabular}{|c|c|c|c|}
\hline I/me/my/myself & you/your & we/us/our & they/their/them/others \\
\hline $\begin{array}{l}\text { "I was really touched } \\
\text { by the prayers and the } \\
\text { type of blessings they } \\
\text { did" }\end{array}$ & $\begin{array}{l}\text { "it just brings your } \\
\text { heart closer to it when } \\
\text { you see that they're } \\
\text { recognizing where our } \\
\text { ancestors went, you } \\
\text { know, where they } \\
\text { walked." }\end{array}$ & $\begin{array}{l}\text { "We got to Village } \\
\text { Creek, and there was a } \\
\text { healer there." }\end{array}$ & $\begin{array}{l}\text { "I guess, they didn't } \\
\text { have the help, you } \\
\text { know, for people to } \\
\text { help them like that. }\end{array}$ \\
\hline $\begin{array}{l}\text { "I kept having these } \\
\text { dreams like in ancient } \\
\text { times." }\end{array}$ & $\begin{array}{l}\text { "You all were just so } \\
\text { kind to us." }\end{array}$ & $\begin{array}{l}\text { "We shared what } \\
\text { grandmothers told us, } \\
\text { what mothers told us, } \\
\text { you know, and what } \\
\text { grandparents told us." }\end{array}$ & $\begin{array}{l}\text { "they slept on trails } \\
\text { anywhere they could, } \\
\text { their children did" }\end{array}$ \\
\hline $\begin{array}{l}\text { "Just to be invited to } \\
\text { go, it was a blessing in } \\
\text { my life to be one of the } \\
\text { ones that got to do it." }\end{array}$ & $\begin{array}{l}\text { "God opens doors for } \\
\text { you and you got to step } \\
\text { through them" }\end{array}$ & $\begin{array}{l}\text { "Yes, that was a good } \\
\text { way of teaching us that } \\
\text { we can eat and get } \\
\text { full." }\end{array}$ & $\begin{array}{l}\text { "And just to think they } \\
\text { didn't, they didn't have } \\
\text { supplies like we did } \\
\text { whereas if they got } \\
\text { hungry they could just } \\
\text { stop and eat." }\end{array}$ \\
\hline
\end{tabular}

Step 3) Contrapuntal Voice: This step listens for the contrapuntal voices. Contrapuntal is term used to describe a form of music that has two melodic lines that play at the same time, the lines are independent of each other but relate harmonically to each other (Sloboda and Edworthy, 1981). Within the context of this research method, the researcher is listening for the contrapuntal voice that are both in tension to and in relationship with each other. This is a method for "creating voice poems to explore the 
ways themes either melodiously interact or are in tension with one another" (Woodcock, 2016, pp. 6). This method offers a way to examine the themes and how they interact and/or overlap with each other. As Petrovic et al. (2015) suggest, I sought to "listen to the data itself than impose my own preconceptions" (pp. 7). I did so by referring to my reflexive notes and highlighting the corresponding text that captured each contrapuntal voice. Contrapuntal voice fell into four categories: motivation, challenges, transformation and embodiment (Table 4).

Table 4: Contrapuntal Voice

\begin{tabular}{ll}
\hline \hline $\begin{array}{l}\text { Contrapuntal } \\
\text { Voice }\end{array}$ & Definition \\
\hline \hline Embodiment & $\begin{array}{l}\text { Captures participant's experiences when they "have no words" to describe } \\
\text { their experiences } \\
\text { Recognize the interdependency between humans and nature, the physical and } \\
\text { spiritual worlds, the ancestors and the future generations } \\
\text { Captures participant's experiences of interconnectedness of the mind, body, } \\
\text { and spirit }\end{array}$ \\
\hline Motivation & $\begin{array}{l}\text { Captures one's motivation to participate in the project or making health related } \\
\text { changes } \\
\text { Providing with a reason to act in a certain way } \\
\text { Having a strong reason to act or accomplish something }\end{array}$ \\
\hline Challenges & $\begin{array}{l}\text { Captures feelings in intimate self-exposure, demonstrating the relinquishment } \\
\text { Discerned by highly personal expression of emotions } \\
\text { Raw, unguarded self-reflections }\end{array}$ \\
\hline Transformation & $\begin{array}{l}\text { Captures participant's evolving journey and self-discovery } \\
\text { Discerned by their transforming perceptions, feeling, attitudes, and emotions } \\
\text { Unexpected awakenings }\end{array}$ \\
\hline
\end{tabular}

By centering the participant's contrapuntal voices, I was able to develop a better understanding of the data that centered the participates voice and experiences. This process also resulted in a deeper researcher-participant relationship. 


\section{Indigenizing Methods}

Both the data collection and the data analysis methods used in this study lend well to an indigenized methodology of decolonized and indigenous research, as these methods lend to the adaptation to indigenous protocols. Indigenous methods of analysis in social sciences are lacking and correlating abstract themes is not culturally responsive to the worldview of AI (Simonds and Christopher, 2013; Wilson, S. 2008), and specifically not to the Choctaw worldview. Simonds and Christopher (2013) find the western research methods are "an aggressive action form an Indigenous perspective because it severs the relationship between learner and storyteller" (pp. 2189). Wilson, S. (2008) expands on this by noting that western research breaks information down into its smallest pieces, he states "Indigenous methodologies includes all of these relationships, if you are breaking things down into their smallest pieces you are destroying all the relationships around it" (pp. 119). The context of the story can be lost in many western methods, I was concerned about this, as I felt the interviews of the participants were deeply powerful, showed vulnerability and were a form sacred storytelling, that is to say the interviews were ceremony/ritual. I sought out a data analysis method that would center the voice of the participants and their experiences and helped me to develop a process of reflexivity and seeking out process of true partnership that equally shared community and researcher voice and to address power in all phases of the research process. Wilson, S. (2008) suggests that methods can be borrowed, or adapted, to a de-colonial framework as long as they address the "ontological, epistemology and axiology of the Indigenous paradigm" (pp. 39). Simonds and Christopher (2013) expand on this by stating "one must be vigilant 
to ensure that the research process comes from a place of respect and gives priority to or centers on Indigenous knowledge and methods" (pp. 2190).

"Indigenism has sought to conceptualize methodological reform using a variety of approaches that advocate a research compatibility with indigenous realities, interests and aspirations" (Rigney, 2006a, pp. 36). Rigney (2006a and 2006b) outlines this research strategy by identifying three key factors in indigenist research: resistance, political integrity and privileging indigenous voice. Within this methodology, I attempted to develop an explicit commitment to indigenous liberation, centering of indigenous voices, and support research that is conducted by an indigenous person with indigenous people and communities. Indigenist research attempts to push our own political agendas that is centered on the liberation of indigenous peoples from colonial oppression. Rigney (2006b) adds that focusing on the lived experiences of indigenous peoples, verse focusing on indigenous people as relics of the past, "enables researchers to speak to the basis of these experiences and are powerful instruments by which to measure the equality and social justice of society" (pp. 116). Indigenist researchers understand that we internalize colonization and are not "free of colonial hegemony." To address this, indigenous researchers become aware of our positionality, are respectful of each other's cultural traditions and use a reflexive process to address these issues of power and positionality. This informs the data methods in this study as indigenized methods of research. 


\section{Chapter 5: Findings}

This study created space for participants to share stories in relation to both their individual health concerns (proximal), and deep love and commitment for the health of their family, community and for future generations (setting-based/intermediary). Many women shared stories of their transformations and health changes, both proximal and setting-based/intermediary, including changes in their health, family and community. Listening for the contrapuntal voice certain voices emerged as the "loudest voices" and occurred most frequently in the data. I gave myself permission to immerse myself in the data while utilizing reflexive journaling to assess my positionality. The contrapuntal voices that emerged were embodiment, motivation, challenges, and transformation (Table 5). Table 5 gives the description of the contrapuntal voice and an example from the interviews to highlight each of the themes.

Table 5: Contrapuntal Voice with examples

\begin{tabular}{|c|c|c|}
\hline $\begin{array}{l}\text { Contrapuntal } \\
\text { Voice }\end{array}$ & Description & Example \\
\hline \multirow[t]{4}{*}{ Embodiment } & $\begin{array}{l}\text { Captures participant's } \\
\text { experiences when they } \\
\text { "have no words" to } \\
\text { describe their experiences }\end{array}$ & $\begin{array}{l}\text { "Yeah, but I don't know how to explain. I was like I } \\
\text { can't explain this. You have to experience this for } \\
\text { yourself. And you take in so much. It's like I said, you } \\
\text { can't explain it." Participant 1003) }\end{array}$ \\
\hline & $\begin{array}{l}\text { Recognize the } \\
\text { interdependency between }\end{array}$ & $\begin{array}{l}\text { "I felt like they (ancestors) were with me." (Participant } \\
\text { 2001) }\end{array}$ \\
\hline & $\begin{array}{l}\text { humans and nature, the } \\
\text { physical and spiritual } \\
\text { worlds, the ancestors and } \\
\text { the future generations }\end{array}$ & $\begin{array}{l}\text { "I can't tell you everything, but because it's more of a } \\
\text { feeling than it is of what I can tell you and express to } \\
\text { you that I did learn on that when we were out there in } \\
\text { the wilderness." (Participant 2002) }\end{array}$ \\
\hline & $\begin{array}{l}\text { Captures participant's } \\
\text { experiences of } \\
\text { interconnectedness of the } \\
\text { mind, body, and spirit }\end{array}$ & $\begin{array}{l}\text { "I don't know if you heard it, but there was nothing } \\
\text { moving. Nothing. It was the most quietest place I've } \\
\text { ever been to in my life. And I was just getting chill } \\
\text { bumps. And when we started walking, it was like there } \\
\text { was spirits behind me pushing me and I went in front } \\
\text { of everyone" (Participant 3001) }\end{array}$ \\
\hline
\end{tabular}




\begin{tabular}{|c|c|c|}
\hline \multirow[t]{3}{*}{ Motivation } & $\begin{array}{l}\text { Captures one's motivation } \\
\text { to participate in the project } \\
\text { or making health related } \\
\text { changes }\end{array}$ & $\begin{array}{l}\text { "(name retracted) asked me. I didn't know nothing } \\
\text { about it. I thought, I can't walk. I can't do that. She } \\
\text { said, yeah you can. Yeah, you can. I said, I don't have a } \\
\text { way to come down here, down there. She said, I can } \\
\text { take you." (Participant 2001) }\end{array}$ \\
\hline & $\begin{array}{l}\text { Providing with a reason to } \\
\text { act in a certain way }\end{array}$ & $\begin{array}{l}\text { "Knowing that someone is watching me like my } \\
\text { children, and knowing that if I eat healthy, they'll eat } \\
\text { healthy." (Participant 3004) }\end{array}$ \\
\hline & $\begin{array}{l}\text { Having a strong reason to } \\
\text { act or accomplish } \\
\text { something }\end{array}$ & $\begin{array}{l}\text { "My nephews are a big part of it, but my health. I got } \\
\text { diagnosed with diabetes. I had an older brother and an } \\
\text { older sister pass away within the last four years, and } \\
\text { they both had bad health. So I put health at the } \\
\text { forefront of my brain" (Participant 3006) }\end{array}$ \\
\hline Challenges & $\begin{array}{l}\text { Captures feelings in } \\
\text { intimate self-exposure, } \\
\text { demonstrating the } \\
\text { relinquishment of control } \\
\text { and some fear } \\
\text { Discerned by highly } \\
\text { personal expression of } \\
\text { emotions } \\
\text { Raw, unguarded self- } \\
\text { reflections }\end{array}$ & $\begin{array}{l}\text { "Well, the walk was challenging in itself. I guess the } \\
\text { whole thing was challenging because I didn't know } \\
\text { what to expect until I got out there. I didn't think I } \\
\text { could be able to do it because of my leg, but the more } \\
\text { you got out there and you're, you're -- that was a } \\
\text { challenge, a big challenge for me because I've been } \\
\text { down for a long time." (Participant 3001) } \\
\text { "The eating was different, yeah. I never really done } \\
\text { straight plain traditional food. Eating healthier was } \\
\text { different. I never really ate so many nuts and peanut } \\
\text { butter in my life." (Participant 3004) }\end{array}$ \\
\hline \multirow[t]{3}{*}{ Transformation } & $\begin{array}{l}\text { Captures participant's } \\
\text { evolving journey and self- } \\
\text { discovery }\end{array}$ & $\begin{array}{l}\text { "I have more energy. When you eat healthy you } \\
\text { actually get more energy and you feel better about } \\
\text { yourself." (Participant 1003) }\end{array}$ \\
\hline & $\begin{array}{l}\text { Discerned by their } \\
\text { transforming perceptions, } \\
\text { feeling, attitudes, and } \\
\text { emotions }\end{array}$ & $\begin{array}{l}\text { "It's real informative. You learn a lot of stuff. You } \\
\text { learn stuff about yourself, too, about your limits and } \\
\text { what you see and how physical active you are or what } \\
\text { have you, how much you can handle." (Participant } \\
\text { 1003) }\end{array}$ \\
\hline & & $\begin{array}{l}\text { "And also really just seeing how much our eating } \\
\text { habits and lifestyle in general has changed, and it } \\
\text { wasn't something that was natural to us in the } \\
\text { beginning." (Participant 3011) }\end{array}$ \\
\hline
\end{tabular}

Although the contrapuntal voices may appear to follow a linear pattern, e.g. as

listed in Table 5, but this was not always the case. The relationship between voices was, at times, much more complex and intertwined with each voice influencing the other. This 
fluid nature of the contrapuntal voice starting with embodiment, moving to motivation, which influences challenges that facilitated transformative experiences. Thus, for some, contrapuntal voices followed a cyclical process.

\section{Embodiment}

The loudest contrapuntal voice in this study was that of embodiment. Embodiment captures the participant's understanding when they "have no words" to describe their experiences. Embodiment is consistent with AI spatial and relational worldview that recognize the interdependency between humans and nature, the physical and spiritual worlds, the ancestors and the future generations. It also captures participants' experiences of interconnectedness of the mind, body, and spirit. For indigenous people, interaction, experiences, and healing happen in places of historical and spiritual significance. Indigenous scholars suggest reconnecting with place and ancestral homelands as a way of connecting with traditional health knowledge, integrating this knowledge into cultural approaches to health promotion and healing historically anchored trauma. Many women addressed this through developing a connection to spirits and their ancestors. The following excerpts are examples of this connection:

"I was laying there.

It was pitch black that night. You could not see anything. And all the sudden there were lights They were like heart beats. they were just everywhere. they were maybe the size of a dime, but they didn't shine like light shines out. They were just there and they were pulsating. 
I was just talking,

pleading

to please help me,

help me be whole again

I felt like I had left myself

in so many places." (Participant 1004)

"as we walk,

I tried to imagine myself there,

imagine myself walking that trail back then.

As elderly,

as a young kid.

Tears rolling down my eyes

they kept going.

They did not let anyone defeat them.

I'm going to start crying again.

Because they wanted a better future for us.

And to our generation to this day,

And I want my kids to feel what I feel.

To know that our people

went through a lot." (Participant 3010)

Additionally, participants made connections to land, nature and spirit. The contrapuntal voice reflected the paradox that is common with indigenous people, individual healing is collective. A participant's experiences in the Yappallí project were not simply individual experiences, but rather communal experiences in relation to others, family, community, ancestors, the land, nature and spirit, proximal and settingsbased/intermediary. Although participants were not asked specific questions about this, these traditional values were commonly expressed and, thus, became the focus of these data.

Kinship or relationship to others, is an important aspect of Choctaw culture, one that provides identity to the individual, family, clan, and village. Specifically, the Choctaw uphold the teachings of their ancestors' original instructions, Chanspo 
Ikhvnanchi, through traditional clans, social activities, and roles managed through seven societal teachings - Nashoba (wolf), Koi (Cougar), Halupa Hishi (Holly Leaf), Issi (Deer), Shawi (Raccoon), Watonlak (Crane), and Mahli (Wind). These teachings are center to the Yappallí project curriculum and some of these original instructions are captured in the following excerpts:

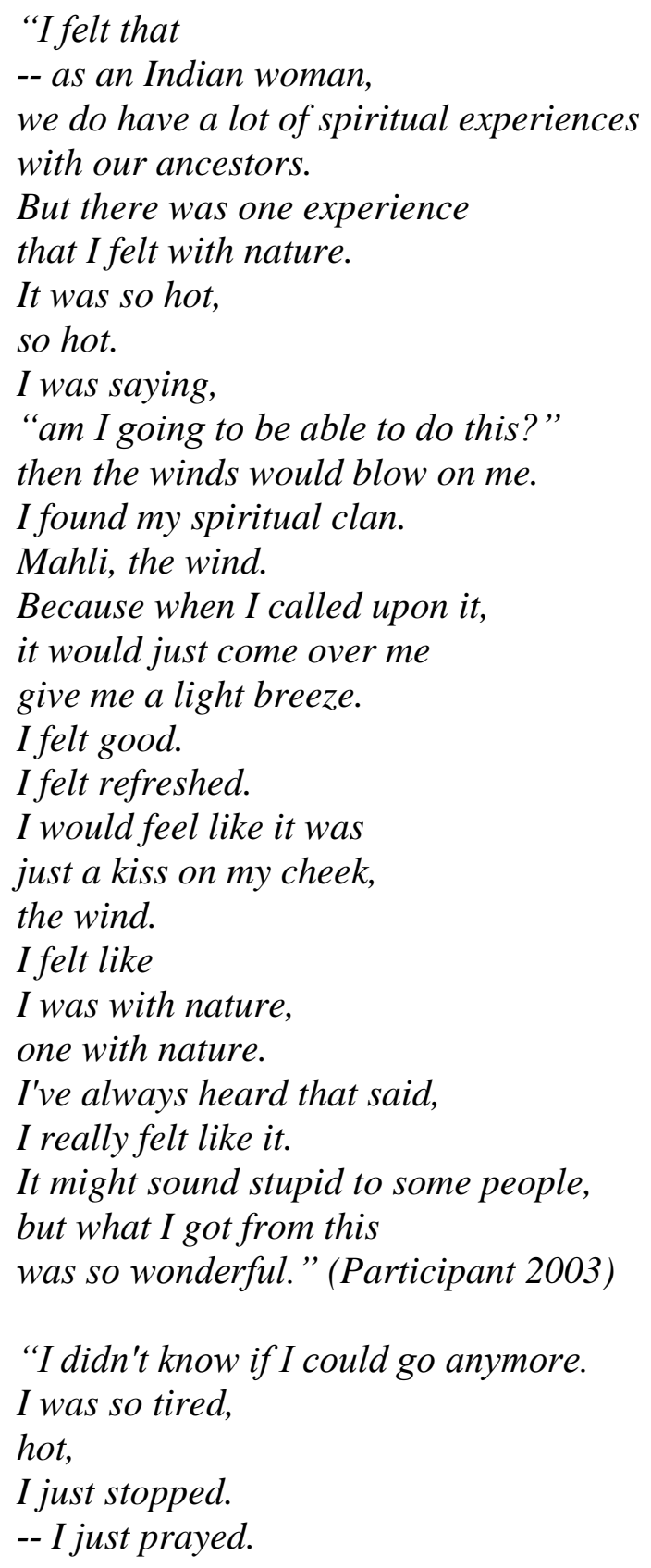


I just prayed to my ancestors.

I said,

"I don't know if I can go anymore."

I said,

"I need help. I don't know if I can do this or not."

after I prayed,

it was just like they answered me.

This cool breeze

just came down on me

that wasn't there before.

it was hot

it was dusty

I was so tired.

then after I prayed,

this cool breeze

just came on me out of nowhere.

I knew then,

I can make it.

I can go on.

So I went on." (Participant 2004)

I can't tell you everything,

because it's more of a feeling than it is

of what I can tell you

express to you

that I did learn on that

when we were out there in the wilderness.

while I was alone,

it was the last leg of the journey,

I felt-- as an Indian woman,

we do have a lot of spiritual experiences

with our ancestors. (Participant 2002)

"Picking a clan

I told her the cougar

was the one that stuck out to me most.

Once she had told me what it represented,

It's kind of like to me,

it's kind of true.

I do try to take care of my family.

I have cousins

sometimes they come to me

they tell me stuff.

I try to help them out as much as I can.

The cougar is a big protector. 
So I kind of related." (Participant 1002)

Addressing some of the settings-based/intermediary aspects of the experiences of participants were the stories about their experience with mahli "wind". This was noteworthy, because the Choctaw believe the wind, mahli is highly significant and plays a critical role in tribal culture and lifeways. It is important in Choctaw culture to keep balance in the imanukfilo (mind), hakshup (body), shilup (spirit), and chukvsh (heart) (Walters and Johnson-Jennings, 2014). For example, as a mind-body-spirit metaphor, mahli is viewed as "heart" and must be cared for, just as we care for our body. It is also a balancing and peacemaking metaphor between the other teachings, tying each to one another. The wind and air are breathed by all to maintain life and help one function and reach one's journey. Mahli, culturally and historically, is thought of as a person with empathy and care for all, serving an important cultural and spiritual life force for the people. To make sure mahli is healthy, the heart and spirit are maintained and balance is sought between the other teachings. Thus, mahli plays both a spiritual and cultural role that is integral to Choctaw peoples' health and wellness (Walters and Johnson-Jennings, 2014).

Nearly every woman interviewed shared a common experience of having "no words", specifically when addressing their experiences of walking the Trail of Tears. When talking about this, many would put their hand on their heart and say "there are no words to express what I went through, you just had to be there."

"but I don't know how to explain

I can't explain this.

You have to experience this for yourself.

take in so much.

It's like I said, you can't explain it. 
It all makes sense.

Everything that I was taught

Everything said goes right with it. (Participant 1002)

"Like I said,

it's hard to explain.

You have to experience it.

There's no words to really say.

you feel all kind of emotion." (Participant 1003)

"I still remember

and feel it.

I think about a lot of it" (Participant 2001)

"I can't tell you everything,

because it's more of a feeling

than it is of

what I can tell you

express to you

that I did learn

when we were out there

in the wilderness.

I just think that

a lot of people on our trail have

-- it's just been something

that's in us now,

something that's

going to stay in us

for the rest of our lives." (Participant 2002)

"you can't really explain it

until you actually do it yourself,

but I have told several people

about the walk

about Yappalli

what it stands for

kind of what we went through

everything we did." (Participant 2004)

"it was something,

I don't even know what it was

to be honest.

we felt something

we were like,

It was just something unknown. 
And it is still to me

-- how do you explain that feeling you had?

I think it is there (points to her heart)" (Participant 3005)

"I'm still processing.

But just to have, just,

a little bit better understanding

of past generations.

I mean, I don't even know really.

I don't really know

what to say about it

other than

I'm just thankful for the experience.

there are so many things

that happened inside

that I can't even

put it into words." (Participant 3011)

The above "I" poems indicate embodiment. The act of putting their hand on their heart, and sharing their common experience of not being able to share in words what they were experiencing also captures the participant's experiences of interconnectedness of the mind, body, and spirit.

\section{Motivation}

The contrapuntal voice of motivation captures one's motivation to participate in the project or make health related changes. It also provides a reason to act in a certain way and a strong reason to act or accomplish something. Participants revealed that their primary motivations were family and health, particularly their experiences with the health-related issue of diabetes that impacts many AI communities today.

"my first child, at the age of 8 and a half years, she was diagnosed with Type 1 Diabetes. 
I lost my mother

when she was 57 years old

due to complications of diabetes.

I swore then

I was not going to have

those bad habits again.

I did my best for a long,

long time.

the very next year,

my daughter was diagnosed

with Type 1 Diabetes

a year after my mother passed away.

in my mind

I was like

we got to eat better,

we got to exercise,

we got to do this." (Participant 1001)

"my girls,

one of them,

she is the same way,

prediabetes,

they think it just runs in the family

because my sister was 13

my daughter is 17

around 14-15 years old

they said she was that way. (Participant 3010)

"I saw the

Yappalli ad

it asked if you would be interested

in being a health leader.

And I thought

that is really important to me

because I don't want my nephews

to end up with diabetes.

I don't want them

to end up with a preventable disease.

That was my main motivation.

It just came in front of me

at that right time" (Participant 3006)

"I got diagnosed

with diabetes

-- I had an older brother 
And an older sister

pass away within the last four years,

and they both had bad health.

So I put health at the forefront of my brain." (Participant 3006)

"I was diagnosed

with Diabetes a few years ago.

So I tried to eat more greens,

and lay off the white stuff.

I'm progressing,

trying to instill that into my grandchildren.

Because before the trip,

it was running a little high.

But with diet and exercise,

I have,

you know,

gotten back where it

-- not where it should be,

but it's not where it was before." (Participant 2006)

The Choctaw Nation of Oklahoma is facing a time when parents will outlive their children due to complications from preventable health diseases, primarily diabetes, substance misuse and suicide. Citizens of the $\mathrm{CNO}$ are experiencing alarming rates of Type 2 diabetes, cancer, and cardiovascular diseases, which have recently been linked to pediatric obesity. AIs die at higher rates than non-AIs from these diseases. Many of the participants shared that their motivation to participate in the Yappallí project was influenced by the impact that diabetes had on their lives, families and a concern for the health of the community and future generations.

"My vision.

they see the understanding

of physical activity

the understanding of eating healthy.

Because I know in our tribe

diabetes is a big issue.

I think there needs to be more programs

for children than adults 
being physically active (Participant 3004)

"I'm thankful to have a greater purpose.

it gave me even more

of a greater purpose to realize

hey, my ancestors came here,

they didn't have diabetes.

They didn't have all these health conditions.

So that is not something

that we are just destined to have.

That is something that can be changed." (Participant 3011)

"I told my kids,

if I can show them

to eat without the fatty foods,

stuff that I know that

-- if we can just boil or bake,

we're going to be okay.

They're going to be okay.

I don't have to worry about

the diabetes

or high blood pressure

or cholesterol.

We'll make it.

That is what I want." (Participant 3006)

This was also highlighted when participants were asked about what their vision of health was for the next generation and how their vision impacted their motivation. They expressed deep concern for the future generations, the need to address diabetes and other preventable diseases, and the importance of being role models to younger generations. These participants expressed feelings of responsibility, in Choctaw atobba hinla and humility chaukash akkalusi to their community, tribe and the next generations. This dedication for the future generations is indicative of traditional AI values grounded in their relationship to the seventh generation.

"My biggest motivation was that I could really see 
that what I do with my one little life

can have a big impact on future generations.

That was my motivation.

I'm just really feel called to that.

a heart for that.

I feel like it's very important

that I break those generational cycles

and, if I don't,

then it is left up to my kids

and it is not their responsibility" (Participant 3011)

"I joined this group because

I saw I was not living

a healthy lifestyle.

I saw I was not eating

or exercising in a healthy way,

I thought this might be something good

that will restructure me

throughout the next year

to eat better

to live better

not just for myself

but for my family." (Participant 1001)

"I've always wanted

to get closer to my cultural roots,

discover them.

Because it was one of those things

now it's good to say I'm Choctaw,

but two generations ago

we don't talk about this.

And so just the change

of how Choctaw Nation is viewed.

And now it is something

to be proud of.

Where I remember my grandmother was

we don't talk about this.

And so I wanted to go back

try to experience that.

then I also asked my

daughter to go, too,

that way we would have

that connection." (Participant 3003) 
The motivation to participate in the project was directly related to these challenges. For example, the inspiration to participate in the Yappallí project was influenced by a desire to be healthier because they experienced a lifetime of healthrelated issues. Additionally, there was a strong desire to participate because of the commitment these women have to the next generation and the desire to break the cycles of unhealthy behaviors. Yet, the challenges they face while involved in the project were significantly impacted by their own health issues, primarily physical ability related to age, weight, diabetes, and high blood pressure. Out of hardship and love for the next generation, they faced these challenges head on and there was a discovery of a different "you" because of it.

Many women shared that they were motivated to participate in the Yappallí project be they wanted to be in the place where their ancestors walked. settingsbased/intermediary motivations.

"I'm going to start crying again.

Because they wanted a better future for us.

And to our generation to this day, And I want my kids to feel what I feel.

To know that our people went through a lot. I want to go back again,

I really do." (Participant 3010)

"I wanted to know

about the group,

the women that a lot of their history.

So that's why I wanted to be part of it.

I wanted to see.

I want to be part of history.

I really believed that the Yappalli program

is a historic program.

If I could express anything,

it would be the fact

that this is so important

to generations. 
Because what I gained,

I'm passing it on down

they're going to pass it own down.

But I wouldn't have had that

had I not become part of this program." (Participant 2003)

"I went on it

because I was on a spirit quest

I knew it from the beginning.

I'll tell you this that three or four years back

I had this dream

that I was going to go on

a Trail of Tears walk.

it was just like I knew

I was going to go someday.

But it came up

I took advantage of it

And then I said I'm going” (Participant 3001)

"I guess just being on the walk

learning some of the things

about what our ancestors went through

kind of made me want to learn more

about my heritage,

so I actually started going

to Choctaw language classes

to try to learn the Choctaw language.

I went a few years ago,

but I never really learned it.

But I'm really going to try to learn it this time.

I would like to try to learn it" (Participant 2004)

I am glad I did.

Like I said, it was very informative

Before you would hear about the walk,

the ancestors,

what they did,

what they went through,

but you really don't pay attention

or realize

until you actually go and do it. (1003) 
This setting based/ intermediary motivation was expressed throughout the study, in varying degrees. They expressed a desire to walk in their ancestors steps and to in the actual place where these ancestors stayed, the participants being on the Trail of Tears motivated them to want to learn more about their culture and heritage. Additionally, participants shared how connecting to the land and the place helped motivate them to continue through the journey, they expressed that the land helped them to "remember" lessons learned in childhood, in ancestral memory and in the Yappallí project.

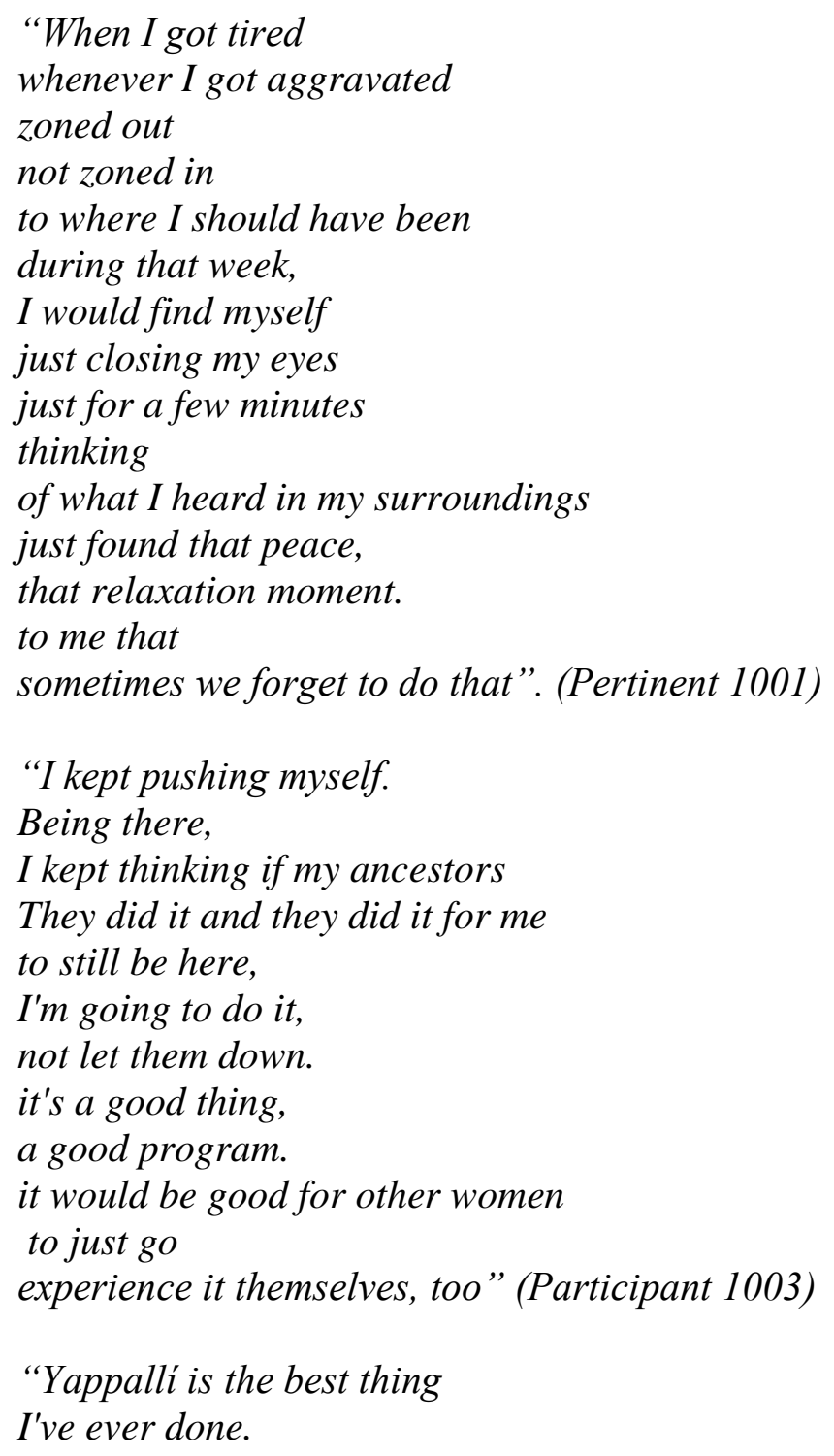


It gave me the opportunity to walk that,

have people that put it on like

you, Karina, Sandy, everyone,

to work

be able to tell the events

as we walked that road,

that path.

And know that you

didn't just do it for us,

but for yourself,

as well as the Native Americans

I loved it.

I hope you all continue.

It's an experience. (3010)

These "I" poems reflect the experience of motivation and settings-

based/intermediary. They reflect how the land and the ancestors on the Trail of Tears

helped to motivate them to continue on the Trail of Tears. Working through the

challenges in this way also enhanced and deepened their experience of transformation.

This setting based/intermediary expression of their experiences is reflected throughout

the interviews.

\section{Challenges}

Expression of motivation was often in tension with the contrapuntal voice of

challenges. The contrapuntal voice of challenges captures feelings in intimate selfexposure and demonstrates the relinquishment of control and some fear, discerned by highly personal expression of emotions and raw, unguarded self-reflections. The participants identified many challenges while walking the Trail of Tears, such as the act of walking nearly 100 miles in a week, the change in diet, and the emotions they were 
experiencing while on the trail, and having to leave their families for a long period of time.

The walking itself was arduous and challenging for the women. Many of them struggled with a lifetime of health related issues, diabetes, high blood pressure, and being overweight. Some participants were elders, "asanochika", over the age of 65 when they participated in the project, and subsequently had physical limitations. Many women had ability issues that created challenges that impacted their experience, e.g. some participants were over 400 pounds when they participated in the project. Despite those challenges, they experienced aiolpanchi (gratitude) and chaukash akkalusi (humility) both facilitated a sense of accomplishment and transformation.

"the walk was challenging in itself.

I guess the whole thing

was challenging

I didn't know what to expect

until I got out there.

I didn't think I could be able to do it

Because of my leg,

but the more you got out there

you're, you're

-- that was a challenge,

a big challenge for me

I've been down for a long time.

I think once after I got through

with all that it was just amazing

I got through that.

But really the whole thing

was challenging." (Participant 3001)

"Seemed like it was a challenge

for me to walk it all.

And, I walked them all,

Even I got blisters on my feet,

my heel,

I still walked it

I made it. 
I thought I was going to lose my breath

I made it" (Participant 2001)

"Just the walking,

the walking.

It was so -- I did a lot of walking,

or I thought I had,

before we went on the trail,

I could only make it so far.

And I was tired.

But just the walking," (Participant 2002)

"the second day,

I was blistered.

My whole feet was blistered.

So I took the boots off

and walked the two miles

just in socks.

I got to keep going.

we had a mile and a half left to go.

Well, I did finish,

I was slow.

that was the most

challenging for me." (Participant 3002)

In many AI communities, it's the women who hold the family together. Women hold tradition, culture and ceremony; they also carry the burden of the loss of life, land, and spirit the givers and keepers of life and wellness, and keepers of the home. It is a significant burden for these women to leave one's home and family to take a journey of self-discovery and to focus on themselves, for any length of time. Some women talked about the struggles they had and the experiences they felt when concentrating on themselves, and how challenging this was for them, while also experiencing a sense of transformation by working through these feelings.

"my husband

had been diagnosed

with terminal cancer. 
one of the biggest challenges

was leaving him.

he strongly, strongly

he wanted me to go

the challenge

was for myself

was to see

how strong a woman

I really was.

Could I do this

without my grandchildren,

without my children,

without my husband?

Could I go on this journey,

just me?

Just concentrate on me

see if I had the strength to do it

It just made me a stronger person," (Participant 2003)

"I realized I was getting nowhere

just because I was divorced

didn't mean I could run around

and do whatever.

I realized

and told my kids

I would never leave them.

So that day was really hard.

I cried

bawled

that first two nights

because my kids were home

and I was away.

What if something happened?

after staying there

seeing what the culture was

listening to them talk about ancestors

what they felt,

listening to (name retracted) outside singing,

it was, wow,

I love this." (Participant 3010)

The most significant challenges expressed were discerned by highly personal expression of emotions and raw and unguarded self-reflections. The participants shared 
experiences of deep reflection and emotion that were both challenging and transformative for them. Throughout the Yappallí project, stories are shared of their ancestors' experiences while walking the Trail of Tears, their love and dedication to the Choctaw people and the vision of health they held for us. Participants expressed gaining a deeper understanding of their ancestors' experiences and this impacted them emotionally and spiritually.

"that was a struggle

in a sense because

I never really had to

Sit,

sit there and listen

just overcome that fact.

And I had to kind of

in my mind

kind of just juggle

how do I make it through this week?

with the bitterness,

but with the happiness too." (Participant 1001)

"It was just emotional

being on the same trail

that they walked on.

But then we seen the signs

where it says the Trail of Tears walk.

it just brings your heart closer

to it when you see that

they're recognizing where our ancestors went,

where they walked.

Yeah, it was very emotional. Still is." (Participant 2002)

"I got up and we started,

I walked in there,

the whole 7.3 miles.

when I walked in there,

it was just so emotional.

I just broke down

started crying

when I walked into

Washington Post there. 
It was really an emotional walk,

that one was." (Participant 2004)

The participants expressed feelings of hullo (love) and aiolpanchi (gratitude) for their ancestors. They also reported developing a better understanding of what their ancestors endured as well as their sacrifices for the future generations. This clearly influenced their experiences. Contemporary Choctaw people were left with a message and letters expressing this love and sacrifice for future generations. In a letter penned by Harkins (1830), he proclaims his love for the seventh generation when he states, "We as Choctaws rather chose to suffer and be free, than live under the degrading influence of laws, which our voice could not be heard in their formation... I could cheerfully hope, that those of another age and generation may not feel the effects of those oppressive measures that have been so illiberally dealt out to us; and that peace and happiness may be their reward." Choctaw leaders were sharing with us a love of the people and a love of the culture. This message was reflected in the following poems:

"It made me want to know more about my ancestors.

who's the one who came over

I wanted to know more

about my family.

I know it had to have been

hard for them, especially during the winter time.

I didn't even walk that far.

I was tired.

So I know

they had to be strong, really strong minded strong hearted to make it here. if my grandparents

If they didn't make it over here then we wouldn't be here." (Participant 1002) 
"I was thinking

about the people

that did make the sacrifices,

what come to my mind

was the mother.

You know,

the mother

how she probably

had to carry her child,

yet she sacrificed

the pain in her feet

and all that." (Participant 2003)

"I've seen visions

I've had dreams,

but this vision,

I seen them from that dream

when I was 7 ,

that's a long time to wait

for a dream to come true.

And, boy, it just hit

me in the face" (Participant 3001)

Although all participants expressed varying degrees of challenges, the processes

by which they worked through these challenges impacted their experiences of

transformation. Many women talked about the physical experiences of being on the Trail

of Tears: the heat, the strenuous activity, pain (both emotional and physical), of feeling

like they would never make it. To work through during these challenges, they

remembered a story, prayed, accepted help form someone, experienced a connection with nature, and found the strength to make it through difficult parts of the trail. The experience of working through these challenges created a deeper sense of understanding of what the Choctaw experienced on the original Trail of Tears. 


\section{Transformation}

Throughout this study, participants expressed profound experiences of transformation. Transformation in this study is defined as capturing participant's evolving journey and self-discovery, discerned by their transforming perceptions, feelings, attitudes, and emotions and unexpected awakenings. The data mirrored this through experiences of health changes and connection to their heritage, spirits and ancestors.

For many women, indigenous or not, self-care and personal health is not a priority. Women find themselves taking care of family, partners, children, elders, work, and community before addressing their own needs. Consequently, and not surprisingly, their health is often compromised in significant ways. In many pre-colonial tribal communities, AI women held significant positions as keepers and teachers of health and wellness practices. Although women historically held positions of influence in precolonial Tribal societies, their current health status is relegated to some of the worst outcomes across all racial groups. Yet, many women expressed wanting to participant in the Yappallí project because of their and their family's health, subsequently experiencing health related transformation themselves.

\footnotetext{
"With me,

it did help me to get better

a better perspective

to eat healthier,

to focus on a healthier

living lifestyle

I have gotten involved

with the bike team.

I have gotten involved

with different fitness challenges

not just for myself
} 
but for my family

My family is my number one priority

if I don't take care of myself,

then I don't show them how

they should take care of themselves

Then that was the main thing to help me to find

a sense myself" (Participant 1001)

"It's been kind of bewildering

I've never went camping before.

I took me camping for my first time.

I've never been camping

with women I barely knew before.

But I wasn't putting myself out there

so it really stretched me.

in good ways

and bad ways,

but in every way

where I could see different ways

that I could grow

and change" (Participant 3005)

"I was 70.

To be 70 years' old

to do something like that.

My mom,

she didn't live past 65.

So I know my life

is a lot different from hers.

I know that our lives are different

from our ancestors that came across

because they didn't have anything.

Just very emotional

because of all the stories that you all told.

It has really helped me,

and I want to live longer.

I know that I have to change everything

to live longer." (Participant 2002)

"I started going to the wellness center

working out

walking

just to prepare myself

for the walk.

I lost weight. 
I was trying to eat healthier.

before then

I was taking pills

for Diabetes,

cholesterol,

high blood pressure.

I was taking quite a few pills.

But after all of that,

I went to see my doctor

my labs came back really good,

he actually took me off

of most of everything I was on.

I've been trying to keep that up

As of today,

he hasn't put me back on any

of those medications." (Participant 2004)

Some participants shared "awakenings" which led into experiences of

transformations. Rediscovering cultural pride, connecting with their heritage and their ancestors via participation in the Yappallí project awakened their desire to take care of and to take time for themselves.

"it created an awakening in me

as to something that,

has become slightly dormant,

and that's a pride in being an Indian woman.

Also the eating habits had changed,

I eat a lot more vegetables.

I drink a lot less sodas.

I drink water.

I just have more of a pride in myself,

I take more

-- I take more time for myself

than I did." (Participant 2003)

"It made me want to know more about my ancestors.

who's the one who came over and stuff like that.

I wanted to know more about my family.

I know it had to have been hard for them,

especially during the winter time.

I mean, I didn't even walk that far. 
I was tired.

So I know they had to be strong, really strong minded

strong hearted

to make it here.

If my grandparents didn't make it over here

then we wouldn't be here." (Participant 1002)

"My grandkids

are what I'm looking to the future for

knowing that my kids

and grandkids were going to be okay.

But when I got ready to go on this trip,

I bawled my eyes out

Going home to my kids,

they knew something was different.

Different in me" (Participant 3010)

The experiences of transformation along with their connection to each other, the land, nature and their ancestors, influenced and moved participants through an experience of embodiment. The contrapuntal voice highlights the tension and relationship between the themes, and offers us insight into the experiences of the participants who participated in the Yappallí project. Specifically, it helps researchers to gather stories and experiences of participants to identify the culturally-based individual level (proximal) motivations, as well as community level (settings-based/intermediary) motivations that influence the health changes relative to substance use and health disparities by addressing the interactions, relationships and tension between the participant's motivation, challenges, transformation and the expression of embodiment. 


\section{Chapter 6: Discussion}

Women of the CNO have some of the highest rates of being overweight, physical inactivity, and excessive drinking prevalence in the country (Walters and JohnsonJennings, 2014). The Yappallí project is a health promotion initiative developed by Choctaw researchers in collaboration with the $\mathrm{CNO}$ and University of Washington. The purpose of this study was to explore the culturally-based individual level (proximal) motivations, as well as community level (settings-based/intermediary) motivations that influence population health changes relative to substance use and health disparities with women from the $\mathrm{CNO}$ who participated in the Yappallí project, an act of decolonization of one's heart and mind to promote healing from a traumatic experience of forced land removal. Twenty-three Choctaw women were interviewed about their experiences with the Yappallí Choctaw Road to Health program. These women shared their stories of embodiment, their motivation to participate in the project, the challenges they faced, and the transformation they experienced due to their participation in the Yappalli project, and particularly the experiences of walking the Trail of Tears and implementing community health events. Their experiences offer new information to further build the body of science linking historical/intergenerational/contemporary trauma and healing and health for indigenous peoples.

Traditional means of coping with life and historic stressors, such as spiritual, cultural, and land-based practices, were systematically stripped away from American Indian people (Braveheart et al., 2011), thereby reducing protective buffers from stress and illness. Federal policies resulted in displacement, land loss, and restrictions on land usage, as well as the disruption of traditional cultural practices. Multiple cumulative 
stressors resulted in historical trauma, which, in turn, has led to significant health disparities for AI women (Braveheart et al., 2011; Walters, Mohammed et al., 2011), which are directly linked to removal from their traditional homelands and traditional cultural ways.

The embodiment of trauma is manifested in poor health outcomes across generations of AI peoples (Walters et al., 2011a). For AI people, the very definition of health and well-being intimately connects to place. “...[D]isease or literally dis-ease (out of balance, disharmony, disequilibrium) is tied to the holistic understanding of the interconnectedness of mind, body, emotion, spirit, and land. Indigenous knowledge recognizes place as integral to one's sense of being ..." (Walters et al., 2011a, p. 173). This is in contrast to western biomedical understandings of health as the absence of individual psychological disturbances and disease. AI peoples conceptualize health as a more holistic connection between physical, emotional, mental, and spiritual dimensions, as well as connectedness with the natural environment (Vukic, Gregory, Martin-Misener, \& Etowa, 2011), as highlighted through the AI tradition of the medicine wheel. Many women who participated in the Yappallí project reported significant health and emotional changes. This included weight loss, decreased consumption of processed foods, sugar, and soda pop, an increased consumption of water, better maintenance of diabetes and blood pressure with diet and exercise, and using fewer medications to manage these conditions. Participants reported living with less physical and emotional pain and stark changes in their mental health, e.g. feeling happier and less depressed and anxious.

The Yappallí project has provided the women of the $\mathrm{CNO}$ an opportunity to develop as health leaders for their community, while addressing their proximal and 
setting-based intermediary motivations for engaging in health skills and behavior change. Many women shared stories of embodiment, motivation, challenges, and transformations. One participant shared that, while involved in the Yappallí project, she weighed over 400 pounds and suffered from diabetes, high blood pressure, depression, and social anxiety. When she was interviewed for this study, she reported that she was under 400 pounds for the first time in her adult life, attended and camped at a music festival by herself, and was currently managing her diabetes and high blood pressure with diet and exercise. She shared:
"There were so many, just so many things that I had to face. I had to face myself out there [on the Trail of Tears]. And I think that is part of how come I've been able to grow because I think I was going through life not facing myself. I had to be because that wasn't the true me, that mousy, shy, afraid person wasn't the true me. So I couldn't have been facing myself because I wasn't facing the brave me." (Participant 3006).

When I interviewed her, there was a stark difference, not only in her physical appearance, but in her emotional body. She looked like a different person: she was radiating life and happiness, she was glowing pink, and she was smiling from her soul.

She shared that she and some of the other women started a walking group, called the Walking Warriors. This group meets regularly to walk a local track in their community. She described the group as doing:

"fun things like spirit fingers, or we do hopscotch or jumping jacks, and different things while we walk around the track. And it's fun and supportive, and everyone is accepted. And it just, when you have a group like that, and you see people are committed, like they come every day, and it just makes you, inspires you to be committed. It was good for me to know that I wasn't alone. But it was 
amazing that I got to start jogging because that is something I had been working up the courage for a long time" (Participant 3006).

The Walking Warriors, as a community health event, has snowballed. They started a Facebook group with the local community members and have now started to engage women and men, not only from the Choctaw Nation, but from all over the world in healthy activities. They walk and engage in challenges proposed by the administrators and post their accomplishments on the group page. These women, living in a small community in Oklahoma, are having a huge impact on the lives of many people and their families across the globe. This is truly a form of holitobit ibbak fohki "sacred giving."

Another woman participated in the Trail of Tears after finding out that her husband was diagnosed with terminal cancer. There were concerns for the participant and staff that her husband would pass away while she was on the Trail, and we developed a support plan for her if this were to happen. She shared with me the anguish that she was feeling about leaving her beloved husband to do something for herself. It was her husband who encouraged her to participate in the Yappallí project, and specifically the Trail of Tears walk. She found that this was both one of her biggest challenges and strengths. She stated:

"I think one of the biggest challenges was leaving him. Although, he strongly, strongly supported me in anything, and he wanted me to go because I had been looking forward to it for so long. I think was challenging myself to see how strong a woman I really was, you know. Could I do this without my grandchildren, without my children, without my husband? Could I go on this more or less of a journey, you know, just me? Just concentrate on me and see if I had the strength to do it." (Participant 2003). 
While on the Trail of Tears, she and I were alone at the end of one of the day's walks. I wanted to give her space because I could see that she was struggling. At a certain point I asked her if she needed a hug; she said yes. As we held each other-with our ancestors, on a beautiful field of wild flowers on the Trail of Tears-I told her that I could see through her joking and laughing that she was strong, that I could see her struggle and her spirit. She wept as I held her, and she thanked me for being there for her. Her husband passed soon after her return from the Trail of Tears. She later shared that it was this experience that helped her, that participating in the Yappallí project gave her the physical, mental, emotional, and spiritual strength to move through her grief and take care of herself and her family.

"It just made me a stronger person. Little did I know that very soon I would be needing that strength. During that time, I came to grips with what was going to occur in my life. My life has changed tremendously. I really believed that the [Trail of Tears] trip conditioned me in a lot of ways. It showed me that I did have the strength to go on alone. I really appreciated that trip very much.” (Participant 2003).

Each woman, in her own way, shared these powerful stories of motivation and transformation, and as their participation in the Yappalli project has changed them, it too has changed me. Being given the space to hear and to haklo ("listen deeply") to their stories has given me the opportunity for reflexivity, anukfilli (deep reflection). For this, I remain eternally grateful and profoundly changed.

I, too, had a healing experience while on the Trail of Tears. In 2013, during the feasibility study, I walked across Arkansas with a smaller group of Choctaw women, in the steps of our ancestors. We walked the Trail of Tears holding a vision of health for the 
next generation. I did not know what to expect on this journey. I wanted to represent my tribe and my ancestors with honor, humility, and respect. On a hot fall day in Camden, Arkansas, I came to understand the depth of the love my ancestors have for me and the sacrifices they made. On this day, I was carrying the grief of 175 years of historical trauma, and I was struggling physically, mentally, emotionally, and spiritually. I was suffering greatly this day. I felt pitiful and small. My body was hurting, I was tired after 5 days of walking with little sleep, and it was hot and humid, but mostly I was missing my family, and I was thinking about what my ancestors experienced in this place. We were in a place where my ancestors had walked and been treated with hate and disdain, treated as if they were less than human. I was weeping with this understanding of the horrific treatment my relatives endured, of what they went through, the sacrifice, for the survival of the Choctaw people. I sought refuge from the heat of the day under an old oak tree and silently wept. A Choctaw elder came to the tree, and without saying a word, began touching it with such reverence and beauty. I watched her for a little while, then asked her what she was doing. She then told me that the Choctaw ate acorns, they were sacred to us, and that this tree was old, old enough to have been there 175 years before. She told me that she imagined that our ancestors might have sought refuge under this same tree, just as I was seeking refuge. I, too, began to touch the tree, feeling the ancestral memory and medicine of the tree and my relatives. In that moment, I felt 175 years of historical trauma and grief transform into gratitude. I suddenly felt immense gratitude for all I had, for the opportunity to walk the Trail of Tears, for the Yappallí project, for all the opportunities I have been afforded, and for the love of my family. But mostly, I felt the 
deepest sense of gratitude for the sacrifice and love my ancestors had for me. Because of that experience,

I now know what it means to have my ancestors walk with me. I know that I am not alone, I know that I am loved, and I know I must now pass this love on, to make my sacrifices, for I have the responsibility to create a better world for the next generations, just as my ancestors did for me. This experience informs this work.

\section{Contrapuntal Voice}

When exploring the proximal and intermediary motivations, what was clear is that they are intimately connected to each other and influence each other. There is tension between them, and this impacts the changes these women experienced. In fact, it is the synergetic intersections, the tension and relationship between embodiment, motivation, challenges, and transformation, that influenced the changes experienced by the women who were interviewed. It is also interesting to note that this was not a linear process, but rather a synergetic and cyclical one. Figure 3 highlights the interactions across and between the contrapuntal voices. A critical aspect of the contrapuntal voice is to address how the themes are in relationship with and in tension to each other. The contrapuntal voice provides an opportunity to extract themes, to emphasize the ways in which participants speak to the experiences of their lives, to illustrate the relational nature of participant's stories, and to focus on the relationships in the stories.

Many participants stated that their initial motivation to participate in the Yappallí project was because of individual health concerns (proximal), but also because of deep 
love, commitment, and concern for the health of their family, community, and for future generations (setting based/intermediary).

Figure 3: Contrapuntal Voice Interactions

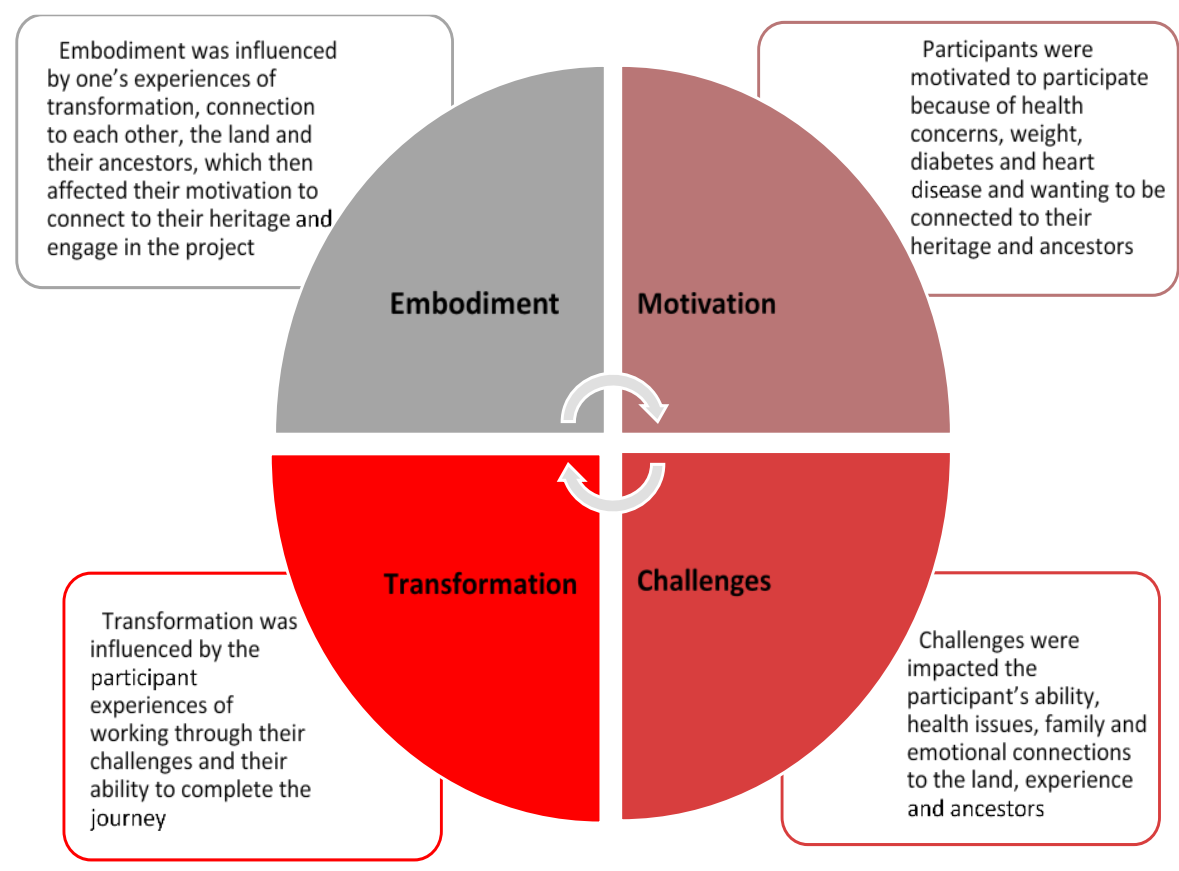

Primarily, there was a deep and sacred relationship created when they walked the Trail of Tears, one that impacted their personal transformations and motivated them to change their health and the health of future generations. When addressing these challenges, they discussed proximal level issues like the impact of long-term health related issues, as well as the setting-based/intermediary challenges of enduring emotional suffering from being in the same setting and location that their ancestors walked. Yet they described their transformations as happening because of these difficulties, working through their own interpersonal struggles, and also engaging in this work with community in the place that their ancestors walked. This led to the experiences of 
embodiment. It was the praxis of love and sacrifice together that impacted their experiences.

The loudest contrapuntal voice was that of embodiment. This was significant because participants were not asked specific questions about embodiment. They were asked specific questions about motivation, challenges, and transformation. For the purpose of this study, embodiment has three components, as outlined in Walters et al. (2011a) work. First, it captures participants' experiences when they "have no words" to describe their experiences; second, it recognizes the interdependency between humans, nature, the physical and spiritual worlds, the ancestors, and the future generations; third, it captures participants' experiences of interconnectedness of the mind, body, and spirit.

Our elders have said that the memory of our ancestors is passed down through our blood. Scholars have shown that there is an epigenetic transfer of historical trauma passed down from generation to generation, and that trauma is held in our bodies (Walters et al., 2010). According to our relatives, trauma is passed down, but so too are love, memories, knowledge, and resistance. The experience of embodiment encompasses trauma and histories of oppression, but it also includes ancestral wisdom, empowering experiences, and histories of liberation. Walters et al. (2011a) note that embodiment is consistent with AI spatial and relational worldviews. "According to AIAN worldviews, environment, mind, body, and emotional health are inextricably linked to human behavior, practices, wholeness, and hence, wellness" (Walters et al., 2011a, pg184). Additionally, Walters et al. (2011a) state that "embodiment acknowledges that while bodies tell [hi]stories, they reveal stories that are also not conscious, hidden, forbidden, or even denied by individuals or groups" (pg. 183). The study of the embodiment of historical trauma and 
health consequences allows us to intervene in the intergenerational patterns of health. Consequently, this knowledge can inform the development of culturally relevant policies and practices intended to alleviate the health inequalities that AI women experience. Additionally, it would benefit social work and health science to address the epigenetic transfer of resistance and ancestral wisdom.

Historical trauma occurs within communities in specific physical places, so it stands to reason that healing should also occur within communities in those locations, such as the Trail of Tears. To address this, Yellow Horse Brave Heart (2004) shares that, for AI people to restore health from their historical traumas, we need to begin by confronting the genocide that occurred. The People should not forget what happened to them within a sociopolitical and environmental context, and to understand the trauma that occurred and the traumatic symptoms that impact our lives and the lives of those around us. She believes that, to release our pain and heal collectively, we must do this through the use of ceremony and ritual and transcend the trauma by connecting to the seventh generation. Additionally, Yellow Horse Brave Heart states that AI communities need to continue to conduct research and collaboration that acknowledges and validates the experience of AI communities (Braveheart Yellowhorse, 1998). Thus, for complete healing to occur, survivors need to revisit those specific places where our ancestors were harmed, not to relive the trauma, but to transform that experience in a contemporary context - that is to say, to renew balance and to create a vision of health and wellness for future generations.

The most significant challenges expressed were discerned by highly personal expressions of emotions and raw and unguarded self-reflections. The participants shared 
experiences of deep reflection that were both challenging and transformative for them. Throughout the Yappallí project, stories are shared of their ancestors' experiences while walking the Trail of Tears, their love and dedication to the Choctaw people, and the vision of health they held for us. Participants expressed gaining a deeper understanding of their ancestors' experiences, and this impacted them emotionally and spiritually. While they walked in their ancestors' steps, they could better imagine what the experience was like for their ancestors, and the deep love and sacrifice that was made for the seventh generation, for them. This experience of walking in their steps was expressed by many of the participants. This is the process of decolonizing one's mind and heart, through reindigenizing and healing the traumatic experience. It gives an opportunity to place new meaning on the traumatic experience. Now these women will replace their internalized oppressive thinking, which influences their behaviors, and share this with their children, family, and communities to change norms and health outcomes. This is an act of decolonization of healing for the health of all, and a deep form of love and sacrifice praxis.

\section{Implications for Practice}

"The social work profession requires a body of scientific evidence supporting the effectiveness of interventions; yet, the social work scientific community could benefit from strengthening its contribution to the profession's body of evidence." (Teater, 2017, pp. 546). Social work is a profession that strives to use research to inform practice. Teater (2017) cites the Social Policy Institute (2010), indicating that social work as a profession addresses policy through: 
"(a) assessing the needs and resources of people in their environments; (b) demonstrating relative costs and benefits of social work services; (c) advancing professional education in light of changing contexts for practice; and (d) understanding the impact of legislation and social policy on the clients and communities we serve." (pp. 549)

This study provides another framework for the development of decolonized and indigenized research and health promotion interventions by using in-depth interviews and haklo ("listening deeply") as a form of narrative and storywork. This storywork centers the experiences of marginalized people, specifically AI women. Through the practice of storytelling and oral traditions, participants were able to develop relationships with themselves, their families, communities, their ancestors, and all of creation. The following "I" poems highlight this learning:

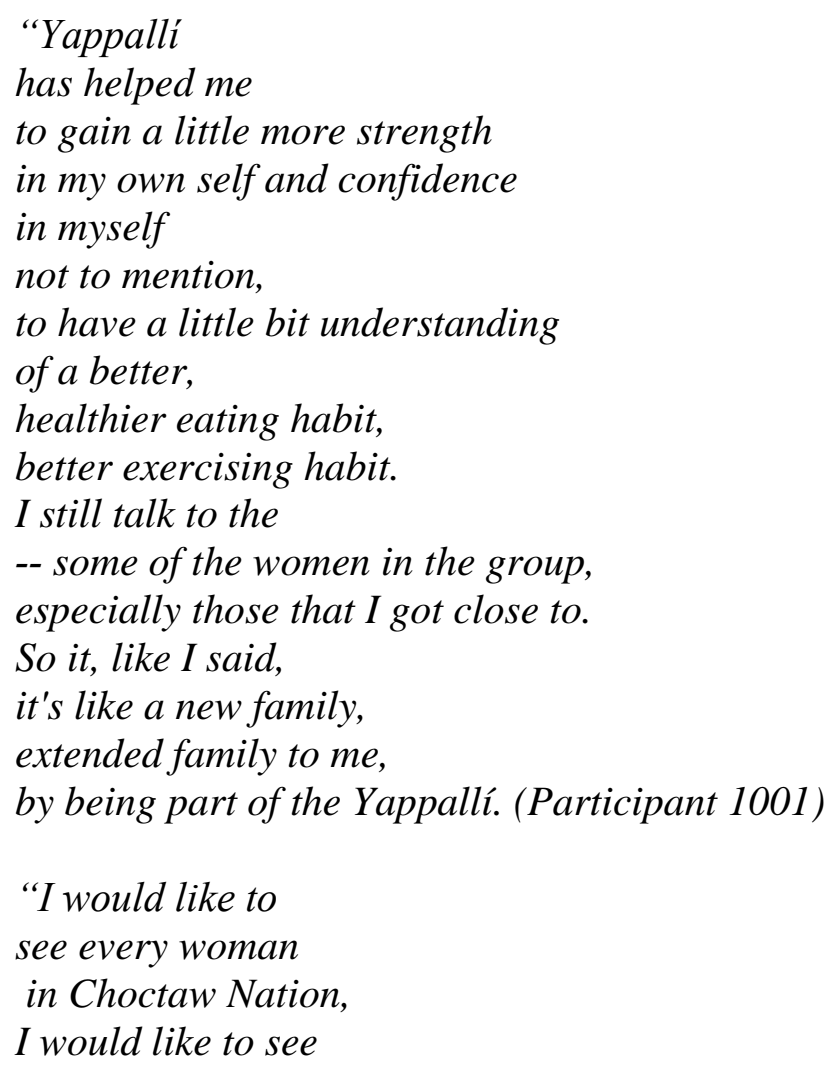


it go through the tribes.

Not just Choctaw,

but as an Indian woman.

We are different,

but it's gave me such a pride

in being an Indian woman,

living in an non-Indian world,

I saw women of different tribes,

You shared some of the traditions

and cultures.

Of course,

it all related with ours.

I think being Indian

is just we have a few variations,

but we're Indian women" (Participant 2003)

"the Choctaw young people

and even old people, too,

they're looking for

a sense of purpose,

visiting the Trail of Tears

connecting with the ancestors,

just even the healthier way of life they had,

I see young people all the time,

I know in native youth

there is an epidemic of suicide,

they're just looking for purpose.

if they connected like we do,

it would make a difference.

It made me feel present.

It made me feel like I exist.

It made me feel like I am here.

I can possibly make a mark.

It made me feel that.

It gave me a sense, a sense of

gave me a sense of purpose, I guess." (Participant 3006)

Additionally, there is a body of scholarship addressing issues around the

experiences and expressions of trauma and the impact on women and non-men, as well as

how that trauma is passed down to their children and grandchildren. Thus, one potential

benefit of this study is that the women and non-men experience healing through the act of 
sharing their knowledge, experience, wisdom, and insights through sacred indigenous storywork. This study was designed to provide women with that role by documenting their visions of health and wellness for future generations. Research shows that this envisioning process is healing for women while allowing them to leave a legacy for their family members, which can also provide a sense of health and well-being. If efficacious, this work can inform the development of health and substance use prevention interventions for AI women across tribal nations. To address the epidemic of health and substance use-related health disparities among AI women, collaborative partnerships must focus on the development of sustainable community-wide health practices that are grounded in TIK systems and worldviews.

This study builds on knowledge and the work of Walters and Simoni (2002) and Walters et al. (2002) and the ISC model (Figure 1) which identifies cultural buffers that can influence the impact of historical trauma and interrupt health disparities. This study adds to that body of work by showing that participants are identifying experiences that are centered on our contemporary experiences of being Choctaw women (identity attitude), connection between land and spirit (traditional health practices), prayer in our everyday lives (spiritual coping), and intergenerational healing (enculturation), which act as cultural buffers. It is clear the Yappallí project provides a venue for Choctaw women to address issues of health and wellness. Health interventions that focus on cultural buffers can increase protective factors and decrease negative health outcomes. "Native people have traditionally used storytelling to examine their communities, as a primary method for illness explanation, as well as to cultivate deeper levels of understanding that facilitate positive changes for community members" (Simonds and Christopher, 2013, pp. 
2190). Further exploration of indigenous storywork as an intervention strategy and research method is necessary, and the exploration of indigenous methods for increasing one's motivation to engage in positive health behaviors is important.

\section{Implications for Policy}

White settler colonialism has contributed to neo-liberal policy that significantly impacts the most marginalized people, specifically impacting AI women. "The policy frameworks have contributed to the perpetuation of the racialization and marginalization of Indigenous people on the part of the white settler colonial state" (Abawi and Brady, 2017, pp. 26). Qualitative, decolonized, and indigenized research is useful to policymakers because it often describes the settings in which policies will be implemented, privileges indigenous knowledge, and centers the experiences of the most marginalized people. Social work and public health systems involve complex human interactions that can rarely be studied or explained in simple terms or through randomized control trials, and the use of more nuanced exploration of the human condition would be efficacious, rather than generalizable knowledge. There are also issues of ethics to be considered when using western methods of research to address the complex nature of culture within marginalized communities. Thus, policy makers would benefit from developing a more nuanced understanding about the complex, multifaceted experience of AIs, and specifically that of AI women and non-men. Moving forward, it is essential that policy incorporates what Abawi and Brady (2017) refer to as a "centric" approach. Indigenous and decolonized policy initiatives do not compete with one another for hierarchical reasons, but rather draw from one another. "The centric approach to 
policy allows for a multitude of perspectives, narratives and social locations to engage in dialogue as shared policy." (Abawi and Brady, 2017, pp. 29). When dialogue regarding policy is inclusive of all those impacted, and positionality and power is critically evaluated through "courageous conversations" (Singleton, 2005), this allows binaries to diminish and policy makers can address the complex needs of all who are impacted.

The United States government holds a trust responsibility with Tribal nations and is a doctrine of U.S. Tribal Law. The legislative, judicial, and executive branches of the U.S. government have acknowledged Tribes' government-to-government relationship with the federal government, mandated through treaties, although the U.S. government has not respected that trust relationship. "Borrowing concepts from trust law, courts have described this relationship... like 'that of a ward to his guardian,"” (Newton, 1982, pp.635). That is to say, the United States is mandated by its own law to assure the health and wellness of AI people by addressing the policies that impact health issues of AI's. Yet, AIs' status, particularly that of AI women, continues to be relegated to the margins in colonial society by political systems that oppress and disempower them. They continue to be disproportionately affected by health disparities resulting from legacies of historical trauma impacted by over 525 years of colonization. American Indian women's survival and voice are inherently political. The impact the Yappallí project has had on the lives of the participants was significant, these changes were interpersonal, collective and relational, and the collective experience of the women involved in this study was healing for the participants.

There is clearly a need for more policy, funding, and research to address the issues that impact the health and wellness of AI women and non-men to develop 
opportunities for culturally-centered and setting-based healing. With the positionality of AI women in our communities, engaging them in the design and implementation of research that aims to improve the conditions of their existence can have a synergetic effect for our communities, as well as the future generations. AI women are resilient and have historically been the givers and keepers of life, land, and culture. AI women still hold knowledge and wisdom that can positively impact their families, communities, and future generations. Implications of this study suggest the need for further health research to address the nuances of how health disparities impact this population. The results of this study can inform future research with this population, as well as community-based interventions and policy research, which is clearly needed in AI communities. It would benefit social work and health promotion program developers to consider the role of AI women and address their perceptions of health and wellness in community-based interventions.

"If we, as Indian people, are forced to reject our own indigenous knowledge and our ways of thought to participate in science, then we will be that much closer to cultural extinction" (Pewewardy, 2001, pp. 21). Despite the good intentions of researchers engaging with AI communities, many times this research does not benefit the communities, and may have an iatrogenic effect. "Western and indigenous knowledge should be mutually understood, respectfully exchanged" (Walters, Stately et al., 2008, pp. 156). Interviews as oral tradition, narrative, and storywork, and as an indigenizing research project, is an important move in the field of social work and health research. More often than not, communities have ideas and solutions to address the issues that impact them the most, but they lack access to the resources to adequately address these 
complex issues. State, federal, and local jurisdictions have a trust relationship and a responsibility to address tribal issues. It is their responsibility to aid these communities and help them develop research project and to fund those projects, to prioritize community-based and participant action research initiatives.

A tool of indigenizing research is to develop policies and protocols that are centered in AI knowledge and worldviews and which disrupt the history and exploitation of western research that have traumatized and to continue to traumatize AI people. The Yappalli project is developed as a health promotion model to center the Choctaw worldview and epistemologies to address the chronic health disparities with Choctaw women. The researchers involved in this project were able to leverage their collective cultural knowledge and positionality as senior researchers to develop an innovative health promotion initiative that bridges western knowledge, while simultaneously leveraging traditional indigenous knowledge specific to the Choctaw worldview. "Our Vision of Health for Future Generations" is an extension of the Yappallí project, which continues to privilege this knowledge, the voices, experiences, and analyses of the participants' social, material, and spiritual conditions. Throughout the process, I took great care in prioritizing the needs of the Yappallí project and participants, developing a decolonized and indigenized study, and developing indigenous methods to knowledge development.

\section{Implications for Research}

Decolonizing and indigenizing research is a process, not a product. Thus, indigenous methodologies are paradigmatic approaches (Kovach, 2010) that acknowledge the interplay and relationship between the "method and the paradigm," 
while centering the indigenous worldview. Simonds and Christopher (2013) state that "decolonizing research is a process and an orientation to research that must be consciously attended to throughout the entire partnership, similar to a CBPR approach" (pp. 2189), which the Yappallí project utilizes as a methodology. Indigenous research is rigorous research practice that has been practiced for countless generations. AI communities are now reclaiming this practice, privileging this knowledge and their rights to their knowledge, and all the privileges that come with that right to science. Thus, decolonizing and indigenizing research includes "deconstructing and externalizing the myth of the intellectually inferior Indian, while simultaneously privileging and centering indigenous worldviews and knowledge to promote revitalization of indigenous epistemologies, research practices, and ultimately, indigenous wellness practices" (Walters, Stately et al., 2008, pp. 148). Since time immemorial, the Choctaw people were gifted scientists who helped develop one of the largest and most powerful pre-colonial nations in North America, specifically centered in their ability to cultivate tachi (corn). Contemporary Choctaws still value science and research and have invested in developing infrastructure to engage in research. The $\mathrm{CNO}$ has an active and engaged Choctaw Nation Historic Preservation Department and institutional review board. The Choctaw Nation Historic Preservation Department relies on current and developing technologies as tools to learn more about Choctaw history and to better protect important historic and cultural places. For example, the CNO is utilizing GPS (Global Positioning System) satellite triangulation to accurately record the traditional locations of sites and tracking the place names of these Choctaw sites. This is a state-of-the-art methodology that utilizes both 
western and indigenous knowledge to preserve the Choctaw culture (Choctaw Nation of Oklahoma, 2018).

To date, it seems that in theory and in clinical practice, there are two separate paths — western knowledge and TIK—which exist with limited interaction or overlap. Interestingly, there has been some discussion in the literature addressing the intersection of indigenous knowledge and western knowledge (Duran and Duran, 1995; Gone, 2012 and 2014; Sinclair, 2003; Tuhiwai- Smith, 1999). There are important and relevant aspects to each path that can build upon and support each other in the development and implementation of interventions, not just for indigenous people, but for all people who are suffering. Kincheloe and Steinberg (2008) believe that indigenous knowledge can reshape western science, that the two worldviews can complement each other, rather than compete. They outlined what academic transformation would look like by utilizing indigenous knowledge. In their view, by focusing on the ways knowledge is produced and legitimated, TIK promotes rethinking the purpose of educators, constructs just and inclusive academic spheres, produces new levels of insight, and demands that educators become researchers. It is important to note that Kincheloe and Steinberg (2008) are not simply trying to criticize western knowledge, but are attempting to generate a conversation about the intersections of these two worldviews - a phenomenon they call a "synergetic dialogue" of "transformative scientist understanding" (pp. 154).

Swadener and Mutua (2008) note that "when decolonizing projects, the possibilities of forging cross-cultural partnerships with, between, and among indigenous researchers and 'allied others' and working collaboratively on common goals that reflect anti-colonial sensibilities in actions are important facets of decolonization" (pp. 40). As 
researchers and scholars, we must understand the importance and value that other methods of knowledge offer. Rather than dismissing indigenous knowledge or western knowledge, we should embrace the strengths of each. Humans need to encounter multiple perspectives in all dimensions of their lives; this is the strength of addressing the intersection of indigenous knowledge and contemporary interventions and a principle of social work practice and ethics. Yet, in many academic and scientific organizations, the work of professionals utilizing indigenous knowledge is not respected or valued to a great extent. Indigenous knowledge can help to see problems in a different way and to develop contemporary solutions to those problems.

In some ways, indigenous cultures are not expected to change and adapt, as if indigenous cultures are ancient relics stuck in time and space. On the contrary, indigenous cultures have been masters of adaptation and change. Indigenous cultures are, in fact, in perpetual state of change that continues today in some of the most beautiful and innovative ways. This has been the survival mechanism that has helped indigenous communities in North America survive colonization for over 525 years. "Any study of Indigenous knowledge in the academy must allow for its evolution and ever-changing relationships" (Kincheloe and Steinberg, 2008, pp. 141). Indigenous cultures have always been influenced by other cultures and have shared knowledge. This is also the case within the context of colonization. Throughout the historical relationships between the United States and tribal nations, we have seen a sophisticated process of adaption, referred to as resilience. When the Choctaw people were removed from their traditional homelands, they were faced with a new land and few resources. They were able to adapt to the new environment to not only survive as a sovereign nation but thrive. Within AI communities, 
we are seeing a resurgence of self-determination and autonomy, reclaiming their traditional ways of knowing for the betterment of all people. There is research being conducted utilizing TIK in the areas of sustainability (Pierotti and Wildcat, 2000), food sovereignty (Nelson, 2008), the treatment of historical trauma (Denham, 2008; Duran, 2006; Yellow Horse Brave Heart, 1998 and 2004) and health promotion (Walters and Johnson Jennings, 2014), and the CNO use of GPS to track and name traditional homelands (CNO, 2018).

Indigenous scientists in the United States don't have a choice but to work within and be impacted by western science (Grande, 2008; Kincheloe and Steinberg, 2008; Tuhiwai- Smith, 1999). Thus, they must become fluent in the two schools of thought. Indigenous scientists play an important role to engage change and move the field forward, to validate and make visible indigenous knowledge and methodologies. "By virtue of living in the Whitestream world, indigenous scholars have no choice but to negotiate the forces of colonialism, to learn, understand and converse in the grammar of empire as well as develop the skills to contest it" (Grande, 2008, pp. 235). Indigenous scientists have the additional responsibility of learning what are, essentially, two languages and cultures. They also have the added responsibility of advocating for the recognition of indigenous knowledge in a system that neither is open to nor values these ideas.

Indigenous scholars (Dumbrill and Green, 2008; Sinclare, 2003; TuhiwaiSmith,1999; Walters et al., 2002; Weaver, 1999) have developed models based in indigenous and decolonizing methodologies, focusing on their cultural worldviews to critique the dominant culture's complacent role in engaging in other forms of thought and 
knowledge acquisition, while simultaneously being respectful of western forms of thought. Because of the long history of colonization and the violence that has been perpetrated against indigenous peoples through colonization, researchers need to be aware of how indigenous knowledge is gathered, interpreted, disseminated, and used. AI communities continue to become regular victims of unethical research practices, which then have long-term implications in indigenous communities. Tuhiwai-Smith (1999) examined these issues and provided insight into how she has dealt with these issues in her work with the Maori community of Aotearoa (New Zealand). Tuhiwai-Smith's (1999) model, Indigenous Research Agenda, addresses elements of research that contributes to the "good of society" (pp. 117). These include decolonization, transformation, mobilization, and healing. Tuhiwai-Smith utilizes the metaphor of ocean tides to create movement, or an ebb and flow of life, mirroring the ebb and flow of research and of knowledge. According to this metaphor, indigenous knowledge is not a linear process for gathering information, but rather a fluid process enmeshed in culture and TIK. This concept provides a framework for indigenous researchers to understand the fluidity of knowledge and the relational aspect of indigenous and decolonized research.

TIK provides researchers with another way to understand the fluidity and paradigmatic approach to this work, and specifically to this study. From this perspective, as an indigenous social worker and researcher, it can be argued that indigenous methodologies should be a reflexive process, locating our positionality within the work, while further reflecting on the praxis of indigenous approaches to research. Kovach (2010) refers to this as "recognizing that our doing is intricately related to our knowing" (pp. 40). It is important to look to the communities themselves to guide our research, 
seeking out indigenous protocols to guide our methods. These protocols should reflect community teaching and should be conducted with respect to the specific cultural worldview and be conducted in a good way. Within this study the paradigmatic approach was the utilization of TIK.

Within the context of this study, chanspo ikhvnanchi (original instructions), relational restoration, and narrative transformation were utilized in the form of in-depth interviews, haklo (listening deeply), and indigenous storywork. Haklo, listening deeply, with aiokpanchi (respect) is the chanspo ikhvnanchi, redeveloping relationships to the $\mathrm{CNO}$, to each other, their families, and their ancestors through the process of engaging in the Yappallí project. The participants shared stories that highlighted this knowledge with the ancestors on the Trail of Tears; restructuring the knowledge of one's family and community is a form of relational restoration. Finally, the telling of one's story and the development of community health events through holitobit ibbak fohki (sacred giving) can be viewed as a form of narrative transformation.

Ritchie (2003) identifies five key features of in-depth interviewing. This method can be borrowed as it fits within an indigenous paradigm. Ritchie (2003) suggests that successful in-depth interviews should 1) intend to combine structure with flexibility;2) be interactive in nature; 3) employ a range of techniques to achieve depth of answer; 4) be generative in that new knowledge is likely to be created; and 5) almost always be conducted face-to-face (pp. 142). "In broad terms, the researcher's task is to ease the interviewee down from the everyday, social level to a deeper level at which they can together focus on a specific topic or set of topics" (Richie, 2003, pp. 144). Additionally, Ritchie (2003) also identifies several key stages the interviewer must engage in, 
including: arrival, introducing the research, beginning the interview, guiding the participant through the key themes, ending the interview, and concluding the interview. One lesson in this study learned that may be relevant for future work is that it was important to utilize probing questions as well as verbal and nonverbal cues to engage in deeper conversation with the participants. Being interviewed can provide a unique experience for individuals to engage in research and to interact with someone who is committed to actively listening and encouraging them to reflect and speak freely about topics that are of importance to them. This has been shown to be a powerful method of data collection and empowerment, if used effectively. The women were encouraged to lead the interview and to create and share their own narrative and story. I viewed myself as a guide through this process. This study focuses on the experiences of Choctaw women because they have had to live with the brunt of the effects of colonization in their communities, are traditionally the givers and keepers of life, and have an informed worldview and perspective on the issues of health and wellness that impact them, their families, and their communities. This is a process of decolonizing and indigenizing methodologies.

Wilson, S. (2008) states that "stories allow listeners to draw their own conclusions and to gain life lessons form a more personal perspective" (pp. 17). Much of this knowledge is expressed through stories, oral history, ritual, legends, ceremony, and song, as well as other means of communication. The following quote highlights how TIK follows original instructions, relational restoration and narrative transformation intertwine. 
"There is a story I know. It's about the earth and how it floats in space on the back of a turtle. I've heard this story many times, and each time someone tells the story, it changes. Sometimes the change is simply in the voice of the storyteller. Sometimes the change is in the details... But in all the tellings of all the tellers, the world never leaves the turtle's back. And the turtle never swims away"(King, 2003, pp.1).

This story of the "turtle island" is a very common creation story in many different AI communities, one that has been passed down for generations. Through the many creation stories, we learn about our cultural values, history, and worldview. Tradition is ever changing and encompasses many different aspects of the individual, family, culture, and tribe. TIK can be perceived differently across cultures, but the original intent is consistent, as outlined in the King quote above.

While some scholars challenge the rigor or storytelling as a research method, e.g. traditional storytelling or indigenous storywork, Sium and Ritskes (2013) state that "the experiences of those who live out decolonization are integral to the integrity of the movement, grounding it to the material realities of the people whose lives bear the scars of colonialism and long histories of resistance and triumph” (pp. III). Indigenous scholars (Beltrán and Begun, 2014; Beltrán et al., 2014; Sium and Ritskes, 2013; Lowery, 1998) are increasingly calling for the inclusion of indigenous storywork into research with indigenous communities as it reflects indigenous ways of knowing and is a decolonized and indigenized research method. These narratives create a body of knowledge that simultaneously creates and regenerates knowledge, while at the same time creating acts of survivance and resistance to colonization. 
Many forms of narrative such as stories, oral history, ritual, legends, ceremony, and song, as well as other means of communication, have historically been the way in which indigenous peoples have gathered and shared knowledge. As such, it can be argued that the use of research methods that align with these traditional ways of knowing would be a benefit to a research process that is working with and engaging indigenous communities. Highlighting the role of digital storytelling as indigenous storywork method in a community-based project with Maori participants, Beltrán and Begun (2014) describe "the process of creating and sharing narratives is a transformational tool for reclaiming knowledge and highlighting resiliencies despite legacies of colonization and ongoing discrimination” (Beltrán and Begun, 2014, pp. 162), and can be viewed as a form of survivance.

Prioritizing TIK through storywork is purposely not objective. That is, through this method, the researcher does not claim to engage in "the emptying of our bodies and experiences from our scholarship" (Sium and Ritckers, 2013, pp. IV). The researcher becomes part of the research. Thus, rigor is developed through other aspects of knowledge acquisition through, not limited to, a deep qualitative process of reflexivity, member checking, peer checking, consulting with elders and/or community stakeholders, and journaling. The purpose, of course, is to address social location and positionality and to create a process of addressing power dynamics in relationship with participants.

This work was deeply personal to me, as I am the great-great-granddaughter of a survivor of the Trail of Tears. I am a citizen of the Choctaw Nation of Oklahoma, and as volunteer staff with the Yappallí project, I developed personal relationships with the participants. I watched them suffer, struggle, laugh, and cry while on the Trail of Tears, 
and I bore witness to their sacrifice to their further generations and their personal transformations. It was a great and humbling honor to be invited into their lives and the spiritual journey they were on, and to gather and hold their sacred stories of embodiment, motivation, challenges, and transformation. It was critically important for me to honor these women and their experiences, not just because they were participants in this study, but because they are my relatives, and I hold them in a sacred trust. In 2013, I was a participant in the feasibility study. I had a deeply transformative and healing experiences while on the Trail of Tears. This work has changed me in so many ways that I cannot adequately express in words what that means for me and my ancestors. I, too, had the experience of embodiment, motivation, challenge, and transformation; I am part of this work. That is why I sought out research methods that could both be rigorous and reflexive. As Wilson, S. (2008) acknowledges, "research is ceremony," and as such is a sacred, and not objective, form of knowledge acquisition. In this sense, this work is not objective, but it remains rigorous.

There are many reasons for social work researchers to engage in decolonized and indigenized research. Tuhiwai-Smith (1999) notes that indigenous people are the most researched people in the world, but they have yet to see any long-term benefit from this research, and that indigenous people all have a different story to share. Steinhauer (2002) suggests indigenizing research increases the possibility that research conducted with indigenous communities will impact and enrich those communities. Martin (2003) notes it is important to reframe, reclaim, and rename research for indigenous communities. While Wilson, P. (2001) and Wilson S. (2008) both suggest that all knowledge and research is relational, they also question, "who should develop an Indigenous research 
methodology?" (Steinhauer, 2002, pp. 72) Wilson P. (2001) answers this by stating, "Indigenous people need to do Indigenous research because we have the lifelong learning and relationship that goes into it. You are not just gaining information from people; you are sharing your information" (pp.179). This ideology goes against the western understanding of rigorous and objective research. What this means for me, as a bourgeoning researcher, is that I have an additional responsibility to hold indigenous people's knowledge as sacred, with honor and respect, to rigorously address my positionality and power, and to understand that my mandate is to not just 'do no harm;" the indigenous researcher's mandate is to heal, and this is done through the development and sustaining of trusting relationships, within and across communities. Thus, training indigenous people to conduct indigenous research is imperative.

\section{Limitations}

Although the participants reported experiencing significant changes in their overall health and wellbeing, these are self-reports have not been verified by a medical or mental health provider. Verifying these findings was beyond the scope of this study. It would be beneficial to cross check these statements with each participant's medical records or to the Yappallí study findings to verify if the description of these experiences is accurate. There is a tension between the subjective experience of one's own body and the objective western descriptors of health.

There is much debate about the use of qualitative methods in exploring causality. Rarely in qualitative research do scientists examine the direct relationships between variables, as many variables are not directly observable (DeVellis, 2012; Guba and 
Lincoln, 1994), such as cultural and community factors as motivations of change. Maxwell (2004) argues that "a realist understanding of causality is compatible with the key characteristics of qualitative research and supports a view of qualitative research as a legitimately scientific approach to cause explanation" (pp. 3). Qualitative research methods have unique strengths in exploring the role of meaning and context in causal explanations, which can add depth to a realist, process-orientated explanation that is facilitated through a qualitative process.

"Qualitative research is often criticized as biased, small scale, anecdotal, and/or lacking rigor; however, when it is carried out properly it is unbiased, in depth, valid, reliable, credible and rigorous." (Anderson, 2010, pp. 2). Petrovic et al. (2015) note that the researcher is an active instrument within qualitative research, and this requires the researcher to partake in reflexivity throughout the entirety of the research process to address issues of bias and objectivity. I am citizen of the Choctaw Nation of Oklahoma, I participated in the Trail of Tears, and I walked with and developed relationships with the participants of this study, which could have affected the participants' responses to the questions presented and their motivation to participate in this study. These factors can also impact the data analysis. During the analysis, important considerations were made regarding my emotions and my experience of repeated words or phrases, contractions, information, or comments that stood out. This Listening Guide as a reflexive method was uniquely suited to assist me in developing a process of addressing positionality in relation with the participants. Throughout this process, referring to my reflexive notes helped me to develop a closer researcher-participant connection and to develop a nuanced understanding of the participant and their experiences. Ultimately, it helped me to "hear" 
their story and center their voice in the process and to address my own bias and positionality.

Although this study was small, and one could argue not generalizable to other populations, this was not the intent of this study. The intent was to interview a specific population to explore their specific experiences. Twenty-three Choctaw women were interviewed for the Our Vision of Health study, out of 77 Choctaw women who participated on the Yappallí project study. Data and information provided by this subset of participants was saturated, with all the participants sharing similar experiences to their motivation, challenges, vision of health, and transformation. I would suggest interviewing additional women for the next cohorts to see if this pattern of data persists.

\section{Reflexivity-Anukfilli "Deep Reflection"}

Because of my positionality and social location in this work, I feel it important to discuss reflexivity. In the Choctaw language, anukfilli refers to "deep reflection," and to develop a thoughtful process to address issues of bias and power. I have walked the Trail of Tears four times_once in 2013 and again annually in 2016 through 2018. In 2013, I participated in a feasibility study; in 2016-2018, I participated as a support volunteer for the Trail of Tears walk. Every time I engage with the Trail of Tears, the land, the participants, staff, and my ancestors, I have deep, transformative experiences that inform this body of work, continue to shape my worldview and are profoundly healing for me. Over 175 years ago, my grandmothers, aunties, and the sisters of my past walked the Trail of Tears. These ancestors held tenderly in their hearts a vision for of health for future generations of Choctaw peoples, defined as "healthy and thriving." Their vision 
was to create health and balance for the People and preserve the Choctaw culture. This, along with their love for the Choctaw people, carried them forward, step after step, across generations to my own. Out of love, our ancestors sacrificed themselves for the wellbeing of their children and their children's children. I am attempting to continue this vison for future generations.

I developed a specific process of self-reflection and reflexivity, anukfilli, to address the issues that impact this work. Recent research has examined the complexity of social locations and identity and recognizes that boundaries between who is an "insider or outsider" are not easily defined (Tuhiwai-Smith, 1999). Concerns exist about the potential for bias in research, as well as methodological issues that arise throughout the research process, because the researcher/researched relationship is complex and intersectional. Koch and Harrington (1998) recognized the value of reflexivity stating that "Reflexivity, in its various guises, occupies a central place in participatory action research, feminist research, ethnographies, and recently in hermeneutic and postmodern/post-structural approaches to research, taking different forms and raising different questions." (pp. 888). Bulter-Kisber (2010) state that a reflexive process "probes more deeply beyond the actual research process to examine political and social influences on the inquiry... (pp.19) and promotes the research as an opportunity to address issues of power and positionality.

I have strengths that I bring to this work. I am an enrolled citizen of the Choctaw Nation of Oklahoma, I was raised in tribal communities in Northern New Mexico, and I grew up with AI people as mentors, relatives, and communities. I have over a 20-year long history as a professional social worker and researcher working with and for AI 
communities, both on reservations and in urban settings. I have always been interested in developing a deeper understanding of my own ethnic identity as a bicultural woman (Choctaw and Scottish) and have worked diligently to develop a strong sense of myself within the multiple complexities and worlds I am able to move through. I also have access to this population as I have been a staff volunteer for the Yappallí project for many years and have worked to develop trusting relationships with the Yappallí project staff, principal investigators, and participants. The limitations are that, although I am an enrolled citizen of the Choctaw Nation of Oklahoma, I am an outsider, in that I was not born or raised within the Choctaw Nation of Oklahoma reserve boundaries, nor do I have a strong connection with the community in Oklahoma. I have light skinned privilege, as I can "code switch" from white to AI communities and from class systems, and I am able to maneuver across and between these communities. My great grandmother, in an attempt to survive colonization and racism, chose to assimilate into white culture and did not pass her cultural knowledge onto her children (my grandmother) or her grandchildren (my father). Consequently, I do not speak the Choctaw language. However, this is not an uncommon experience for people of my age group, due to acculturation policies. I am also an academic and scholar, which places me as an outsider within the cultural tribal context. Although the $\mathrm{CNO}$ values education, very few AI women receive graduate education and even fewer Choctaw women have doctorate degrees. I have worked hard to learn how to maneuver across and between these communities, and I have worked to act as a "translator" of this knowledge for communities to access. I believe that my knowledge, skills, and values as a multi-racial social worker, substance use counselor, and mental health provider for over 20 years contribute to this work. It is an honor for me 
to be able to participate in the Yappallí project and to provide a space for Choctaw women to share their stories and experiences of walking the Trail of Tears.

Marcus (1994) identifies four types of reflexivity; "self-critique and personal quest” (pp. 569), “sustaining objectivity” (pp. 570), “politics of location” (pp. 571) and “feminist experiential reflexivity...positioning assumes all work is incomplete and requires a response (and thus engagement) from others positioned differently" (pp. 572). Within the context of this study, I embrace all of these types of reflexivity, but specifically the "politics of location," which acknowledges that interpretation of data exists in a complex intersection of meaning and "derives its critical power and insight from this awareness" (Marcus, 1994 p. 571). The focus, here, is on historical connections, my social location, my personal connection to the work within my tribal community, and personal experiences of transformation and healing while walking the Trail of Tears. A reciprocal reflexivity process is associated as indigenous research methods and was utilized in this study. It would benefit social work professionals and researchers to incorporate a process of reflexivity and reflection in their work, specifically to incorporate the aspects of what Marcus (1994) outlines of "self-critique and personal quest," "sustaining objectivity," and "politics of location" to address issues of positionality and power. 


\section{Chapter 7: Conclusion}

Health disparities and substance misuse are increasingly prevalent, costly, and deadly in Indian Country. AI health is anchored in a historical context and manifested across generations which impacts contemporary forms of health. One of the consequences of these policies was the forced removal of indigenous peoples from their traditional homelands, such as the Trail of Tears for the Choctaw Nation of Oklahoma. Removal from traditional homelands severed tribal people's connections to resources, such as the land, that gave meaning to their identity from which their creation stories originated. This traumatic act has manifested across the generations for many, as profound soul wounding and unhealed grief, which continues to impact their health in contemporary times. This study serves as a framework and builds on the work of Walters et al. (2011a and b) and Walters et al. (2012) to understand culturally-based individual level (proximal) motivations, as well as community level (settings-based/intermediary) motivations that influence population health changes relative to substance use and health disparities that occurred for the participants of this study and how health promotion and motivation may be examined. The participants of this study shared their stories of how walking the Trail of Tears, engaging with and developing relationships with themselves, the other women and with their ancestors motivated them to both participate in the Yappallí project and with making changes in their health.

The embodiment of trauma is manifested in poor health outcomes across generations of AI peoples (Walters et al., 2011a). For AI people, the very definition of health and well-being intimately connects to place, “...disease or literally dis-ease (out of balance, disharmony, disequilibrium) is tied to the holistic understanding of the 
interconnectedness of mind, body, emotion, spirit, and land. Indigenous knowledge recognizes place as integral to one's sense of being ..." (Walters et al., 2011a, p. 173). This is in contrast to western biomedical understandings of health as the absence of individual psychological disturbances and disease. AI peoples conceptualize health as a more holistic connection between physical, emotional, mental, and spiritual dimensions, as well as connectedness with the natural environment (Vukic, Gregory, Martin-Misener, \& Etowa, 2011), as highlighted through the AI tradition of the medicine wheel. Many women who participated in the Yappallí project reported significant health and emotional changes. This included weight loss, decreased consumption of processed foods, sugar, and soda pop, and an increased consumption of water, better maintenance of diabetes and blood pressure with diet and exercise and using less medications. Participants reported living with less physical and emotional pain and stark changes in their mental health, e.g. feeling happier and less depressed and anxious.

"Our Vision of Health for Future Generations" builds on and improves scientific knowledge by using innovative qualitative research methods, in the form of indigenized research methods, indigenous storywork and the Listening Guide method to address the proximal and intermediary motivations of Choctaw women to engage in the Yappallí project. These research methods inform social work and health research, and the development and use of culturally-centered research practices. It gives social work and health researchers opportunities to develop a more nuanced understanding of the complex and intersectional issues that affect people's lives that in turn can inform intervention development specifically by including the narrative and storywork of the communities that are most effected by health disparities. 
This study can also help us to better understand the influence of information on the motivation of AI women and how this impacts women's motivation to engage in health promotion activities, both at proximal and setting-based/intermediary levels. When this knowledge is shared in a collective capacity, by utilizing traditional indigenous knowledge and practices such as indigenous storywork, we can move from simply understanding the information to developing a shared and collective motivation to change, along with a process for reinforcing that change. This change is centered on the praxis of love and sacrifice.

Based on the findings of this study, it is clear that the women who participated in the Yappallí project benefited significantly from the project, from walking the Trail of Tears and from the opportunity to become health leaders in their community by developing a community health project. It is recommended that the Yappallí project continue to support Choctaw Nation of Oklahoma citizens to address health related issues using traditional indigenous knowledge. 


\section{References}

Abawi, Z., \& Brady, J. (2017). Decolonizing indigenous educational policies. Emerging Perspectives, 1(1), 20-31.

Akers, D. L. (2004). Living in the Land of Death: The Choctaw Nation, 1830-1860. Michigan State University Press.

Aldworth, J. (2009). Results from the 2007 National survey on drug use and health: National findings. DIANE Publishing.

Anderson, C. (2010). Presenting and evaluating qualitative research. American Journal of Pharmaceutical Education, Special Articles. 74(8). 1- 7.

Anti-Defamation League (2005) Lewis and Clark: The Unheard Voices. Retrieved from http://www.adl.org/

Arvin, M.; Tuck, E. Morrill, A. (2013). Decolonizing feminism: Challenging connections between settler colonialism and heteropatriarchy. Feminist Formations, 25 (1), 8 34.

Ausubel, K. (2008) Remembering the Original Instructions. (xxi-xxiv). Nelson, M. K. (Ed.). (2008). Original instructions: Indigenous teachings for a sustainable future. Inner Traditions/Bear \& Co.

Beals, J., Manson, S., Whiteshell, N., Spicer, P., Novins, D., \& Mitchell, C. (2005). Prevalence of DSM-IV disorders and attendant help-seeking in 2 American Indian reservation populations. Archives of General Psychiatry, 62(1), 99-108.

http://dx.doi.org/10.1001/archpsyc.62.1.99

Beltrán, R., Alvarez, A., Fernandez, A. (Accepted). (Re)membering the Colonial Legacy of Gen(der)ocide: A Poetic Analysis of Queer and Two-Spirit Indigenous Youth Experiences in a Culture-Centered HIV Prevention Curriculum. In Lee-Penehira, M., \& Pihama, L. (Eds.). Mana Wahine: Native Women, Wellbeing and Identity. Huia Publishing, Ltd. Auckland, New Zealand.

Beltrán, R., \& Begun, S. (2014). 'It is Medicine' Narratives of Healing from the Aotearoa Photovoice telling as Indigenous Media Project (ADSIMP). Psychology \& Developing Societies, 26(2), 155-179.

Beltrán, R., Olsen, P., Ramey, A., Klawetter, S., and Walters, K. (2014). Narrowing the Achievement Gap for Native American Students: Paying the Educational Debt. (2014). ProtoView, ProtoView, Dec, 2014. 
Berkes, F., Colding, J., \& Folke, C. (2000). Rediscovery of traditional ecological knowledge as adaptive management. Ecological Applications, 10 (5), 1251-1262.

Bombay, A., Matheson, K., \& Anisman, H. (2009). Intergenerational trauma: Convergence of multiple processes among First Nations peoples in Canada. International Journal of Indigenous Health, 5(3), 6-47.

Burton's Legal Thesaurus (BLT), 4E. (2007). Survivance. (2n.d.) Retrieved October 18 2018 from https://legal-dictionary.thefreedictionary.com/survivance

Boven, K. and Morohashi, J. (2002). International Council for Science / Council International pour la Science (March 2002). Science and Traditional Knowledge: Report form the ICSU Study Group on Science and Traditional Knowledge. Retrieved from http://www.icsu.org/publications/reports-and-reviews/sciencetraditional-knowledge/Science-traditional-knowledge.pdf.

Brockie, T., Elm, J., \& Walls, M. (2018). Examining protective and buffering associations between sociocultural factors and adverse childhood experiences among American Indian adults with type 2 diabetes: A quantitative, communitybased participatory research approach. BMJ Open, 8(9), E022265.

Brown, D. (2016). Daughters of the Drum: Decolonizing Health and Wellness with Native American Women. AlterNative: An International Journal of Indigenous Peoples, 12(2) 109-126.

Brown, S. (2007). Cultural worldview assessment placement: Establishing the validity of the Native Self-Actualization Placement Assessment (NSA-PA). Graduate Department of Clinical Psychology George Fox University as a Dissertation for the Psy.D.

Brown, L., \& Gilligan, C. (1992). Meeting at the crossroads: Women's psychalogy and girls' development. Cambridge, MA: Harvard University Press.

Brown, L., \& Strega, S. (Eds.). (2005). Research as resistance: Critical, indigenous and anti-oppressive approaches. Canadian Scholars' Press.

Buchwald, D., Beals, J., and Manson, S. (2000). Use of traditional health practices among Native Americans in a primary care setting. Medical Care, 38(12), 1191-1199.

Cajete, G. (1994). Look to the mountain: An ecology of indigenous education. Kivaki Press, 585 E. 31st St., Durango, CO 81301.

Cajete, G., Mohawk, J., \& Rivera, J. V. (2008). Re-indigenization defined (pg. 252-264). In Nelson, M. (Ed.) Original instructions: Indigenous teachings for a sustainable future. Rochester, VT: Inner Traditions/Bear \& Co. 
Castleden, H., \& Garvin, T. (2008). Modifying Photovoice for community-based participatory Indigenous research. Social Science \& Medicine, 66(6), 1393-1405. http://dx.doi.org/10.1016/j.socscimed.2007.11.030

Center for Disease Control. (2014). Minority Health Populations. Retrieved from http://www.cdc.gov/minorityhealth/populations/REMP/aian.html

Chenault, V. (2011). Weaving strength, weaving power: Violence and abuse against Indigenous women. Carolina Academic Press.

Chino, M., Haff, D., \& Dodge Francis, C. (2009). Patterns of commodity food use among American Indians. Pimatisiwin. Journal of Aboriginal and Indigenous Community Health, 7(2), 279.

Choctaw Nation of Oklahoma. (2016). Government Treaties. Retrieved from https://www.choctawnation.com/history-culture/history/government-treaties

Daley, A. (2010). Reflections on reflexivity and critical reflection as critical research practices. Affilia, 25(1), 68-82. http://dx.doi.org/10.1177/0886109909354981

Deci, E., \& Ryan, R. (2008). Self-Determination Theory: A Macrotheory of Human Motivation, Development, and Health. Canadian Psychology-Psychologie Canadienne, 49(3), 182-185.

Denham, A. (2008). Rethinking Historical Trauma: Narratives of Resilience. Transcultural Psychiatry, 45(3), 391-414.

De Rosier, A. (1981). The removal of the Choctaw Indians. University of Tennessee Press.

DeVellis, R. F. (2012). Scale development: Theory and applications (Vol. 26). Sage publications.

Dumbrill, G., \& Green, J. (2008). Indigenous Knowledge in the Social Work Academy. Social Work Education, 27(5), 489-503.

Dunbar-Ortiz, R. (2014). An indigenous peoples' history of the United States (Volume 3). Beacon Press.

Duran, E. (2006). Healing the soul wound: Counseling with American Indians and other Native peoples. New York: Teachers College Press.

Duran, E., \& Duran, B. (1995). Native American postcolonial psychology. Albany, NY: SUNY Press 
Duran, B., \& Walters, K. L. (2004). HIV/AIDS prevention in "Indian Country": Current practice, indigenist etiology models, and postcolonial approaches to change. AIDS Education and Prevention, 16(3), 187-201. doi.org/10.1521/aeap.16.3.187.35441

Erney, D. (1996). Long live the Three Sisters. Organic Gardening. November, 37-40.

Evans-Campbell, T. (2008). Historical trauma in American Indian/Native Alaska communities a multilevel framework for exploring impacts on individuals, families, and communities. Journal of Interpersonal Violence, 23(3), 316-338.

Evans-Campbell, T.; Lindhorst, T.; Huang, B. and Walters, K. (2006). Interpersonal Violence in the Lives of Urban American Indian and Alaska Native Women: Implications for Health, Mental Health, and Help-Seeking. American Journal of Public Health. 96(8): 1416-1422.

Faiman-Silva, S. (2000). Choctaws at the crossroads: The political economy of class and culture in the Oklahoma timber region. University of Nebraska Press.

Fisher, W. A., Fisher, J. D., \& Harman, J. (2003). The information-motivationbehavioral skills model: A general social psychological approach to understanding and promoting health behavior. In J. Suls \& K. A. Wallston (Eds.), Social psychological foundations of health and illness. (pp. 82-106). doi:10.1002/9780470753552.ch4

Freire, P. (1970). Pedagogy of the Oppressed. New York, NY: Continuum International Publishing Group.

Freire, P. (1998). Teachers as Cultural Workers: Letters to Those Who Dare Teach. Translated by Donoldo Macedo, Dale Koike, and Alexandre Oliveira, Westview Press, Boulder, CO.

Foreman, G. (1972). Indian removal: The emigration of the five civilized tribes of Indians (Volume 2). University of Oklahoma Press.

Galloway, P. (1998). Choctaw Genesis, 1500-1700. University of Nebraska Press.

Garrett, M. (1999). Understanding the "Medicine" of Native American traditional values: An integrative review. Counseling and Values, 43(2), 84-98.

Garrett, M., \& Pichette, E. (2000). Red as an apple: Native American acculturation and counseling with or without reservation. Journal of Counseling and Development, 78(1), 3-13. 
Garrett, M., \& Wilbur, M. (1999). Does the worm live in the ground? Reflections on Native American spirituality. Journal of Multicultural Counseling and Development, 27(4), 193-206.

Gilligan, C. (1982). In a different voice. Cambridge, MA: Harvard University Press.

Gilligan, C. (2015). The listening guide method of psychological inquiry. Qualitative Psychology, 2, 69-77.

Gilligan, C., Brown, L., \& Rogers, A. (1990). Psyche embedded: A place for body, relationships, and culture in personality theory. In A. I. Rubin \& R. Zucker (Eds.), Studying persons and lives. (pp. 86-147). New York, NY: Springer.

Gilligan, C. \& Eddy, J. (2017). Listening as a path to psychological discovery: An introduction to the Listening Guide. Perspectives on Medical Education, 6(2), 7681.

Gilligan, C., Spencer, R., Weinberg, M., \& Bertsch, T. (2006). On the listening guide: A voice-centered relational method. In S. N. Hesse-Biber \& P. Leavy (Eds.), Emergent methods in social research (pp. 253-271). Thousand Oaks, CA: Sage.

Glancy, D. (2008). The Naked Spot: A Journey toward Survivance. In Gerald Vizenor (Ed.) Survivance: Narratives of Native Presence, pp. 271-283. University of Nebraska Press, Lincoln, Nebraska.

Grande, S. (2008). Red pedagogy: The un-methodology. In Denzin, N.K.; Lincoln, Y.; Tuhiwai- Smith, L. (Eds.), Handbook of Critical and Indigenous Methodologies. 233-254. Thousand Oaks, CA. SAGE Publishing.

Goeman, M., \& Denetdale, J. (2009). Native Feminisms: Legacies, Interventions, and Indigenous Sovereignties. Wicazo Sa Review, 24(2), 9-13.

Gone, J. (2007). "We never was happy living like a whiteman": Mental health disparities and the postcolonial predicament in American Indian communities. American Journal of Community Psychology, 40(3-4), 290-300.

Gone, J. (2012). Indigenous traditional knowledge and substance abuse treatment outcomes: The problem of efficacy evaluation. The American Journal of Drug and Alcohol Abuse, 38(5), 493-497.

Goodluck, C., \& Moran, James R. (1998). Understanding Navajo Ethnic Identity: Weaving the Meaning through the Voices of Young Girls, ProQuest Dissertations and Theses. 
Guba, E. \& Lincoln, Y. (1994) Competing paradigms in qualitative research. Denzin, N \& Lincoln Y. (Eds). In Handbook of Qualitative Research. 105-117. Sage Publications. Thousand Oaks CA.

Haag, M., \& Willis, H. (2001). Choctaw language and culture: Chahta anumpa (Vol. 1). University of Oklahoma Press.

Harkins, G. (1832). Farewell letter to the American People. W. Moquin, C. Van Doren (Eds.), Great Documents in American Indian History, 151, DaCapo Press, New York, NY (1995) (Original work published 1832)

Henderson, K. and Ainsworth B. (2003). A Synthesis of Perceptions About Physical Activity Among Older African American and American Indian Women. American Journal of Public Health. 93, 313-317

Henry, H. (1901). The Choctaw Creation Legend. Publications of the Mississippi Historical Society, II. 269-70.

Hesse-Biber, \& Leavy. (2010). The practice of qualitative research. Sage Publications.

Hill R. (2001). Regenerating identity: repatriation and the Indian frame of mind. (Eds.) Bray, T., The future of the past: archaeologists, Native Americans, and repatriation. New York, Garland Publishing. Pp. 127-138

Hume, K. (2007). Gerald Vizenor's metaphysics. Contemporary Literature, 48(4), 580612. http://dx.doi.org/10.1353/cli.2008.0005

Indian Health Service. (2006). Facts on Indian healthcare disparities. 2006. Retrieved from http://info.ihs.gov/Files/DisparitiesFacts-Jan2006.pdf

Ink, L. (2004). Remaking Identity, Unmaking Nation: Historical Recovery and the Reconstruction of Community In the Time of the Butterflies and The Farming of Bones. Callaloo, 27(3), 788-807.

Jacobs, M. (2005). Maternal Colonialism: White Women and Indigenous Child Removal in the American West and Australia, 1880-1940. Western Historical Quarterly, 36(4), 1 November 2005, pg. 453-476, https://doi.org/10.2307/25443236

Jahoda, G. (1975). The trail of tears. Henry Holt \& Company.

Jaimes, A. (1992). State of Native America, The: Genocide, Colonization and Resistance. South End Press. Boston. 
Jiwani, Y. \& Young, M. (2006). Missing and murdered women: reproducing marginality in news discourse. Canadian Journal of Communication, 31, 895-917. DOI: https://doi-org.proxy.lib.pdx.edu/10.22230/cjc.2006v31n4a1825

Johnson-Jennings, M. Belcourt, A., Walls, M., Town, M., Walters, K. (2014). American Indian LGBT Two Spirit smoking as related to discrimination and pain. Journal for Healthcare for the Poor and Underserved, 25(4), 1667-1678. http://dx.doi.org/10.1353/hpu.2014.0193

Johnson-Jennings, M., Tarraf, W., \& González, H. M. (2015). The healing relationship in Indigenous patients' pain care: Influences of racial concordance and patient ethnic salience on healthcare providers' pain assessment. International Journal of Indigenous Health, 10(2), 33-50.

Johnson, L. and Strauss, K. (1993). Diabetes in Mississippi Choctaw Indians. Diabetes Care. 16(1): 250-252

Jones, D. S. (2006). The persistence of American Indian health disparities. American Journal of Public Health, 96(12), 2122-2134.

Kincheloe, J.; Steinberg, S. (2008). Indigenous knowledge in education. In Denzin, N.K.; Lincoln, Y.; Tuhiwai-Smith, L. (Eds.), Handbook of Critical and Indigenous Methodologies. (135-156). Thousand Oaks, CA. SAGE Publishing.

King, T. (2003). The truth about stories: A Native narrative. Minneapolis, Minn.: University of Minnesota Press.

Kirmayer, L., Simpson, C., and Cargo, M. (2003). Healing traditions: Culture, community and mental health promotion with Canadian Aboriginal peoples. Australasian Psychiatry, 11(s1), S15-S23.

Koch, T., \& Harrington, A. (1998). Reconceptualizing rigour: the case for reflexivity. Journal of Advanced Nursing, 28(4), 882-890.

Kovach, M., 2010. Conversational method in indigenous research. First Peoples Child and Family Review, 5 (1), 40-48.

LaFromboise, T., Heyle, D., \& Ozer, A. (1990). Changing and diverse roles of women in American Indian cultures. Sex Roles, 22(7), 455-476.

LaPensée, E. (2014a). "Survivance as an indigenously determined game.". AlterNative: An International Journal of Indigenous Peoples. 10(1). 263-275.

LaPensée, E. (2014b). Survivance: An Indigenous Social Impact Game. Dissertation. Simon Fraser University, 2014. 
Lefley, H. (1974). Social and Familial Correlates of Self-Esteem among American Indian Children. Child Development, 45(3), 829-833.

Leighton, D. and Kluckhohn, C. (1947). Children of the People. Cambridge, Harvard University Press.

Lewis, A. (2012). Ethics, Activism and the Anti-Colonial: Social Movement Research as Resistance. Social Movement Studies, 11(2), 227-240.

Lewis, R., \& Ho, M. (1975). Social work with Native Americans. Social Work. 20(5). 379- 382.

Lowan, G. (2009). Exploring Place from an Aboriginal Perspective: Considerations for Outdoor and Environmental Education. Canadian Journal of Environmental Education, 14(1), 42-58.

Lowery, C. (1999). The sharing of power: Empowerment with Native American women. In L. Gutierrez \& E. Lewis (Eds.), Empowerment with women of color. New York: Columbia.

Lowery, C., and Mattaini, M. (1999). The science of sharing power: Native American thought and behavior analysis. Behavior and Social Issues, v9, pp. 3-23.

Marcus, G. E. (1994). What comes (just) after "post"? The case of ethnography. Handbook of Qualitative Research. 563-574.

Martin, K. (2003). Ways of knowing, being and doing: A theoretical framework and methods for indigenous and indigenist re-search. Journal of Australian Studies, 27(76), 203-214.

Maxwell, J. (2004). Causal explanation, qualitative research, and scientific inquiry in education. Educational Researcher, 33(2). 3-11. https://doiorg.proxy.lib.pdx.edu/10.3102/0013189X033002003

Mihesuah, D. (2003). Indigenous American Women: Decolonization, empowerment, activism. Lincoln, NE: University of Nebraska Press.

Moreton-Robinson, A. (2000). 'Talkin' up to the White Women: Indigenous women and Feminism'. University of Queensland Press, Australia.

Native American Rights Fund. (2013). National Indian Law Library. Retrieved from www.narf.org 
Neely, S. (1991). Snowbird Cherokees: People of persistence. Athens. GA: University of George Press.

Nelson, M. (2008a). About Bioneers. (pg. xvii-xviii). Nelson, M. (Ed.). (2008). Original instructions: Indigenous teachings for a sustainable future. Inner Traditions/Bear \& Co.

Nelson, M. (2008b). Remembering the Original Instructions. (pg. xxii-xxiv). Nelson, M. (Ed.). (2008). Original instructions: Indigenous teachings for a sustainable future. Inner Traditions/Bear \& Co.

Newcomb, S. (1992). "Five Hundred Years of Injustice." Shaman's Drum. p. 18-20. Retrieved from http://ili.nativeweb.org/sdrm_art.html

Newton, Nell Jessup. (1982). Invoking the federal-Indian trust relationship after Mitchell. Catholic University Law Review, 31(4), 635-683.

Noley, G. (1985). The early 1700s: Education, economics, and politics. In C. K. Reeves (Ed.), The Choctaw before removal. (pp. 73-119). Philadelphia, MS.: University Press of Mississippi and Choctaw Heritage Press.

Novins, D., Aarons, G., Conti, S., Dahlke, D., Daw, R., Fickenscher, A; Fleming, C., Love, C. Masis, K.; \& Spicer, P. (2011). Use of the evidence base in substance abuse treatment programs for American Indians and Alaska Natives: Pursuing quality in the crucible of practice and policy. Implementation Science, 6(1), 63.

Opai, K. (2017). Racism filled schooling. Retrieved from https://www.altogetherautism.org.nz/a-time-and-space-for-takiwatanga/. Retrieved on November 12, 2018.

Mayberry, L., \& Osborn, C. (2013). Validation of an Information-Motivation-Behavioral Skills (IMB) Model of Diabetes Medication Adherence. Diabetes, 62, A197.

Pesantubbee, M. (1999). Beyond domesticity: Choctaw women negotiating the tension between Choctaw culture and protestantism. American Academy of Religion. Journal of the American Academy of Religion, (2), 387-409.

Pesantubbee, M. (2005). Choctaw women in a chaotic world: The clash of cultures in the colonial Southeast. University of New Mexico Press.

Petrovic, S., Lordly, D., Briogham, S., \& Delaney, M. (2015). Learning to listen: An analysis of applying the Listen Guide to reflection papers. International Journal of Qualitative Methods. 1-3. doiorg.proxy.lib.pdx.edu/10.1177/1609406915621402 
Pewewardy, C. (2009). Decolonization. In Finkelman, P.; Garrison, T.A. (Eds). Encyclopedia of United States Indian Policy and Law. 251-255. C.Q. Press, Washington D.C.

Pierotti, R., \& Wildcat, D. (2000). Traditional ecological knowledge: the third alternative (commentary). Ecological applications, 10(5), 1333-1340.

Portland State University, Human Subjects Review Committee. (2015). Standard Operating Procedures. Retrieved from https://drive.google.com/a/pdx.edu/file/d/0B6loa6zCCxqNRndOWEZJZkRvTkU/ view

Quinn, A. (2007). Reflections on Intergenerational Trauma: Healing as a Critical Intervention. First Peoples Child and Family Review, 3(4), 72-82.

Ritchie, J. (2003). The applications of qualitative methods to social research. In Qualitative research practice: A guide for social science students and researchers (Eds. Ritchie, J. and Lewis, J.), pp. 24-46. Sage Publications, London.

Richie, J., Lewis, J., Nicholls, C. and Ormston, R. (2013). Qualitative research practice: A guide for social science students and researchers. Sage Publications.

Rigney, L, (2006a). Indigenous Australian Views on Knowledge production and Indigenist Research, in Kunnie, J., \& Goduka, N., (Eds) (2006) Indigenous peoples' wisdom and power. Affirming our knowledge through narratives. Ashgate Publishing Ltd, England.

Rigney, L. (2006b). Indigenist research and Aboriginal Australia. In J. Kunnie \& N. Goduka (Eds.), Indigenous peoples' wisdom and power: Affirming our knowledge through narratives, 2nd ed., (pp. 32-48). Aldershot, UK: Ashgate

Ross, L. (2009). From the "F" word to Indigenous/feminisms. Wicazo Sa Review, 24(2). $39-52$.

Sam, M. (2008). Ethics from the land: Traditional Protocols and the Maintenance of Peace. In Nelson, M. (Ed). Original Instructions: Indigenous Teaching for a Sustainable Future. (39-41). Rochester, VT. Inner Traditions/Bear \& Co.

Schultz, K., Walters, K., Beltran, R., Stroud, S., \& Johnson-Jennings, M. (2016). "I'm stronger than I thought": Native women reconnecting to body, health, and place. Health \& Place, 40, 21-28.

Silverberg, R. (1986). The Mound Builders. Ohio University Press. 
Simonds, V., \& Christopher, S. (2013). Adapting Western research methods to indigenous ways of knowing. American Journal of Public Health, 103(12), 218592.

Simpson, L. (2002). Indigenous environmental education for cultural survival. Canadian Journal of Environmental Education, 7(1), 13-25.

Simpson, L. (2004). Anticolonial strategies for the recovery and maintenance of Indigenous knowledge. The American Indian Quarterly, 28(3), 373-384.

Singleton, G., \& Curtis L. (2005). Courageous conversations about race: A field guide for achieving equity in schools. Thousand Oaks, CA: Corwin Press.

Sinclair, R. (2003a). Indigenous research in social work: The challenge of operationalizing worldview. Articulating Aboriginal Paradigms: Implications for Aboriginal Social Work Practice. 5(1). 117-139.

Sinclair, R. (2003b). Indigenous research applications in social work. Unpublished paper. University of Calgary, Faculty of Social Work.

Sium, A., and Ritskes, E. (2013). Speaking truth to power: Indigenous storytelling as an act of living resistance. Decolonization: Indigeneity, Education and Society, 2(1). $\mathrm{I}-\mathrm{X}$.

Sloboda, J. \& Edworthy, J. (1981). Attending to two melodies: The key of relatedness. Psychology of Music. 9, 39-43.

Smith, A. (2015). Heteropatriarchy and the three pillars of white supremacy: Rethinking women of color organizing. Transformations: Feminist Pathways to Global Change. 66-73. South End Press.

Smith, B. (1978). Variation in Mississippian Settlement Patterns. Mississippian Settlement Patterns. 479-503. New York Academic Press, New York.

Steinhauer, E. (2002). Thoughts on an Indigenous Research Methodology. Canadian Journal of Native Education, 26(2), 69-81.

Stites, D. (2001). The Challenges and Limitations of Assimilation: Indian Board Schools. Brown Quarterly. 4(3). Retrieved from http://gayleturner.net/Indian_Boarding_Schools.pdf

Stromberg, E. (Ed.) (2006). American Indian rhetorics of survivance: Word medicine, word magic. Pittsburgh: University of Pittsburgh Press. 
Swadener, B.; Mutua, K. (2008) Decolonizing performances: Deconstructing the global postcolonial. In Denzin, N.K.; Lincoln, Y.; Tuhiwai-Smith, L. (Eds.), Handbook of Critical and Indigenous Methodologies. (31-43). Thousand Oaks, CA. SAGE Publishing.

Sweet, V. (2014). Rising waters, rising threats: The human trafficking of indigenous women in the circumpolar region of the United States and Canada. The Yearbook of Popular Law Online. Retrieved from

http://booksandjournals.brillonline.com.proxy.lib.pdx.edu/content/journals/10.116 3/1876-8814_007.

Swanton, J. (1931). Source Material for the Social and Ceremonial Life of the 1931 Choctaw Indians. Washington, DC: United States Government Printing Office

Teater, B. (2017). Social Work Research and Its Relevance to Practice: "The Gap Between Research and Practice Continues to be Wide". Journal of Social Service Research, 43(5), 547-565.

Thompson, V., Johnson-Jennings, M., Bauman, A., Proctor, E. (2015). Use of culturally focused theoretical frameworks for adapting diabetes prevention programs: a qualitative review. Preventing chronic disease, 12.

Torres Slimming, P.; Orellana, E.R.; \& Suarez Maynas, J. (2014). Structural determinants of Indigenous Health. AlterNative: An International Journal of Indigenous Peoples, 10(2), 123-133.

Tuhiwai-Smith, L. (1999). Decolonizing methodologies: Research and indigenous peoples. Dunedin, NZ: Zed books.

United States Census Bureau (2010). The American Indian and Alaskan Native Population Reports 2010. Census 2010 Brief. Retrieved from http://www.census.gov/aian/.

United States Department of Health and Human Services. (2014). Obesity and America Indians/Alaska Natives. Washington, DC: Peggy Halpern Available: http://aspe. hhs. gov/hsp/07/AI-AN obesity. Accessed Dec.

United States Department of the Interior, Bureau of Indian Affairs. (2018). Document Library: Retrieved from https://www.doi.gov/tribes

Vizenor, G. (1994). Manifest manners: Narratives on postindian survivance. Lincoln and London: University of Nebraska Press. 
Vizenor, G. (2008). The aesthetics of survivance. In G. Vizenor (Ed.), Survivance: Narratives of native presence, 1-24. Lincoln and London: University of Nebraska Press.

Volkow, N., \& Wise, R. (2005). How can drug addiction help us understand obesity?. Nature neuroscience, 8(5), 555-560.egies: A Vision for 2020 for Women's Health Research. Bethesda, MD: National Institutes of Health. http://dx.doi.org/10.1038/nn145

Vukic, A., Gregory, D., Martin-Misener, R., \& Etowa, J. (2011). Aboriginal and Western Conceptions of Mental Health and Illness. Pimatisiwin: A Journal of Aboriginal \& Indigenous Community Health, 9(1), 65-86.

Walls, M., Johnson, K., Whitbeck, L., \& Hoyt, D. (2006). Mental health and substance abuse services preferences among American Indian people of the northern Midwest. Community Mental Health Journal, 42(6), 521-535.

Walters, K. (1999). Urban American Indian identity attitudes and acculturation styles. Journal of Human Behavior and the Social Environment, 2(1-2), 163-178. doi.org/10.1300/J137v02n01_11

Walters, K. L., Beltran, R. E., Huh, David, Evans-Campbell, T. (2011a). Dis-placement and Disease: Land, Place and Health among American Indians and Alaska Natives. In: Burton, Linda M. Kemp, Susan P. Leung, Man Chui, Matthews, Stephen A., Takeuchi, David T., (EDs). Communities, Neighborhood, and Health: Expanding the Boundaries of Place. Springer Science Business Media, LLC; Philadelphia, PA. p. 163-199.

Walters, K., Beltran, R., Evans-Campbell, T., \& Simoni, J. (2011 b). Keeping our hearts from touching the ground: HIV/AIDS in American Indian and Alaska Native Women. Women's Health Issues, 21(6), S261-S265. doi.org/10.1016/j.whi.2011.08.005

Walters, K. \& Johnson-Jennings, M. (2014) Yappallí: Choctaw Road to Health. National Institutes of Health. Grant R01DA037176-02. National Institutes of Health. Dissemination and Implementation Research in Health (R01). PAR-07-086. Retrieved from http://grants.nih.gov/grants/guide/pa-files/par-07-086.html

Walters, K., LaMarr, J., Levy, L., Pearson, C., Maresca, T., Mohammed, S., \& Jobe, J. (2012). Project həli? dxw/ Healthy Hearts Across Generations: Development and Evaluation Design of a Tribally Based Cardiovascular Disease Prevention Intervention for American Indian Families. The Journal of Primary Prevention, 33(4), 197-207. doi.org/10.1007/s10935-012-0274-z 
Walters, K., Mohammed, S., Evans-Campbell, T., Beltrán, R., Chae, D., and Duran, B. (2011). Bodies don't just tell stories, they tell histories: Embodiment of historical trauma among American Indians and Alaska Natives. Dubois Review, 8 (1), 179189.

Walters, K., \& Simoni, J. (2002). Reconceptualizing Native women's health: An "indigenist" stress-coping model. American Journal of Public Health, 92(4), 520524. http://dx.doi.org/10.2105/AJPH.92.4.520

Walters, K., Simoni, J., \& Evans-Campbell, T. (2002). Substance use among American Indians and Alaska Natives: Incorporating culture in an "indigenist" stress-coping paradigm. Public Health Reports, 117(Suppl. 1), S104.

Walters, K., Stately, A., Evans-Campbell, T, Simoni, J., Duran, B. Schultz, K. Stanley, E. Charles, C and Guerrero, D. (2008). "Indigenist" collaborative research efforts in Native American communities. In: Stiffman AR, ed. The Field Research Survival Guide. New York, NY: Oxford University Press; 2009:146-173.

Waziyatawin, A.; Yellow Bird, M. (2005). For Indigenous Eyes Only: A Decolonizing Handbook. Santa Fe, New Mexico. School of American Research.

Weaver, H. (1999). Indigenous people and the social work profession: Defining culturally competent services. Social Work, 44(3), 217-225.

Weaver, H., \& Yellow Horse Brave Heart, M. (1999). Examining two facets of American Indian identity: Exposure to other cultures and the influence of historical trauma. Journal of Human Behavior in the Social Environment. 2(1-2), 19-33.

Webb, S., \& Webb, B. (1975). Methods of social study. Cambridge University Press.

Wilson, K. (2003). Therapeutic landscapes and First Nations peoples: an exploration of culture, health and place. Health \& Place, 9(2), 83-93.

Wilson, P. (2001). Transcription of discussion regarding Indigenous research methodologies. Unpublished transcript.

Wilson, S. (2008). Research is ceremony: Indigenous research methods. Black Point, Nova Scotia. Fernwood Publishing.

Wright, M. (1928). The removal of the Choctaws to the Indian Territory: 1830-1833. Chronicles of Oklahoma, 6(2), 103-128.

Woodcock. C. (2016). The Listening Guide: A how-to approach on ways to promote educational democracy. International Journal of Qualitative Methods. 1-10. doiorg.proxy.lib.pdx.edu/10.1177/1609406916677594 . 
Yellow Horse Brave Heart, M. (2004). The historical trauma response among Natives and its relationship to substance abuse: A Lakota illustration. In E. Nebelkopf \& M. Phillips (Eds.), Healing and mental health for Native Americans: Speaking in red. (pp. 7-18). Walnut Creek: Alta Mira Press. Also in Journal of Psychoactive Drugs, 35(1), 7-13.

Yellow Horse Brave Heart, M. (1998). The return to the sacred path: Healing the historical trauma and historical unresolved grief response among the Lakota through a psychoeducational group intervention. Smith College Studies in Social Work, 68(3), 287-305.

Yellow Horse Brave Heart., Chase, J., Elkins, J., and Altschul, D. (2011). Historical trauma among indigenous peoples of the Americas: Concepts, research, and clinical considerations. Journal of Psychoactive Drugs, 43(4), 282-290. 


\section{Appendix A. Interview guide}

Research Aim 1: Identify culturally-based individual level (proximal) motivations among study participants:

- When did you participate in the Yappallí project? What events did you participate in (Cultural Knowledge Immersion, Ceremonies (naming/vows), Leadership Development, Individual MI sessions, Clan-Based group sessions, Culture Boot Camp, Trail of Tears walk)?

- What was your experience like participating in Yappallí project? What were some of the challenges? What are some of the lessons you kept with you? Did this affect your motivation to change health behaviors? if so in what ways? *ask for each event

- Have you seen any significant changes in your behaviors around health-related issues since participating in the Yappallí project?

- What motivated you to participate in the Yappallí project?

- What motivated you to make the health changes you made?

- What are some of the long-term changes you have seen within yourself, your family and your community?

- What is your vision of health for the future generations? How did the Yappallí influence this?

Research Aim 2: Identify the community level (settings-based/intermediary) motivations for population health changes that address health disparities:

- What cultural factors influenced your motivation to engage as community health leaders?

- What are your experiences around becoming a community health leader?

- Describe your community health event? And Why did you choose this event to implement?

- How has the community responded to your initiated prevention efforts?

- How has your family, community, and leadership been impacted by your changes and by the Yappalli program?

- How have others in your community changed their behaviors or attitudes due to your efforts and/or due to Yappallí project? 


\title{
Appendix B. Human Subjects Approval
}

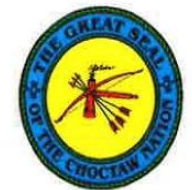 \\ GARY BATTON \\ Choctaw Chief \\ JACK AUSTIN, JR. \\ Assistant Chief

\section{CHOCTAW NATION OF OKLAHOMA Institutional Review Board} \\ OHRP FWA Number: 00001128 \\ OHRP IRB Number: 00004293 \\ Sylvester Moore \\ Community Co-Chair \\ David Wharton \\ Scientific Co-Chair \\ Teresa Jackson \\ Federal-Wide Assurance \\ Institutional Officer
}

February 10, 2017

Danica Love Brown, CAC III, MSW, ABD

Northwest Native American Research Center for Health (NW NARCH), Fellow

Indigenous Substance Abuse Medicines, and Addictions Research Training (ISMART), Fellow

Council of Social Work Education, Minority Program Fellow Alumni

Portland State University

School of Social Work

RE: Our Vision of Health for Future Generations

CNO IRB Protocol Number: 17-0233

Protocol Approval Date: January 25, 2017

Dates Covered by this Approval: February 1, 2017 through January 31, 2018

Dear Ms. Brown:

The Choctaw Nation Institutional Review Board (CNO IRB) has reviewed the above referenced research study, and granted approval of the research on January 25, 2017. This study meets the criteria of the Choctaw Nation of Oklahoma, following the guidelines set forth in 45 CFR 46, and the principles of the Belmont Report, for the protection of human research participants. It is the judgment of the CNO IRB that the rights and protection of the individuals who may be asked to participate in this study will be respected; and the proposed research, including the informed consent process, will be conducted in a manner consistent with the requirements of 45 CFR 46 or 21 CFR 50 \& 56 as amended. The research will also be conducted in a manner that insures no more than minimal risk to participants as outlined in the submitted research proposal.

As principal investigator of this protocol, it is your responsibility to insure this study is conducted as approved. Any modifications to the protocol or consent process will require prior approval by the CNO IRB. All research study related records, including copies of signed consent forms, need to be retained in a manner consistent with the intent of the Health Information Portability and Accountability Act (HIPAA), for a minimum of three (3) years following the termination date of the research project. 
Approval from the CNO IRB requires that you promptly report to the CNO IRB any unanticipated adverse events experienced by participants during the course of this research study, whether or not these events are directly related to the research study protocol. For multi-site protocols, the CNO IRB must be informed of serious adverse events at any and all sites, not only the Choctaw Nation sites. Failure to promptly report any unanticipated adverse events, or any legal or ethical issues encountered, may jeopardize, not only your research protocol, but any and all protocols supported by your sponsoring institution, and active with the Choctaw Nation Institutional Review Board.

Any modifications to the protocol or consent process will require prior approval by the CNO IRB. All research study related records, including copies of signed consent forms should be retained in a manner consistent with the intent of the Health Information Portability and Accountability Act (HIPAA), for a minimum of three (3) years following the termination date of the research project. This initial approval granted by the CNO IRB expires on January 31, 2018. In order to maintain this protocol in an active status beyond that date, you will be required to provide the CNO IRB with a Request for Continuing Review, which will include a Progress Report summarizing research study results for the year. You are ultimately responsible, as the Principal Investigator, to submit a Request for Continuing Review, or Protocol Closure (if the research project is complete), no later than January 2, 2018.

The CNO IRB reserves the right for editorial review and comment on any material to be published or presentations given to individuals not affiliated with the Choctaw Nation of Oklahoma. The CNO IRB should be notified well in advance of any intent to publish material related to this research. It is your responsibility to allow the CNO IRB at least 20 days for this review, and approval must be obtained prior to final submission of the material for publication or presentation.

As Principal Investigator, it is your responsibility to insure that you and your institution are covered by professional liability insurance appropriate to this research study's activities. In the event your sponsoring organization's IRB takes any action to modify or suspend this research protocol, the CNO IRB must be notified in writing (e-mail is acceptable) within 10 business days for modifications or 3 business days for suspension. Notification must include the action taken and the rationale for the action.

If you have questions concerning these procedures or need any additional assistance from the CNO IRB, please contact me at 580-286-4724 or dfwharton@cnhsa.com; or Dannielle Branam, CNO IRB Administrative Director at 918-302-7317 or debranam@cnhsa.com.

Sincerely,

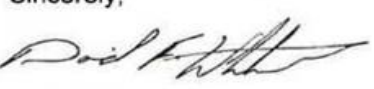

David Wharton

Scientific Co-Chair

Choctaw Nation of Oklahoma Institutional Review Board

\section{Protecting Our People and Our Heritage}

One Choctaw Way • Talihina, OK 74571 • 580.286.4724 • 918.302.7317 


\title{
\& Portland State
}

\begin{abstract}
Post Office Box 751
Portland, Oregon 97207-0751 503-725-8170 fax

Research Integrity (Research \& Strategic Partnerships)

IRB (Human Subjects Research Review Committee)

hsrrcepdx.edu
\end{abstract}

Date: March 20, 2017

To: Roberto Orellana / Danica Love Brown, School of Social Work

From: Lindsey Wilkinson, IRB Chair

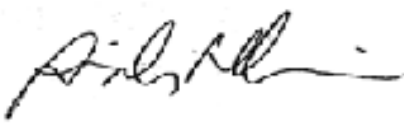

Re: IRB approval for your protocol \# 174092, entitled: "Our Vision of Health for Future Generations"

Approval-Expiration: March 20, 2017 - March 19, 2018

Notice of IRB Review and Approval - Initial Review

Expedited Review Categories 6, 7; as per Title 45 CFR Part 46

In accordance with your request, the PSU Institutional Review Board (Human Subjects Research Review Committee) has reviewed and approved the project referenced above for compliance with PSU policies and DHHS regulations covering the protection of human subjects. The $\mathbb{R} B$ is satisfied that your provisions for protecting the rights and welfare of all subjects participating in the research are adequate. Please note the following requirements:

Approval: You are approved to conduct this research study only during the period of approval cited above, and the research must be conducted according to the plans and protocol submitted (approved copy enclosed).

Consent: You must use IRB-approved consent materials with study participants.

Changes to Protocol: Any changes in the proposed study, whether to procedures, survey instruments, consent forms or cover letters, must be outlined and submitted to the IRB immediately. The proposed changes cannot be implemented before they have been reviewed and approved by the IRB.

Continuing Review: This approval will expire on 03/19/2018. It is the investigator's responsibility to ensure that a Continuing Review Report is submitted to the IRB two months before the expiration date, and that approval of the study is kept current. The Continuing Review Report is available on the Research Integrity website.

Adverse Reactions and/or Unanticipated Problems: If any adverse reactions or unanticipated problems occur as a result of this study, you are required to notify the Research Integrity within 5 days of the event. If the issue is serious, approval may be withdrawn pending an investigation by the $\mathbb{R} B$.

Completion of Study: Please notify the IRB as soon as your research has been completed. Study records, including protocols and signed consent forms for each participant, must be kept by the investigator in a secure location for three years following completion of the study (or per any requirements specified by the project's funding agency).

If you have questions or concerns, please contact the Research Integrity office in Research \& Strategic Partnerships at hsmc@apdx.edu or (503) 725-2227. 


\title{
Appendix C. Informed Consent
}

\author{
PORTLAND STATE UNIVERSITY \\ SCHOOL OF SOCIAL WORK \\ Participant Informed Consent \\ We need your help!
}

\section{Our Vision of Health for Future Generations}

"Our Vision of Health for Future Generations" is a study with participates of the Yappallí project, to explore how culture impacts your motivation to change health behaviors.

Who is doing this? I am an enrolled member of the Choctaw Nation of Oklahoma and a graduate student in the School of Social Work at Portland State University in Oregon. I am doing this study as a requirement for the degree of Doctor of Philosophy in Social Work and Social Research. This study is the under the supervision of a professor at Portland State University and Yappallí project staff.

What's involved? You will be asked to meet for an interview for 1-2 hours, with follow up interview if needed. You will be asked questions about your experience in participating in the Yappallí project, the Trail of Tears walk, and/or the Community Health Event.

Why me? You are being asked to participate because you are:

- a member of the Choctaw Nation of Oklahoma;

- are participating in the Yappallí project;

- are learning about health and wellness practices;

- you have direct experience that can help to shed light into this aspect of culture;

- and you can help us to better understand how to bring culture into other health projects.

Where and When? We will schedule an interview at your convenience over a three to four-month period, estimated between May-August 2017, at a private location that you will chose.

What will I get in return? This is a chance for you to tell your story about your experiences in the Yappallí project. There is no instant return for your time. The information you provide will help us better understand how to bring culture into other health projects.

Who sees the information? We will meet one on one to conduct the interview in a private location chosen by you. I will take notes and digitally record the interview for my use. All notes will be coded with a made up name that ONLY I will track. I will be the only person who will see the information with your identifying information.

What are the potential risks and benefits?

- There is always a small risk that privacy could be broken in some way. "How am 
- I protected?" talks about what we are doing to ensure that this doesn't happen. By law, I MUST report abuse of any child or elder, or if danger of immediate harm is suspected.

- There are some times when I cannot promise to keep your name private. If you report that you plan on harming yourself or someone else, by state law, I MUST report this to the proper authorities.

- In the event that during the study it becomes clear that I am required to report or therapeutic response is needed, then I may need to respond by calling 911 .

- There is no direct benefit; except the small gift you will be given. We hope this study may help to improve care for others in the future.

How am I protected? I will make every effort to protect your privacy. No one will be able to find out who you are or what your responses are. Any information that can be linked to you will be kept in a locked file cabinet, in a locked office, in Portland Oregon. No one else will have access to it. All information will be destroyed upon completion of this study.

The information you give me will be used for my dissertation and may be used for articles or presentations in the future. I won't use your name or information that would identify you in any publications or presentations.

Is participation required? NO. Being in this study is voluntary and will not affect your participation in the Yappallí project. If you agree to participate in this study. You have the right to change your mind and stop participating in the study at any time, and for any reason. If you choose not to participate in the study, you may request the any information I have collected to be deleted and destroyed.

You need to know... I will report the physical or sexual abuse of any child/elder or if the danger of immediate physical harm is suspected.

Questions? If you have any questions related to this study please call me, Danica Love Brown, at (303) 827-5720 or at dlb4@pdx.edu. You may also contact my supervisors, Dr. Roberto Orellana at orellana@pdx.edu or Dr. Karina Walters at kw5@uw.edu. Thank you for your time and consideration!!!

Yakato!!!

Participant's Statement: I have read this form or it has been read to me, and I understand what it says. My questions (if any) have been answered. A copy of this form will be given to me if I request it. By signing below, I am stating that I am willing to participate in this study:

Please Print Full Name of Participant: Date:

Participant's Signature: 
Certification: I certify that I have explained the nature and purpose of the study project as well as the potential benefits and risks associated with participating in this study project. I also have answered any questions that have been raised. I have witnessed the above signature.

Researcher Signature: Date:

If you have questions regarding your rights as a research participant, you may contact the following Institutional Review Boards (IRB). The IRB is a group of people from Portland State University, Choctaw Nation of Oklahoma and the community who provide independent oversight of safety and ethical issues related to research involving human participants.

Portland State University/ Office of Research Integrity (ORI) For more information, you may also access the IRB website at https://sites.google.com/a/pdx.edu/research/integrity

PSU Institutional Review Board

Research Integrity, Research \& Strategic Partnerships

1600 SW 4th Ave., Market Center Building, Ste. 620

Portland, OR 97201

(503) 725-2227 or 1 (877) 480-4400

Choctaw Nation of Oklahoma Institutional Review Board

Dannielle Branam, CHRC

CNO IRB Administrative Carey Fuller, Director

720 Bryan Dr.

Durant, OK 74701

Phone: 580-924-9706 ext. 30313

debranam@cnhsa.com 


\section{Appendix D. “I" Poems}

\section{Cohort 1 "I" Poems}

1001

I think

it was really good

as a project for women that,

you know,

especially some of the women,

not just myself

but for me it helped me

with the confidence of speaking

other women,

of speaking

with other groups

to continue to carry on

not just our culture

our heritage,

but to carry on

an experience

to share with other people

of a better life

a healthier life

to live,

With me, 
it did help me to get better

better perspective

all though this year

I have fallen off

but to eat healthier,

to focus on a healthier

living lifestyle

I have gotten involved

with the bike team.

I have gotten involved

with different fitness challenges

not just for myself

but for my family

My family is my number one priority

-- you know,

to me,

because if I don't take care of myself,

then I don't show them how

they should take care of themselves

Then that was the main thing to help me to find

-- I guess

a sense myself

to feed off of that to,

like I said, have more confidence

to share with other people

And the walk was really unique 
because I am Choctaw, my great grandmother

full blood Mississippi Choctaw.

doing the walk helped me

to open up

see that portion coming to here

to Oklahoma

to revamp our lives.

For myself

because I know

that some days

everyone was tired

bitter.

And so to me,

I'm just

-- that was a struggle

in a sense because

I never really had to

sit

sit there

listen

just overcome that fact.

And I had to kind of

in my mind

kind of just juggle

how do I make it through this week

with the bitterness, 
but with the happiness too.

When I got tired

or whenever I got aggravated

or

zoned out

not zoned in

to where I should have been

during that week,

I related back to that lesson.

I would find myself

just closing my eyes

just for a few minutes

thinking

of what I heard in my surroundings

just found that peace,

that relaxation moment.

And to me that -

- sometimes we forget to do that.

I tell me kids,

even myself at times,

just breathe.

Just close your eyes

and breathe.

To me

one of my favorite things

it brought back something 
that I already knew how to do.

I just let it go.

My eating habits got bad.

I don't know if you want to know this or not,

I grew up in a family

that my mother and my father worked constantly

-- all the time.

I grew up with working parents.

There were five of us children,

my mother worked regular

-- pretty much regular hours,

by the time she got home,

you know,

it was late.

My dad, he worked seasonal.

So we had ups and downs

of income.

So we also had ups and downs

of life itself.

I had my first child

at the age of 8 and a half years

she was diagnosed with Type 1 Diabetes.

I lost my mother when she was 57 years old

due to complications of diabetes.

I swore then 
I was not going to have those bad habits again.

I did my best for a long,

long time.

the very next year

my daughter was diagnosed with Type 1 Diabetes

a year after my mother passed away.

in my mind

I was like

we got to eat better,

we got to exercise,

we got to do this.

we did it for years.

when my oldest graduated,

which was in 2006

that's when my bad eating habits came back.

Whatever,

junk foods, whatever.

I was working full time

I would get stressed

I would relate to food

I joined this group

it was mainly because

I saw I was not living

a healthy lifestyle.

I saw I was not eating or exercising in a healthy way,

I thought this might be something good 
that will restructure me throughout the next year

to eat better

to live better

not just for myself

but for my family.

So it's helped me

it's helped my oldest daughter

because whatever I learn

I share it with her.

I share with my youngest daughter

even if it's the relaxation skills,

even if it's the eating habits,

even if it's the exercise,

even if it's about our culture

-- that --

I have always tried to keep culture

heritage taught to my kids

as much as possible.

Even with my grandchildren,

I share it with them.

I feel deep down

that's what my mother and grandmother want me to do.

I was 27 years old

when my mother passed away.

That was devastation on my part.

then to lose my dad 
in 2010

that was even more devastating to me.

It was like,

I got to the feeling that I had no one here.

I have sisters,

but there's kind of been a wall

brought up between us

now since dad has passed away.

it's just -- it's been different.

to me it's also being part of the

Yappalli group

I have kind of encountered

a new family almost,

an extended family

Yappalli

has helped me

to gain a little more strength

in my own self and confidence

in myself

not to mention,

to have a little bit understanding

of a better,

healthier eating habit,

better exercising habit.

I still talk to the

-- some of the women in the group,

especially those that I got close to. 
So it, like I said,

it's like a new family,

extended family to me,

by being part of the Yappalli.

I think to me

I guess I would say

as far as future generations,

the healthy living to me,

if I can do it

I can promote it within

share it with other people

share it with my own family,

then to me that's promoting it for future generations to

-- and, you know, this day and time there's so many people.

I see it day to day

within the job that I'm working in,

bad lifestyles.

I don't want my children to have that.

I don't want their children to have that.

I think that being part of Yappalli

promoting a healthier lifestyle

within myself

I can share that with other people

to promote it with them

for future generations.

I wouldn't say 
I am a community health leader,

although in this past year

since my grandchildren have been here living with us,

or living close to us,

we have been more involved with kids,

my husband

myself

through soccer,

through softball,

through bicycling,

through running $5 \mathrm{Ks}$.

That in a sense, yes,

we're helping promote

with other kids that she's associated with.

if that's the way I see it,

then I want to help those children too.

But as far as an actual leader,

I don't call myself a leader.

\section{Yappalli}

was a big influence on me.

I didn't realize

what exactly I was getting into,

but I'm glad

I was able to be part of it.

I hope that other women

in the ten and a half counties 
of Choctaw Nation

get that chance

that opportunity as well.

Because it's a really neat experience.

1002

I have little cousins

I take care of.

Sometimes I get on to them

just like my kids.

I even have big cousins

or cousins

that are my age that

I still try to talk to them.

"Hey, you don't need to be doing that".

I try to encourage them.

I do feel like I kind of relate to the lioness.

Sometimes that's how I feel.

I have to take care of,

like,

everybody in my family.

Picking a clan

I told her the lion

was the one that stuck out to me most.

Once she had told me what it represented,

I guess --

like what it's kind of like to me, 
it's kind of true.

I do try to take care of my family.

I have cousins and sometimes they come to me they tell me stuff.

I try to help them out as much as I can.

The panther is a big protector.

So I kind of related.

I talk to my kids all the time

about being healthy,

eating right.

I always tell my kids,

you don't want to be that way.

My cousin,

she's 44 years old,

she's just recently got her second leg amputated

because of Diabetes.

She's going blind.

I always tell my kid,

you can't eat like that.

I try to hell her that.

Cut out the bread.

Even her daughter.

Her daughter will come to me.

Sometimes she's crying because worried about her mom and stuff.

And I tell her, try to tell her to eat healthy. 
It made me want to know more about my ancestors.

You know, like,

who's the one who came over and stuff like that.

I wanted to know more about my family.

I know it had to have been hard for them, especially during the winter time.

I mean, I didn't even walk that far.

I was tired.

So I know they had to be strong,

really strong minded

strong hearted

to make it here.

I would like to know that I did.

Because if my grandparents didn't make it over here

then we wouldn't be here.

If they didn't make it over here then

we wouldn't be here.

So with that in mind, you know,

I want to be a better person.

I don't want to be like an alcoholic

or drug addict.

Because I know my grandma and grandpa

Sacrificed

a lot to get here.

I know if they seen me

or my cousins acting that way,

they probably would be ashamed, you know. 
"We walked all this way

because we thought we would have a better future. And look at you. You're just wasting your life away."

I don't want to do that.

So now I work hard.

I always did.

I try to be friendly

to everybody.

II just recently won an award for my hard work.

To me I think that's paying off

1003

I found it informing

I learned a lot about ancestors,

history, and

the best part of it is

I got to do it with my Ipokni,

which is grandma.

She got to go with us on some of the stuff and with my aunts.

My mom was in it as well.

I wanted to finish.

My ancestors did it with no shoes.

I can too.

but I don't know how to explain

I was like I can't explain this.

You have to experience this for yourself.

take in so much. 
It's like I said, you can't explain it.

It all makes sense.

Everything that I was taught

Everything said goes right with it.

Since when my mom got sick and passed,

I gained all my weight back.

I went back into the old

-- how I was.

I have more energy.

When you eat healthy

you actually get more energy

you feel better about yourself.

There's really nothing like that that had been in our area before.

I thought it was just going to be a great experience,

which it was,

to try something different

and new.

I am glad I did.

Like I said, it was very informative

Before you would hear about the walk,

the ancestors,

what they did,

what they went through,

but you really don't pay attention

or realize 
until you actually go and do it.

Before I had high blood pressure and stuff.

I drank

-- like I said,

I kind of went back

because I started taking my medicine again,

but for this whole past year I didn't take

-- my blood pressure was under control

because I was drinking water.

I was exercising more and stuff.

So, yeah

I was even smoking at the time

we did the smoking thing, too, smoking cigarettes,

I quit smoking.

I could not say yes, to being a leader

because I am not into the community

as much because

I'm so busy

with life

and my kids.

As far as being a part of the community,

doing things with the community, no.

I just wanted to do something,

like give back. 
Do something

where everybody could be involved.

You know,

they said that we could go to the community center

start like a little garden or plant,

stuff like that.

our community here gets left out on a lot of things.

We've got lots of kids here.

So we thought let's do something

where all ages can get involved.

I would like for this to continue on

so other women could get that experience.

Like I said, it's hard to explain.

You have to experience it.

There's no words to really say.

Because you feel all kind of emotion.

It's real informative.

I kept pushing myself.

I kept thinking if my ancestors

They did it and they did it for me to still be here,

I'm going to do it,

not let them down.

I mean,

it's a good thing,

a good program. 
Like I said,

it would be good for other women

to just go and experience it themselves, too

1004

Well, before we ever left,

I kept having these dreams

like in ancient times, you know.

I didn't even know about the Yappalli project.

Then I went to the cabin

I was just laying there.

When I was a little girl

I would always go get my little brother.

we would go in a circle

I would just sing songs.

I don't have a clue what they were now.

I felt

really

-- all of that,

just everything seemed so raw.

So I was laying there.

I had turn out the light.

It was pitch black that night.

You could not see anything.

And all the sudden there were like

They were like heart beats. 
But it was like

they were just everywhere in the room.

they were maybe the size of a dime,

but they didn't shine like light shines out.

They were just there and they were pulsating.

I was just talking,

pleading

to please help me,

help me be whole again

because I felt like I had left myself in so many places.

I was a wanderer until I had children.

Then I kind of settled down.

I don't know how,

but I know you do can make me whole again.

And all the sudden there was this thing,

probably about this big round.

It was black.

It had this color around it.

It looked like diamonds kind of.

Then all the sudden it just opened up,

and the grandmothers came through.

They were just coming everywhere.

And I was crying.

I said,

just please, just hold me.

And they did. 
they whispered in my ear

-- it sounded like whispers --

that it was okay; just rest.

But I knew then when I was dancing

when I was little,

they were always protecting us.

That my grandmothers loved me

regardless of what I felt for my actual family.

The next day I got up.

Normally,

I had my cane

And I was struggling to walk.

And that day I got up.

I felt like my body was healed.

And I helped out in the camp.

I helped put the dinner out

set everything up

make sure everything was ready for the walkers

when they came in.

I was so excited.

I just felt rejuvenated

in every molecule of my body.

That was what I took away,

the feeling of being protected

loved

being whole 
I was experiencing a tremendous healing, a spiritual healing.

I'm talking about how things appear to me.

It was brighter.

It was healthier.

at that time I cleaned up my diet.

\section{Anyway, \\ I pleaded \\ prayed}

that I would see my kids grow up.

Then they grew up.

I was very, very blessed.

Then I prayed

I would see my first grand baby.

And I saw her

and now I've got five

There's a place called village creek,

lots of people feel the presence of,

you know,

of women

from a long ago.

It was women.

And I thought,

you know, 
I have got to go.

And I thought

I wouldn't get to go.

I didn't really get to participate fully.

And like I said,

I had to go to a room at night.

I couldn't sleep outside.

I hated that.

That seemed to me at night come the stories.

When you're sitting around the fire.

\section{Cohort 2 "I" Poems}

2001

You know,

I never thought about our ancestors' walk.

I learned a lot of stuff.

Especially the one when we went in that -- where all the trees and bushes.

You know,

I felt that more than anywhere else.

You know,

I felt -- I never did felt nothing until we went down there (Village Creek).

I didn't feel like

-- I don't know, what do you call it?

I felt like they were with me.

seemed like I heard water.

And there was no water around. 
I don't know what you would call it.

You just feel like,

I don't know,

some feeling just come on you.

I just feel like

I could feel them.

I don't know

what you would call it.

Seemed like it was a challenge for me

to walk it all.

I walked them all,

but one time,

me and this lady got on the bus.

It was just a few minutes

and we got back off

and I walked the rest. Even

I got blisters on my feet,

my heel,

but I still walked it and I made it.

I thought I was going to lose my breath.

I still remember and feel it.

I think about a lot of it

Because I was eating too much.

And now -- and my breathing, 
I had wheezing.

I thought, well,

I better start doing something else.

That gets into your lungs.

So I'm on this

-- I call it my diet.

And I'm doing pretty good.

The sweets,

I can just give up, really.

Like today,

that cake,

II didn't want it.

I had to work on that pop.

I didn't know nothing about it.

I thought,

I can't walk.

I can't do that.

She said,

yeah you can.

Yeah, you can.

2002

just to me

just to be invited to go,

it was a blessing in my life

to be one of the ones that got to do it

Just the walking, 
the walking.

It was so

-- I did a lot of walking,

or I thought I had,

before we went on the trail,

but I could only make it so far. And I was tired.

That's when we would ride.

But just the walking,

I could not walk a lot on the trails.

Then I noticed that the trail,

the Trail of Tears,

was the county roads.

They had made them into county roads o

the city streets.

And I thought,

that's unbelievable how it's easy for us to walk.

You know,

a lot of times I went to bed

and I was hungry,

but it was a good hungry.

It wasn't, oh, I'm really hungry.

I drink more water.

I try.

I really try

to drink more water.

When I was on the walk,

I really didn't drink a soda. 
I did start drinking more water

and less soda.

I really did that.

I never thought about that until now.

But I did.

I guess that had a big impact on me

because I try to drink

as many bottles of water as I can a day.

Hmmm. Okay.

I still have pop every once in a while,

but not very often.

I treat myself.

Just the walking.

I think the walking just really

-- all though,

I walked before,

it was just because I needed to lose weight.

Now when I go out for a walk

it's for a purpose.

I learned that my ancestors

could walk a long way,

you know.

So now it's like --

thought it would be fun.

When we first heard about it, 
I'm like, yeah,

I'll do it.

I didn't know it was going to be as much walking.

I like doing new things like that.

I thought walking the Trail of Tears

might be interesting.

So, yeah,

I thought, yeah,

I'll do it.

And just going different places.

I guess

I just wanted to do it.

I guess

they say that God opens doors

for you and you got to step through them,

so I think that's what that was, a blessing.

I can't tell you everything,

because it's more of a feeling than it is

of what I can tell you

express to you

that I did learn on that

when we were out there in the wilderness.

I just thought it would help a lot of our older people.

Of course, my grandson, too.

I guess that would make us

one if we do the garden and we talk to them.

Maybe a little bit, 
I guess. I never thought of that.

I've never thought of myself as being a leader,

a community leader,

but I love being with the people

just talking to the people.

Like I said, a lot of them

-- the people I've talked to

about it has asked me

-- they want to do it

have asked me how that we got into doing it.

I told them, you know,

we had been asked if we were interested in doing it.

I was just telling everybody

when I first got back.

So the garden,

I'm really happy with it.

I'm really happy

that she talked to me about doing it

asked me to help her.

I just loved being with all the women

I heard the horse,

you know.

I don't know

-- I heard the horse one night crossing that bridge.

I laid there 
and heard the horse

nobody believed I heard that horse.

I heard a horse.

Because what he said,

Nickered,

oh, there's that horse.

And then somebody told me there was a horse ranch or something nearby.

Then while we were walking the small trail,

there was a hoof print in that mud

I just enjoyed the whole thing.

I enjoyed all of you young ladies that were there,

the walking everywhere.

I got home

and I was so tired.

But coming into Tuskahoma,

I enjoyed that.

And everybody went in,

you know.

I was 70.

To be 70 years old

and to do something like that.

My mom,

she didn't live past 65 .

So I know my life is a lot different from hers.

I really do.

I know that our lives are different 
from our ancestors

that came across

because they didn't have anything.

Just very emotional

because of all the stories that you all told.

It has really helped me.

It has really helped me,

and I want to live longer.

I know that I have to change everything

to live longer.

So like I say

-- and I never thought

about drinking more water

until you said that,

I realize I do drink a lot more water

I will keep trying.

I will keep knowing that I can walk.

I can eat my vegetables out of the garden.

Hopefully, everybody else will learn.

I know vegetables are expensive when you go in a store.

If you just buy one or two and make that with your meal.

2003

I think

it created an awakening in me

as to something that,

you know, 
has become slightly dormant,

and that's a pride in being an Indian woman.

And also the eating habits had changed,

you know.

I eat a lot more vegetables.

I drink a lot less sodas.

I drink water.

I just have more of a pride in myself,

I think,

you know.

I take more

-- I take more time for myself

than I did.

my husband

had been diagnosed

in January

with terminal cancer.

I think

one of the biggest challenges

was leaving him.

Although,

he strongly,

strongly

supported me in anything,

he wanted me to go 
because I had been

looking forward to it for so long.

And the challenge

I think

was challenging

myself to see

how strong a woman

I really was,

you know.

Could I do this

without my grandchildren,

without my children,

without my husband?

Could I go on this

more or less of a journey,

you know,

just me?

Just concentrate on me

see if I had the strength to do it

It just made me a stronger person,

I think.

little did I know

that very soon I

would be needing that strength.

During that time,

I came to grips with

what was going to occur in my life. 
And my life has changed

tremendously.

Life goes on,

you know.

I lost my husband shortly after that

I really believed

that the trip conditioned

me in a lot of ways.

It showed me

that I did have the strength

to go on alone.

I really appreciated

that trip very much.

I was kind of on a mission

to find me,

you know.

I wasn't going to give up till I did,

until I found

--But that time alone,

I was Tad.

You know,

I was Tad.

I found that I can do.

I had the endurance.

I had the strength.

I had the spiritual resources I need,

I also had the support of every lady there. 
I've always had a competitive spirit,

but I wasn't competing

I wasn't trying to get away from anyone.

I just needed that.

It was good.

It was good.

I got what I needed.

while I was alone,

and it was the last leg of the journey,

I think,

where all during the journey

I felt the

-- as an Indian woman,

we do have a lot of spiritual experiences

with our ancestors.

But there was one experience

that I felt with nature.

It was so hot,

so hot.

they would stop by

give us water

and all.

But I was saying,

am I going to be able to do this?

Am I going to be able to do?

And then the winds would blow on me. 
I found my spiritual clan.

Holly, the wind.

Because when I called upon it, it would just come over me

give me a light breeze.

I felt good.

I felt refreshed.

Then whenever

I got to whenever I was going,

I would feel like it was

just a kiss on my cheek,

you know,

the wind.

I felt like

I was with nature,

one with nature.

I've always heard that said,

I really felt like it.

It might sound stupid to some people,

but what I got from this

was so wonderful.

I was thinking

about the people

that did make the sacrifices,

what come to my mind

was the mother.

You know, 
the mother

how she probably

had to carry her child,

yet she sacrificed

the pain in her feet

and all that.

I got to thinking

about some of the foods

that they probably

had to eat,

you know,

from the ground,

whatever they had to fix

and all.

I thought,

you know,

it's not necessarily

all these fatty things.

They had to take in nourishment

to keep going.

And that's what I was doing.

I know they did that walk.

And I thought, you know,

I don't need all this store bought stuff.

I can grow my own food.

So that's what we're doing.

My grandchildren 
And I are planting.

We've already planted.

I want them to know

the benefits of

eating healthy

keeping their body healthy.

we walk more.

I enjoy walking,

listening to them,

you know.

I do tell them,

you know,

I don't want it to die out.

I tell them

about their ancestors.

I show them

the pictures that I took on the trip

I wanted to know more

about the women

that came came before me,

you know.

Not just my family,

my grandmother.

I wanted to know

about the group,

the women that a lot of their history.

So that's why I wanted to be part of it. 
I wanted to see.

I want to be part of history.

I really believed that the Yappalli program

is a historic program.

If I could express anything,

it would be the fact

that this is so important

to generations.

Because what I gained,

I'm passing it on down

they're going to pass it own down.

But I wouldn't have had that

had I not become part of this program.

I think that since I

did reduce a lot of the sodium,

I have reduced a lot of the carbs.

I can't tell it with my weight,

but I can sure tell it with my strength.

I have less pain.

I don't take pain meds.

Well, if I do a really hard day's work,

and I'm talking about in the garden

and all that,

then I might take an ibuprofen or something.

I think it's really helped my mental health, 
you know,

to be a part of something

that I can say,

I belong to Yappalli.

I really believe

that it will be in our history books

what these women did this.

Or it should be.

\section{I think}

that the health

of future generations

should consist of

more walking,

more natural foods,

more exercise,

more mental exercise,

visiting,

putting phones down,

playing games,

you know.

Like I said,

mine was more of a spiritual journey

that I took.

I wanted to see

-- I feel that everybody needs quiet time. 
I feel that everybody needs to kind of,

like I said,

get in tune with themselves.

So I had suggested

a prayer garden,

where if nothing else they just sit and enjoy the plants.

I think that my family has.

A lot of my friends knew I took that trip.

They were fascinated with the fact that the map,

you know,

the territory that it involved,

I showed it,

and they were fascinated with that

I would like to

see every woman

in Choctaw Nation,

I would like to see

it go through the tribes.

Not just Choctaw,

but as an Indian woman.

We are different,

but it's gave me such a pride

in being an Indian woman,

living in an non-Indian world,

you know.

I saw women of different tribes, 
you know.

And you all shared things.

The night when we went to the

-- where we had the blessings

and all that,

it was wonderful.

You shared some of the traditions

and cultures.

Of course, it all related with ours.

I think being Indian

is just we have a few variations,

but we're Indian women

2004

it was a great experience for me.

I learned a lot

I didn't know

what our ancestors went through.

people I went through it with,

I knew some of the people,

some I didn't.

I made a lot of new friends.

And some of the people that I knew,

But it was a great experience,

I would encourage anybody else

to go through that

if they have a chance 
I guess just being on the walk

learning some of the things

about what our ancestors went through

kind of made me want to learn more

about my heritage,

so I actually started going to Choctaw language classes

to try to learn the Choctaw language.

I went a few years ago,

but I never really learned it.

But I'm really going to try to learn it this time.

Yeah, I would like to try to learn it

I started going to the wellness center

working out

walking

just to prepare myself

for the walk.

I lost weight.

then I was trying to eat healthier.

before then

I was taking pills

for Diabetes,

cholesterol,

high blood pressure.

I was taking quite a few pills.

But after all of that,

I went to see my doctor 
and did labs,

and I had not been taking anything,

actually.

I didn't refill my stuff.

I admitted to him that

I had kind of stopped taking anything.

But my labs came back really good,

he actually took me off of most of everything I was on.

I've been trying to keep that up

work out

try to just be healthier.

As of today,

he hasn't put me back on any of those medications.

So that's kind of one way it helped me,

just preparing for that

seeing what it did caused me to want to keep it up,

just try to keep healthy.

\section{I joined Yappalli}

learned about the walk

everything that we were going to be going on,

so that kind of motivated me

to go ahead

get started

just to get in shape for the walk.

My vision of health. 
I guess,

it's being physically healthy,

but not only that,

mentally healthy, too.

I've got two granddaughters,

teenagers.

I know today there's

so many things

that I go through

that we didn't go through

when we were younger.

And I'm hoping that,

you know,

by them being stronger

maybe see what I'm doing

then maybe that will help them

to cope better,

you know,

when they face challenges.

I don't know

if I consider myself

a community health leader.

I mean, I try to

-- I don't know.

I'm not sure what

a community health leader, 
what you mean by that

And I'm really proud of what we did.

I talk to anybody about it, you know.

If they ask,

what is Yappalli?

Even around here

when we did the health fair,

we had the Yappalli shirts.

Somebody asked,

what is Yappalli?

What does it mean?

So I told them

I went on to tell them

what we did

about the walk

everything.

You know,

I have told several people about it.

I want them to know

what we learned

what we went through.

I mean,

you can't really explain it

until you actually do it yourself,

but I have told several people 
about the walk

Yappalli

what it stands for

kind of what we went through

everything we did.

So I guess in a way that's kind of --

I've told several people.

Whenever somebody mentions

Yappalli

or anybody

who wants to listen,

you know,

I tell them about what the project is.

I've got a much greater appreciation

of what our ancestors went through.

I know a couple of walks

got really emotional for me.

I know one time I was walking.

You know,

we were supposed to stay with a group.

Somehow I had gotten separated

from everybody

I was by myself.

I just stopped.

I didn't know if I could go anymore.

I was so tired 
hot,

we had those bags.

I just stopped.

I just

-- I just prayed.

I just prayed to my ancestors.

I said, I don't know if I can go anymore.

I said,

you know,

I need help.

I don't know if I can do this or not.

And, you know,

after I prayed,

it was just like they answered me.

This cool breeze

just came down on me

that wasn't there before.

Like I said,

it was hot

Dusty

and I was so tired.

But then after I prayed,

like I said,

this cool breeze

just came on me out of nowhere.

I knew then,

you know, 
I can make it.

I can go on.

So I went on.

And then later

on we were probably about a mile,

mile and a half from the end,

one of the support staff,

she was with me then,

and she was walking with me.

Then I was tired.

I got tired again.

And I just didn't know

if I could make it or not.

But I wanted to make the whole walk.

I looked at her,

I said, no.

I said, I'm going to finish this.

I am not going to ride.

I got cooled down.

We just sat there.

Finally I got up

we started,

I walked in there,

the whole 7.3 miles.

And when I walked in there,

it was just so emotional.

I just broke down 
started crying

when I walked into Washington Post there.

It was really an emotional walk,

that one was.

I was not going to ride.

I thought

of what my ancestors had gone through.

I thought,

you know, can I do this.

If they can survive

what they went through,

you know, I can do this small part here.

Like I said,

I walked in there to Washington Post

saw other people there

that had come in before me.

It was really just an emotional time.

I broke out and started crying

when I walked in there.

I was just like

I felt a small part

of what they felt when they came to Oklahoma.

There were a couple of times

that were really emotional for me

on those walks.

I'm so glad I got to go on it. 
Unless you've actually done it yourself,

it's hard.

I can tell people about it,

but unless you've actually gone on it,

you can't really explain the feeling you get.

I would tell them

to take it up where this leaves off

let more people go through it.

Let men go through it,

families who want to go together.

Don't just stop here.

It's such an experience,

you know,

to go through.

I would tell them

carry it on

let more Choctaws go through this

so they can see.

They can experience

what we experienced.

That's what I would tell them.

I hope they can do that.

2005

It was very informative learning about my ancestors.

I've always been proud of my heritage,

but I was never really involved a lot in knowing a lot. 
My grandmother on my father's side, she was the full blood Choctaw, but she died when I was fairly young, so I didn't -- I don't remember a whole lot.

I know she spoke English and Choctaw, but I didn't grow up with any native language.

Dad would say a few words, but he wasn't proficient.

He could understand, but he didn't speak, so I'm just proud to be Choctaw

I'm overweight, that was part of the problem, but I had been walking before "The Walk" so I was okay with that.

I did learn, you know,

I knew the native medicines were

-- you know, the plants and herbs they used is, you know, is still being used today. I mean, they were smart. $\mathrm{T}$ hey knew what helped heal.

So that, 
you know,

was a discovery that,

you know,

I felt was needed,

you know,

to continue on to pass on

to our children and grandchildren.

I was diagnosed

with Diabetes a few years ago.

So I tried to eat more greens,

you know,

and lay off the white stuff.

I'm progressing,

trying to instill that into my grandchildren.

Because before the trip,

it was running a little high.

But with diet and exercise,

I have,

you know,

gotten back where it

-- not where it should be,

but it's not where it was before.

I think

it was just some friends

at the center 
that said there's going to be a program,

it's for your health

try to get you healthier.

That's how I got there.

it helped to enforce

that 15 minutes twice a day.

Because I knew

I was going to be going on the walk

I had to build up stamina

help the perspective of being walking every day.

But I'm trying to instill that in my grandchildren.

I have three granddaughters,

and I'm trying to say.

But they're still young,

so they're running and going.

But try to tell them,

eat healthy,

drink more water.

Drink water.

Not sodas.

I know some of the other groups

did just one-day events,

but I was thinking this is for my health also.

It would make me get out and be active.

I mean, 
I'm just aware

-- I mean,

I like to eat from the garden.

That's one of the positives.

I love, you know.

But it's a lot of work.

When you're by yourself,

I am not that type of person.

I'm learning, right.

I think that was pretty much

-- and my brothers, encouraged me.

Because they know I'm overweight

I need to -- I have a runner brother.

He says, are you walking?

And I said, yes, beforehand, so I could work up to "The Walk."

some of my church lady friends.

They were, you know,

talked about it was a good, you know,

good thing for your health

I hope it would be continued

so that other people could

have the opportunity to enjoy it

to learn from it.

I mean, it was 
-- just meeting new people.

Because I didn't know everybody that came.

I just learned about different people, different,

you have different personalities

different ages.

I learned,

about them

was able to share a little.

I am not really a talker,

but I did,

meet new people

learned.

I was one of the oldest,

so I was a lot of the times

way back in the pack,

but I always had support back there. T

There was always a worker

or one of my fellow walkers

that walked as slow as I did

or got tired about the same time

we rested together.

I was impressed by the staff that was with us.

2007

I liked learning

I liked meeting new people.

Having the experience with my daughter was really good. 
I felt like, for me,

it made me more open-minded

on how things are, you know.

I just liked

how everything was

still about faith and believing.

how that has trickled down

through all of us growing up.

So I like that part.

I've always been pretty active, you know.

So just being active.

My daughter runs,

I still walk.

Keep them all -- you know,

do something

instead of just sitting around the house

not doing anything,

but get out and do something, you know.

Of course, I volunteer around here at the center as well.

And I've been getting my granddaughter to go with me so she'll know the meaning of volunteer.

Just trying to be more active. 
Trying to walk more.

Because during the winter times

I don't walk that much.

But just being more active

doing things.

Like I said,

volunteering more and helping.

I am not sure about a leader,

but I'm hoping to be.

I think I can help out there

share my thoughts

and stuff.

It may help in ways.

With my experience,

I really enjoyed it.

It made me think a lot.

I think in that time

I was kind of feeling down on myself

a little bit.

And going through that

made me realize,

you know,

I'm stronger than

what I think I am.

You know, 
I was able to take that

what I thought was a big problem

really wasn't a big problem.

I was kind of down on myself,

but after I came back from that, you know,

I felt much better, a little stronger.

And like I said,

my little problem --

to me it was a big problem,

but in the end

it was just a little problem,

but I was taking a big issue out of it

because I was not confident enough.

So it helped a lot.

\section{Cohort 3 "I" poems}

3001

It let me get closer to my heritage

Mainly the walk was really inspiring.

Very, very spiritual for me.

it also learn me nutritional ways.

But the spirit part was very emotional during the walk.

I guess I could say that

I was really in tune with the spirits because

I was hearing drums,

I was hearing crying, 
at one point I was crying

where they had died with cholera.

When I reached to one area

where they was buried

at I could feel pain, crying myself.

I didn't know what was going on

until they told me that they were buried

right in that area where I was at.

And when I was walking

I could see spirits behind me.

I could see spirits behind me.

I could see spirits behind me

when we finished our last part of the walk

coming into Tuscahoma.

I looked behind me

I could see spirits coming behind us.

It was really, really breathtaking for me

to see all this.

Sometimes it is hard to explain to anybody, but I felt every bit of that.

I didn't think I could be able to do it because of my leg, but the more you got out there

And you're, you're

-- that was a challenge, a big challenge for me 
because I've been down for a long time.

I think once after

I got through with all that

it was just amazing

that I got through that.

But really the whole thing was challenging

I don't have any younger children.

I don't have any children at all.

But I see we have a lot of work ahead of us

to get them to understand our ways.

A lot of them don't even realize.

I had three members die

on the trail of tears in my family.

And, I don't know,

I guess walking that,

I could just feel them.

I could feel the whole thing

if I could sit and talk with a bunch of kids

try to talk to them

what the feeling is of being

Choctaw and our ancestors,

I would love to do that,

get together with young kids

and tell them.

Because anymore they don't know.

They don't.

A lot don't tell their children these things. 
If we had some kind of program

where they would gather them,

it would be good.

But we don't have something like that

I don't think.

I don't see it up here.

But our children need to know

and try to learn.

But, like I said,

I don't think it's up around here as much as it is down there

When I was driving to the first area,

like I said,

I hear drums

and crying.

It was just like,

like I can't explain it.

the main one was connecting

with the ancestors.

That was amazing.

And I would sleep outside

because I was wanting to feel it all.

that's the reason I did that.

But I would see them,

I would see them

if we would be camped out,

I would see them 
out doing whatever they do

And that was really amazing

when we went through that tunnel.

I don't know if you heard it,

but there was nothing moving.

Nothing.

It was the most quietest place

I've ever been to in my life.

And I was just getting chill bumps.

And when we started walking,

it was like there was spirits

behind me

pushing me

and I went in front of everyone.

Do you remember that?

And I was just saying

you all get out of my way

because I can't stop.

It was like they were pushing me.

And when I got there

I was exhausted

because of what was happening.

I was going wow.

I looked behind me

and I could see them behind

me pushing me. 
I was looking forward to it,

but it didn't quite turn out like we planned

so everything we had there

we gave out to the children

because it was a little backpack

with knick-knacks in it,

healthy knick-knacks

and water. But the

A lot of people get scared

of things they don't understand.

at that point in time

I didn't tell anything

about that dream or vision,

whatever you call it.

I've seen visions

I've had dreams,

but this vision,

when I seen them for real

when I was 33

I seen them from that dream

when I was 7,

that's a long time to wait

for a dream to come true.

And, boy, it just hit me in the face. 
From there

that's when my Indian side

was just starting to open up.

I mean really opening up

I go now to my district

-- I've been going every Wednesday.

And when I've got time

I stop by there if I'm in that area.

But kind of getting involved with more stuff.

I think I could help out

with a lot of things if they let me.

I think my brothers understand,

but they don't want to admit it.

Of all the things I've been through.

I didn't tell them about the trip except

one brother

and he understood what I was saying.

I just want to say one thing.

I appreciate you all.

I'm happy to have the opportunity

to go because it brought a lot

of insight to me through my heritage.

I've talked to several people

after I came back

I would tell them how emotional that trip was for me.

They grasped what I was talking about. 
But I appreciate that opportunity to go.

I honor that opportunity that I got to go.

It was very honoring.

Very honoring.

I guess what really caught me

through this whole thing

is being able to go on that trip

walk where they walked.

Because that was so emotional for me.

It brought me to tears.

But through all of it,

that would be the part.

I went on it

because I was on a spirit quest

I knew it from the beginning.

I'll tell you this that three or four years back

I had this dream

that I was going to go on a Trail of Tears walk.

I called my nephew

I said, let's go.

You drive and you follow me.

I really didn't know where I was going,

but I would have found it.

And he said yeah, let's do it.

But he really had no time.

Then bingo, here Rachel calls me 
it was just like I knew

I was going to go someday.

But it came up

I took advantage of it

Because I was saying

-- and I really didn't want to listen to the rest of it.

And I said I got to go.

And everything was trying to stop me from going.

I had so much trouble the week before we went, up to the day we went

trouble after trouble after trouble trying to keep me from going.

And then I said I'm going

3002

I enjoyed it,

I really did

because I wasn't raised in a traditional Choctaw home.

So learning about the different aspects of the culture

then talking about the different animals and the clans,

I thought that was all very interesting.

I liked learning more about the history

that sort of thing while we were on the trail, too.

I thought it was very,

it was very neat.

Just being in a group of women

even though we're from different types of backgrounds

we still have this commonality between us all, 
So we could at least bond

through that

get to know each other better

I just liked the whole aspect

of what kind of ancestors our ancestors

want us to be.

I'm pretty athletic

as it was so

the walking wasn't that difficult.

the dietary restrictions,

I was fine with it.

I just enjoyed

doing something out of the ordinary

learning about all the different aspects.

my mom and dad have always gardened.

My mom grows herbs.

She has like 60 different types of herbs

so we cook with a lot of things

do a lot of things

so I'm very interested in learning

the medicinal properties

all the different things,

the natural ways of healing,

the traditional medicine.

I'm interested in that.

I don't know a lot of about that 
we were being taken around

this is edible

everyone said, can we eat this?

I thought that stuff was really neat, too.

I've slacked

a little bit

on the dietary restrictions,

but I am more active

than I was.

I made it a deliberate point

to be more active

because my job,

I mean I'm up

around some,

but it is mostly sitting in front of a computer,

so I've just made it a point to,

say hey,

let's go walk 15 minutes at lunch.

That sort of thing.

I've lost about 15 points

since January to now,

I've lost like 15.

Just making better eating choices

for the most part.

Not every day,

but overall. 
Just working with a group of ladies

from our area

to try to better our community.

I mean,

that's what I've always wanted to do

Was to do something to empower

other people.

I just completed

a master's in counseling

because I want to empower other people,

I work with college students

and try to get them motivated

to be able to help themselves

To make better decisions.

So just the idea

of affecting the whole community

as a whole is much needed.

I do because they see

how excited I am about it.

especially my daughters

because they want to know more,

I wasn't raised in a traditional home,

so they weren't raised in a traditional home

so talking to them about the importance of choices

the history and things. 
They're excited.

now my youngest daughter

she was going to major in biological science

and now she wants to change to nutrition.

Choctaw nation needs nutrition.

You could do so much with this.

I can see there's a lot more people

that I'm close to

that are starting to do the $5 \mathrm{k}$ 's

starting to get more active

those types of things

that is becoming the more popular thing to do.

More and more people are signing up.

So I think that's a good start.

So when we put all the nutrition

and all that together,

I think it could have a pretty big beneficial effect.

I missed my family,

but I wasn't ready to come home

because it's rare that you get to kind of bond

with other ladies like that.

I just enjoyed everything from

-- I enjoyed all the trails.

I enjoyed just,

getting away with different women

learning about all the different things. 
Just everything,

I thought it was pretty cool so.

3003

I have noticed

health wise

I choose better options.

I stay away from the pop

the junk food as much as possible.

I always go back when we were at Village Creek

walking there on Military Road.

It's just amazing.

An amazing experience.

I said that's one place

I'll make sure that I take my offspring,

my grandchildren

to whenever they start asking about their culture.

It was eye opening

I've always wanted

to get closer to my cultural roots,

discover them.

Because it was one of those things

now it's good to say I'm Choctaw,

but two generations ago

we don't talk about this.

And so just the change

of how Choctaw Nation is viewed. 
And now it is something

to be proud of.

Where I remember my grandmother was

we don't talk about this.

And so I wanted to go back

try to experience that.

And then I also asked my daughter to go, too,

that way we would have that connection.

I can go walk seven miles,

not even if I had to,

I can do it.

And so before this experience

I -- someone would say,

do you want to go walk

and I would go, "no".

So now I say,

"oh, yeah, I can do that".

And my husband even challenges me,

well, you did it for that walk,

so I think can you do it here at home.

So, yeah, it relates.

It just appealed to me.

This is for Choctaw women

who want to connect to their culture,

to eat healthier,

so it was just right place,

right time. 
I've maintained my weight.

I have not increased.

So that's good for me right now.

Right now being on the road as much as I can,

so I am making healthier choices

staying with that.

This is not pop, it's tea, so no sugar

3004

It's shown me different ways to be, like doing things I normally wouldn't do.

Like doing community project.

I've never had to do that

to be organized

because I'm the one who ordered

and got everything down for everybody.

The walking.

I never knew that it was, it would be as emotional as it was.

It was a different experience.

But it was good.

It was nice knowing

that I had people beside me

that they wouldn't leave me stranded somewhere, you know

The eating was different, yeah.

I never really done straight plain traditional food. 
So that was different.

Eating healthier was different.

I never really ate so many nuts and peanut butter in my life.

But it helped because

I did come home

I did eat bananas and peanut butter.

I cut down on a few things

I drink more water

I started to walk more.

Finding out more about my history

and it was a women's program,

that was interesting.

Knowing that someone is watching me

like my children,

knowing that if I eat healthy,

they'll eat healthy.

I would have to say

I'm more active now than I used to be.

I want to participate more

in different activities that the Nation has,

like different sports and stuff.

I try to get involved with that.

Walks

My vision.

they see the understanding 
of physical activity

the understanding of eating healthy.

Because I know in our tribe

diabetes is a big issue. I

think there needs to be more programs

for children than adults being physically active.

That was one of the big things

I was looking forward to

was going on to see,

getting to be able to walk

where they walked,

getting able to see

where we come from

because I've read about it,

but I never really got to go see

or experience it or anything

I even walked by myself.

And normally I wouldn't walk

by myself

especially in the woods

because I'm not an outdoor person.

But I felt a sense of security by myself.

So being able to walk by myself

being able to stop

look at everything was nice.

I know I can do more. 
I'm trying to think

of different ways to stay active,

keep her active,

and just

-- I know there's more that needs to be done

especially in our town

I told her every place we went

and where we got to walk.

I don't know if she really paid attention

because she's five

I've told a few people about the Yappalli Project

it would be good to go through

and that was some people that I worked with

because there are some ladies

that was wanting to know

when I left what I was doing.

So when I came back

and I told them,

they were like,

"well, that sounds interesting".

I'm just glad

that I did have

some of my family there

because it helped me

have that experience of knowing

that your family was there.

I kind of felt like 
I knew how they were

whenever their families

had to comfort them when they were

sore or broken down

3005

I came into it because

my sister brought it up to me.

And at the time

I was already competing in a couple of 5k's

trying to lose the weight,

I got down to 23-pounds

and went, "okay".

So when she brought that up to me

I thought that would be a great experience

to learn how to stay on that track of being healthy

On the trail was hard.

The trail was really hard

because for one,

I like control.

I'm one of them people

I have to have control.

I have to establish dominance

wherever I'm at.

I'm always the boss.

I'm the eldest of seven kids.

And then on top of that, 
I was quitting smoking

so I did have one of my nicotine patches,

so I had that.

Like I don't have the migraines anymore.

My stomach doesn't hurt

like it used to all the time.

And I'm happier, like,

emotionally.

I'm happier being more active

I still,

I don't even know what is going on.

It was just something that just went over me.

What do I do? (Laughter).

But it keeps us going on.

my legs are a lot stronger,

You can work on the muscles in your stomach, you know.

I'm getting there,

I'm getting there.

But I do feel better.

And this double chin is not as prominent

as it used to be.

But I can tell a difference.

I can definitely tell a difference.

I keep telling people out on the trail,

this is not me. 
My friends and stuff were in shock

because it was like

I was throwing a fit every day.

And I'm one of the people that

is a wall flower.

I'll throw a fit if I have to throw a fit.

But every day, every day got me.

I haven't smoked at all.

But that is also from my pure stubbornness.

I'm almost at four months,

in a couple weeks I'll be at 4 months.

But it helped a lot that one of the woman

on the trail made me mad on the first night.

She was one of the smokers

and I thought, I'm not going to her for a cigarette.

Like the very next day I woke up

and I was, like, I woke up,

like, I'm still alive,

talking to the animals and stuff.

Yeah, I'm good, I'm good.

And everybody else woke up in a bad mood,

and I thought

"what is up with you all?

"What is going on?"

Gabby was like,

"when you were asleep all that negative energy just hit everybody else"

I feel like a blank canvas 
when it comes to Choctaw, you know.

But I still feel like a blank canvas

when it comes to the Choctaw way of life.

Like I'm learning more than I did in the past

because I grew up,

I had a bunch of white friends

versus being friends with the native girls,

like, they are just too much.

I don't know if I get that calling or not,

but I finally might know where I want to lead.

Because this whole time

I was like,

"how am I supposed to know what I want to do for the rest of my life?"

I don't know.

But now, if I can do the work,

I would like to become a nutritionist.

And that's tough,

but I feel like that is what my calling is.

But I have to do the work.

I can't just jump into something.

I have to make sure that's what it is.

3006

I always dreamed

of being a runner

being with these women

in the walking group, 
I got the courage

to start running,

well, not running fast,

but jogging.

So that was,

that was a pretty neat experience.

I got diagnosed

with diabetes and my older

-- I had an older brother

And an older sister

pass away within the last four years,

and they both had bad health.

So I put health at the forefront of my brain.

There was a period

where I couldn't hardly get out of bed.

I was thinking,

"is this how life is going to be?"

So I got on the Internet

I was looking up things

that people who couldn't walk could do.

Like I looked up scuba diving.

I saw people in wheelchairs

they would still go scuba diving

it started making me think creativity.

I just had a lot of people 
just start encouraging me

about the same time.

And I felt like God was sending

all these people into my life

to set a fire in me.

I was like if God is putting that much effort

to get me fired up

and encouraged,

I might need to go with this.

And about that time

I started walking just around

the living room at first.

And then I would go to the mailbox

and back.

And then I made it,

I think I made it a block.

And then I saw

the Yappalli ad

and it asked if you would be interested

in being a health leader.

And I thought

that is really important to me

because I don't want my nephews

to end up with diabetes.

I don't want them

to end up with a preventable disease.

That was my main motivation. 
It just came in front of me

at that right time

when I was toward making a change

It's been kind of bewildering

because I've never,

I've never went camping before.

So I took me camping for my first time.

I've never been camping

with women I barely knew before.

But I wasn't putting myself out there very much

so it really stretched me.

Because I didn't know those women very well,

and it really stretched me

in good ways

and bad ways,

but in every way

where I could see different ways

that I could grow

and change,

and maybe even things

that were good about me.

But it made me less afraid

of making new relationships.

And even some of those relationships

with other women of the group

that I struggled with. 
I've seen some of those relationships redeemed

grow into something

that is really positive now.

that it might have been tough in the moment,

but there was something on the other side,

it is kind of bewildering,

but I felt that the bewildering things in life

turn out to be the best ones sometimes

There were so many,

just so many things

that I had to face.

I had to face myself out there.

And I think that is part of how come

I've been able to grow

because I think I was going through life

not facing myself.

I had to be

because that wasn't the true me,

that mousy,

shy,

afraid person

wasn't the true me.

So I couldn't have been facing myself

because I wasn't facing the brave me

I've been able to get off diabetes medication.

Just with exercise 
and eating better

Because on the last day,

the seven-mile hike,

when I got to the top of the hill,

Karen and I had walked up the hill together,

and when we got to the top of the hill,

I turned around

I looked back

I was like, did we just come from that direction?

and it hit me.

I told Karen,

I said, I can never again say "I can't".

Like, whatever I face,

I'll have to at least say

"I'll try"

because I can't just say "I can't".

And that was big for me.

That was big for me because

I struggled with, struggled,

part of my depression was feeling

like I couldn't do anything.

I felt helpless.

Just felt like I didn't have any choices

or I couldn't make anything happen for myself.

And I've gone back to school

to be a graphic designer,

and I didn't have the courage to do that before. 
I just always wanted to please everybody.

But now I'm like,

I got a more clear,

more clarity about who I am.

I feel a strong responsibility

toward Choctaw people.

I used to

-- I used to want to be an activist,

but I got sidetracked.

I think a lot about getting involved again.

The language,

my people,

they mean a lot to me.

The language means a lot to me.

And sometimes,

sometimes the places I go,

like even in Christianity

I might be the only brown face in the room,

and so sometimes I feel like,

I almost feel like

I'm kind of like an ambassador for Choctaw people.

My family is kind of overwhelmed.

My mom doesn't know

what to think about me 
going to Colorado.

She was blown away

just by the music festival.

My Aunt even called

and chewed her out

and said,

"you let her go camping by herself?"

"What is wrong with you?"

My mom said

"I think she can handle it."

I think the Choctaw young people

and even old people, too,

I think they're looking for

a sense of purpose,

and I think visiting the Trail of Tears

and connecting with the ancestors,

and just even the healthier way of life they had,

I think that might be the missing link.

Because I see young people all the time,

and I hate it.

Because I know in native youth

there is an epidemic of suicide,

and they're just looking for purpose.

I think if they connected like we do,

it would make a difference.

It made me feel present. 
It made me feel like I exist.

It made me feel like I am here.

And I can possibly make a mark.

It made me feel that.

It gave me a sense, a sense of

-- gave me a sense of purpose, I guess.

3007

The project as a whole,

it really brought me closer

to what my ancestors

somewhat dealt with,

The biggest impact

I had on the trail was

I can't remember the name of it, but where you could see how

many people actually walked through

because of all the weight

that the soil had on it,

and it caved down to the pressure

of the people that walked on it

I think that was the most emotional one

because you could

-- it was towards the end of our week there,

and then we also,

like,

just everyone's feelings were in it. 
Nobody was really complaining anymore

That (Washington Post) was probably

the biggest challenge for me,

and a lot of the women,

as well

because it was just so flat

and as they said when you go from

the gray earth to the read earth,

it's a big difference.

And how hard it is to walk on certain areas

It taught me to appreciate

my food a lot better,

and see it as a medicine

and not to abuse it.

Since the walk

I've been prepping my meals

and portioning them out

so that way I'm not tempted

to go to the Sonic

and buy all the ice cream

I'll calculate I can have this much sweet today.

And I'm increasing my water

like how much water I'm drinking,

and I've cut pop out.

I'm trying to make a better health decision

for our future generations 
I've been waking up

and having energy

to do things instead of,

I'm tired, I'm laying in bed,

I don't want to go get on the row machine today

and do some meters.

I'm waking up,

I'm more active.

I'm able to do more school work

without being groggy.

Just an energy boost

I think seeing the struggle

of what other women

that have worse health conditions

than I do wanting to change,

and that got me wanting to change

because I know if I keep continuing

how I am, I'm going to wind up with

the same health conditions and my future generations will, as well.

Because I was one of the youngest members

of the Yappalli group.

My goal is to become more active,

but, like, vision overall,

I just want to see us strive.

I don't want us to be the people 
riding around in the motorized Scooters

and people just going,

why aren't you taking care of yourself

when it's, like,

my grandkids if they were the ones in the Scooters,

it would be my fault

because I didn't eat right.

I don't want to be the one

to blame for my children's bad healthy habits.

I went in not with a positive attitude.

I think it was you on the walk that said

if you don't have a positive attitude,

it's just going to make you hurt.

And like being positive,

you can't feel like your twisted ankle and all that.

All you have to do is keep looking forward and keep going.

That is kind of what motivated me

throughout the week.

I need to change the way

I'm viewing things

because I went in negative,

not completely negative,

but I was skeptical.

I don't know why I'm really here

besides for my mom

and to learn a little bit.

But throughout the week 
it really motivated me

3008

when I first went

I wasn't sure I wanted to go,

but as I went the ladies that I met,

I really enjoyed them.

I enjoyed hearing stuff from them.

I enjoyed the walking.

I enjoyed going to the archives

where you could see.

I liked when you walked.

And when we walked

I was thinking,

my poor ancestors.

They didn't get a van driving by

asking if someone wanted a bottle of water.

They didn't get lunches and breaks.

And I thought how sad.

Not only that,

but they had completely been dislodged

from everything they knew

owned and had.

And it kind of, it broke my heart.

I mean,

I would think about it,

I'm one of those people that kept thinking, 
don't dwell on it too much

because it makes me really sad.

But I would say,

they went across there with their babies

if they couldn't keep up, too bad.

They say women don't sweat,

so all I can say is no.

I was just dripping.

And it was a little bit rough.

But I was glad I did it.

And then I would walk

I know I don't hear their voices,

but it made me sad

because I'm thinking

of all those people.

It bothered me.

It really did.

I was born and raised in California.

I was like that one lady said that night,

"I have a Choctaw card, it's like whoopee."

I would like to say,

well I wanted to know all about my history,

but I wanted something to do.

I wanted something to do.

Somewhere to go. 
Anyway.

I thought,

well there will be fun,

and I will meet people.

And I had met Laurie

and a few other people up there.

And I didn't know how involved it was though.

I really didn't.

I didn't know you went as often as you did for meetings.

I didn't realize how involved the camping trip was

and the walking and everything.

But I'm glad I went.

I was really glad I went.

I walked quite a bit.

Well, you have to remember

I've come from 260-pounds to this.

So I was already working on it,

but I had been working on my walking

a whole lot more,

and I take my dog

and we try to walk at least

-- sometimes we walk

a couple times a week five to six miles,

But I'm trying.

I think -- it focused me again on trying to --

I want to keep my blood pressure down. 
My diabetes,

which I really don't have a problem.

If you get up in the morning

and you walk five miles,

it just kind of naturally curbs it.

when my doctor first took me off of it

and I wanted to lose weight,

he said I've got a diet for you.

If you're going to stay on it,

quit taking your medicine.

If you're not, he said,

then keep taking it.

So I'm not having to take

-- with getting back on to the things that I re-instilled,

and I'm like, okay,

I don't have to take all that medicine

and I like that.

I do feel better

I just think a healthier eating style.

There are so many Choctaws that are obese.

And I think we should be teaching

our children

to eat better

and to actually like each other

as a group instead of segregating this

over here, 
this one,

this one.

I think we should learn to be kinder

to each other

I learned that you need to be healthy

as far as your physical body.

I would go up to the Choctaws

because I found it interesting

and talking with some of the people.

I've been trying to improve things

and have a decent meal.

And, of course,

not go to the store

go cruise the ice cream aisle.

I can stay out of chips and candy,

but every now and again I weaken

Well, I'm terrible.

If I bring something home,

I'm going to eat it.

And not over an extended period.

I mean,

I'm going to eat it.

So I thought you're better off not to.

If you buy it,

you'll sure eat it,

stay away.

Stay away. 
That really helped.

I would have never met these amazing people.

I wouldn't have had that enjoyment of going on that walk,

learning about ancestors,

hearing the different stories.

People would tell the stories

and I was like, wow.

I mean I was not aware of that

3009

It has gotten me enthusiastic

to want to get out

and get healthier

because I'm not getting any younger.

I really enjoyed it.

Even though we griped,

it wasn't nothing serious to gripe about.

And the friendships

that we've made

and still have,

I've enjoyed that.

Just walk.

It's hot.

I have 
-- the way I look at it my little feeble mind,

the ancestors that did that walk,

it was a horrendous

they would have left me back in a mound somewhere.

I don't think I would have made it.

Because me walking

and our group walking,

we had all the things we needed.

Access to the cool air,

the cool water,

the food

everything,

you know,

we wasn't bitten by the insects

stuff that,

you know,

and they didn't have that.

But I learned to appreciate that more,

you know.

And just be thankful

how good we have it,

you know,

because we're blessed,

blessed people.

We really are.

And the way the people,

our ancestors, 
were treated

it's disheartening

and you still hear younger generations

they make negative remarks about stuff,

and they really don't,

they really have no perception of what it actually was,

just, you know.

But I can kind of imagine,

but I really can't

because if you didn't experience it,

you don't know.

But as far as doing the Trail of Tears walk,

I would do it again.

Just doing it.

I didn't see none, nothing

I couldn't accomplish or overcome.

I really enjoy it.

I look forward to doing it.

To be more active, I think.

Technology it's going to be more

and more and more every day,

I guess. Back when I was raised up,

we didn't sit in the house.

I would like to see

the younger generations be

more health-wise and 
be more active.

Because I see so many

come through

when I volunteer at the election,

and they're just so crippled up.

They're younger than me,

20 years.

Just had a young man

-- my neighbor's grandson passed away

at 27 years old of a heart attack.

I've been in nursing all my life, for 43 years.

I try to tell people, you know, to quit smoking.

Everybody says that.

I used to be a smoker.

Smoked three to four packs a day,

just blowing and a going.

Community-wise,

I think maybe because I see

-- well, there's people from the church

I know that are walking

and running out there at the track

For me it's given me more incentive

to do and stay healthy. 
Like I say,

I'm getting older.

I'm almost 70.

I'm kicking up to 70 pretty quick now.

And my husband is, he's 76.

And he got run over by a cow the other day.

And I think he's got bruised ribs

and busted elbow and all this,

but in general he's healthy.

And I just want my family

to be healthy

and stay healthy.

I have a son that's kind of,

he's lost weight,

but he could stand to get in shape.

He's not -- health wise,

his feet are terrible.

My youngest son just turned 17

a few days ago and

my husband is like,

he's just lazy, you know.

He's 17.

I just like to see them all

-- and the younger kids and my family,

I would like for them all to stay healthy

and be healthy.

To live a long life 
and be productive.

3010

It was fascinating.

I loved it.

It made me dig a little bit further

into my ancestors.

Actually, you know,

being Native American,

I knew, you know,

you get a lot of advantages,

benefits from it,

but it made me look a little bit further

realize that we are,

we were missing a great grandfather and grandmother.

So digging for our native blood

so I was fascinated.

If it wasn't for this I wouldn't have done it.

And I'm digging for some more.

Because I really don't know

-- there is still not a lot of our ancestors alive,

our older generations,

haven't found anyone

I knew that walked the Trail of Tears.

I'm still digging.

I want to know,

I want to feel that. 
Because when we did that walk

it was experiment.

I mean it was heartwarming and overwhelming.

I cried.

And when I came home to my kids,

I just hugged them

and cried

and told them,

you know, there is a lot more to it

than saying we're Native Americans

My experience walking the trails,

as we walk,

I tried to imagine myself there,

imagine myself walking that trail back then.

As elderly,

as a young kid.

Tears rolling down my eyes

because to this day a lot of people

say we have it easy.

Yes, we do.

But back then I can say

that was the easy part because they kept going.

They did not let anyone defeat them.

I'm going to start crying again.

Because they wanted a better future for us.

And to our generation to this day,

And I want my kids to feel what I feel. 
To know that our people went through a lot.

I want to go back again,

I really do.

So my household has changed,

our food-wise

but that is not like we used to every other day.

And I see a lot of change.

My kids said that I have,

whatever it was I had experienced,

whatever it was,

I came home as a different person.

I'm not as mean and grouchy.

And I did talk to my kids about the Trail of Tears.

I told them it was something I want them to experience.

And that seven mile walk that seemed like it was 15-miles,

that was what really got me.

But pushing myself to keep going

when I felt like I needed to get in a car,

but I kept going

because that is something

that I know my ancestors done.

It was wonderful.

I try not to cook with fatty foods.

Well, my meat are baking.

But there is the vegetables,

I'm not really big on vegetables, 
but what you all had,

what was on the trail,

which I cooked,

I watched and seen what they used

and I tried some of that at home.

I did have a grandmother,

bless her soul,

I love her so much,

but she was the meanest lady.

But now I understand.

When she cooked,

you eat everything

because to this day,

it's very hard.

I'm a mother of four

and trying to raise them

and put them in school,

and money is tight,

and what I buy they were like,

“ew, no, mom.”

But now,

"it's oh, this is really good."

"how did you learn to make this?"

Well, I watched them.

This is what we ate when we went on that trail.

They went 
"oh, my gosh, Mama,"

but now they love it.

knowing that some of the girls

I was going with were going.

I knew that I would be okay

because they were there.

I could still socialize with someone

because meeting new people,

Like I told my kids,

if I can show them

to eat without the fatty foods,

stuff that I know that

-- if we can just boil or bake,

we're going to be okay.

They're going to be okay.

I don't have to worry about

the diabetes

or high blood pressure

or cholesterol.

We'll make it.

That is what I want.

I have a granddaughter

she is eight months old

and I told them that,

I hope to see her grow up. 


\section{But if not,}

what I taught my girls

and my son

that they will pass on to her,

she needs to know.

It's not all about being yay,

"I'm Indian and I can go to the health services for free medical".

There's a lot more to it.

I was on the pre-stage

of diabetes

before I went on this walk.

I did have to

-- they did give me some medicine

for the diabetes

and they said I was pre-stage.

I don't take them as much as I used to.

My A1Z has actually dropped.

And my girls,

one of them,

she is the same way,

prediabetes,

they think it just runs in the family

because my sister was

13 and my daughter is 17 and around 14-15 years old

they said she was that way.

But I haven't taken mine every day.

Everything seems good. 
The doctors even told me

that I don't have to take it.

Maybe once a month

or so because everything looked really good.

I have thought about it.

Me and my kids,

my girls have talked about it.

But I have to know us first

before I can do something else for someone else.

I'm still digging and looking

and trying to figure out

what steps to go

and who to see if they know

any more about my ancestors.

My grandkids

are what I'm looking to

the future for

and knowing that my kids

and grandkids were going to be okay.

I was talking about

a lot of those

and my kids were like,

"wow, Mama, what is this trip doing?"

I said,

"I don't know."

I said 
"I like it."

They said

"I do, too".

But when I got ready to go on this trip,

I bawled my eyes out

Going home to my kids,

they knew something was different.

I think they were testing me.

So that day we got home and they were like,

"Mama, I'm sorry I didn't clean the house or pick up."

I said "that's okay",

"we'll do it".

"Let's help."

"I'll help you."

"You do this, I'll do this."

"Abigail, you do this."

They were like,

"Mama what is wrong with you."

"You usually gripe at us if it's not clean

when you come back."

And I said,

"I know, you probably think

I take advantage of you all,

do your chores,

do the dishes,

do this,

but if you all help, 
I will help.

I will meet you."

This walk has changed me.

I was like sit down because they asked,

"what changed you, Mama, besides you being really nice."

I said sit down.

You see this turtle I told you about.

What our strength was

and what our future is going to be?

And I put you and my grand baby

and when I want to go out

and get away from you when you get on my nerves.

This walk,

I drew pictures

and I showed them the pictures

and I was crying.

And they said,

"Mama, that really changed you."

And I said, "yes."

I want you to know what I felt.

I showed them Washington Post

when I was coming up the hill

before you got to the school,

I showed them that picture

and I was thinking, just think,

I walked that.

And think of what our ancestors walked. 
I said it wasn't paved in.

It was all dirt, rocks.

It might have been raining that day, too, and probably muddy.

They made it.

And when I walked up to that school,

I realized I made.

If I can do anything.

And they were like,

"you can Mama".

And I said

"that is what you alls going to do."

"You all can do anything you want."

"Set your mind to it."

"Don't ever forget how you got here."

And they were like,

"we can't, Mama"

"because you're sitting in front of us."

"Mama, I know what you mean."

"If it weren't for our ancestors we wouldn't be here.

And I said

"that's right."

Yappalli is the best thing I've ever done.

It gave me the opportunity to walk that,

have people that put it on like

you, Karina, Sandy, everyone,

to know,

to work 
and be able to tell the events

as we walked that road,

that path.

And know that you didn't just do it for us,

but for yourself,

as well as the Native Americans

I loved it.

I hope you all continue.

It's an experience.

It made me start thinking,

but if there is anyone out there

that is willing to go

and do the effort,

keep it because one day,

like I said it's going to be lost.

I hope it is never lost.

But it is worth it.

3011

I'm just really thankful,

just very thankful,

I really feel like it was almost,

really kind of a divine appointment for me.

I had it on my heart

that I needed to change my health.

I really seen that my eating habits,

my health habits in general 
were something that I was

just really taught by my parents

it was something that came natural

to me because that is what I was taught.

But I seen the destruction of it,

I seen that

I need to make those changes

not only for myself,

but for my future generations.

it was even having an impact

on my ability to reproduce,

and it was directly,

it is directly related

to my eating habits.

so I'm really, really thankful

for that whole experience.

I'm thankful to have a greater purpose.

it gave me even more

of a greater purpose to realize

hey, my ancestors came here,

and to just, they didn't have diabetes.

They didn't have all these health conditions.

So that is not something that we are just destined to have. That is something that can be changed.

my experience on the trail

-- I'm still processing it honestly. 
I'm still processing.

But just to have, just,

a little bit better understanding of past generations.

I mean, I don't even know really.

I don't really know what to say about it

other than I'm just thankful for the experience.

there are so many things

that happened inside

that I can't even put it into words.

But since I've come back,

just coming against a bunch of mindsets that have,

that I've had to just tell myself,

just thinking about thoughts

that I had not only about body image

And things that I've had from my life,

but also things that have been

passed down to me from my family.

And thinking my culture and how,

growing up,

my Grandma she was

full blood Choctaw

and she went to Wheelock,

and she was just an awesome woman.

And it was an unspoken thing,

you know, you can be proud to be Choctaw,

but it is almost not okay to really,

traditional ways were not necessarily okay. 
But now I have a better understanding of why.

It was kind of a protection thing.

I mean, it wasn't good for you.

It was something she just didn't want us

to be harmed by that like she was.

So just more of an understanding on those type of things.

it is a little bit hard,

I guess.

I just really have a heart for people.

I just love people.

I just want to help just any way I can

I believe in God.

And I believe he directs me, and at the time I first heard of Yappalli

I was working in Utah,

I believe,

and I had come in just for a few weeks,

and I was at one of the tribal plazas in Wilburton

and I seen a flyer.

And I was just reading a bulletin board

and it said

"are you a Choctaw woman that would like to better your health for you and future generations?"

And I was like, "yes, yes, and yes."

So yes, I wanted to call, 
but I knew that I couldn't

-- but, I did call and I got a voicemail

and I didn't leave a message.

But I was,

I don't know,

something inside of me drew me to that.

And so I go back off to work

and I was gone for several months

and I ended up coming home

for an extended period of time,

and I seen this flyer again somewhere else.

And same thing, that draw inside,

like you need to call.

So, yeah, so I called

My biggest motivation

was that I could really see

that what I do with my one little life

can have a big impact on future generations.

That was my motivation.

And I'm just really feel called to that.

And a heart for that.

And I feel like it's very important

that I break those generational cycles

and, if I don't,

then it is left up to my kids

and it is not their responsibility. 
So I had that walking stick

there was someone who had,

someone else had a walking stick

and they had a feather on it.

And I was like, oh, that is really awesome.

This walking stick needs a feather.

And I was really thinking about that,

and then that one day, you know,

I found that feather.

This is awesome!

This is for the walking stick.

And thank you.

You hear me,

and you love me,

and you care about me.

And He does all of us.

But it was just really awesome.

So there was this one day on the trail,

several days later,

I had lost the feather off of the stick in a tree,

but I happened to see it

and I grabbed it

and put it back on.

One time I dropped it on the ground

and picked it up,

and put it back on. 
this happened three times in one day.

And I was like, oh, my goodness,

isn't this just like our health,

creator blesses us with health,

and things in life or circumstances

or just whatever

can try to take those things away.

So many things whether it is us or,

external circumstances.

I've lost 17 pounds

I feel like my hormones are more regulated,

and I feel better.

But more than any of that,

my mindset,

my mindset has been changed

and just really thankful for that.

Just really excited about the future of that.

And just continuing on in that,

I didn't have a whole lot of medical history

because I didn't go to the doctor very often

so really to compare that numbers

to numbers or anything like that,

but I know I'm doing better

and I know I will continue to do better.

I do feel like there was something,

that I don't even understand. 
something innate that was,

that I was just able to let go of,

and I don't even know what that is.

But, yeah.

I really do see the Choctaw Nation

as not having diabetes.

I really see them coming to,

with a whole different understanding

of medicine in general.

And just seeing the truth.

The truth of how these pharmaceutical drugs affect them

and the truth of how food really can be your medicine.

And how the truth

of who they were really created to be

and walking that freedom.

And in relationship with creator.

And it is not some religious thing

or this or that,

but a natural thing

that you can walk and talk

with creator

and have that relationship.

So I do see those things.

But I know I'm going to be involved.

And I'm also reaching out to our elder community. 
And at first I didn't think of them.

I was thinking

we really need to meet the next generation,

but for some reason

I really feel like it's important

to get our elders involved so that way

-- because I mean,

all of their families,

and this is something that you can teach the kids,

but it has to be reiterated at home.

And I've talked to community center leaders

about that,

and I'm excited about having the opportunity to talk with them about it

I mean, every single person

that is part of the Yappalli program

has their sphere of influence

and it is going to ripple.

So, yeah, of course.

And there's just little,

there's people that I'm reaching out to

and we're walking together

and I'm sharing with these stories,

and even though they might not be a part of the Yappalli program

per se,

they still have that heart to see those things. 